\title{
China's grassland policies and the Inner Mongolian grassland system
}




\section{Thesis committee}

\section{Promotor}

Prof. Dr W.J.M. Heijman

Professor of Regional Economics

Wageningen University

\section{Co-promotors}

Prof. Dr J. Huang

Professor of Agricultural Economics

China Centre for Agricultural Policy (CCAP), Peking University

Dr L.K.E. Dries

Associate professor, Agricultural Economics and Rural Policy Group

Wageningen University

Dr X. Zhu

Associate professor, Environmental Economics and Natural Resources Group

Wageningen University

\section{Other members}

Prof. Dr J.D. van der Ploeg, Wageningen University

Dr N.B.M. Heerink, Wageningen University

Prof. Dr Robert Finger, Swiss Federal Institute of Technology in Zurich, Switzerland

Prof. Dr P.P.S. Ho, Delft University of Technology

This research was conducted under the auspices of the Wageningen School of Social Sciences (WASS) 


\section{China's grassland policies and the Inner Mongolian grassland system}

Min Liu

\section{Thesis}

submitted in fulfilment of the requirements for the degree of doctor at Wageningen University by the authority of the Rector Magnificus,

Prof. Dr A.P.J. Mol, in the presence of the

Thesis Committee appointed by the Academic Board to be defended in public

on Tuesday 24 January 2017 at 4 p.m. in the Aula. 
Min Liu

China's grassland policies and the Inner Mongolian grassland system 163 pages.

$\mathrm{PhD}$ thesis, Wageningen University, Wageningen, NL (2017)

With references, with summary in English

ISBN: 978-94-6343-024-1

DOI: $10.18174 / 399371$ 


\section{TABLE OF CONTENTS}

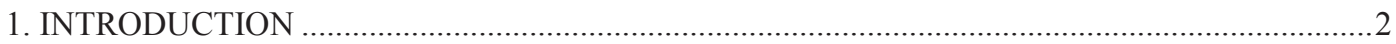

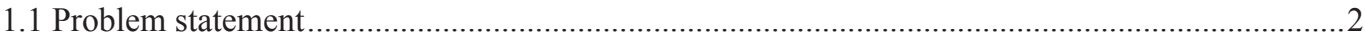

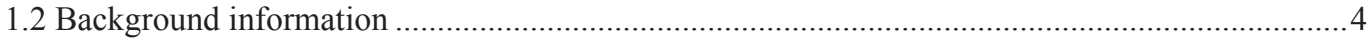

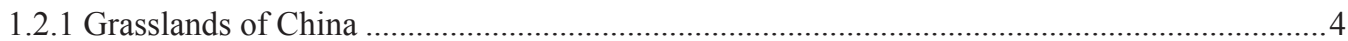

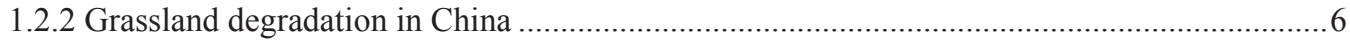

1.2.3 Livestock production in the pastoral areas of China ...............................................................

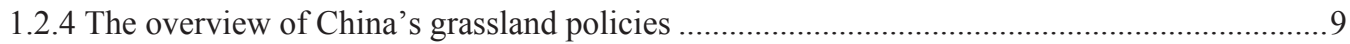

1.2.5 Research region: the pastoral areas of Inner Mongolia.........................................................10

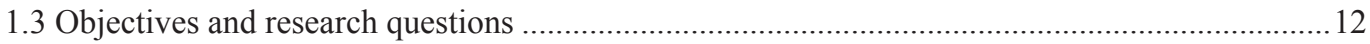

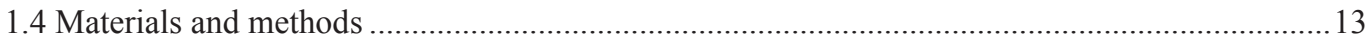

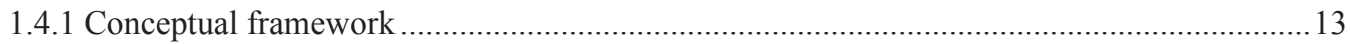

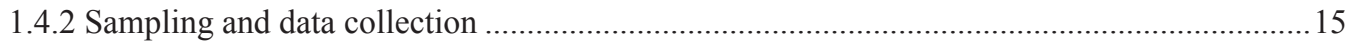

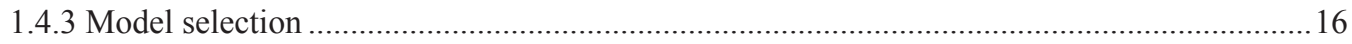

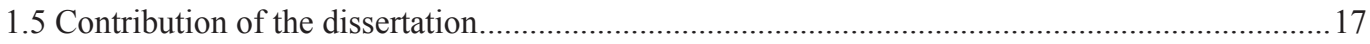

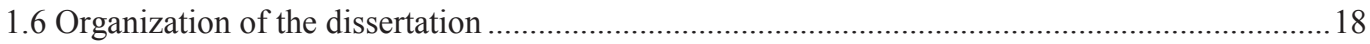

2. RURAL LAND ALLOCATION IN ECO-FRAGILE REGIONS OF NORTHERN CHINA..........21

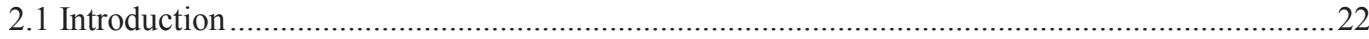

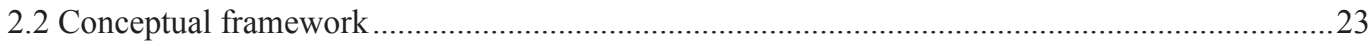

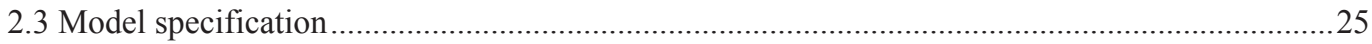

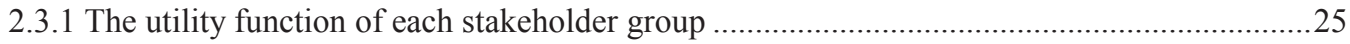

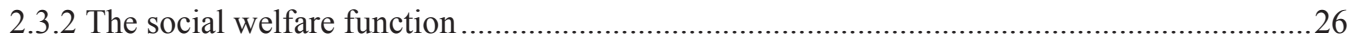

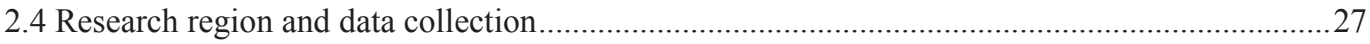

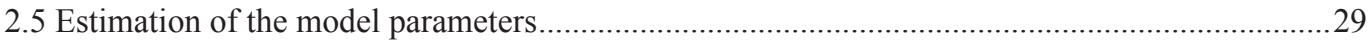

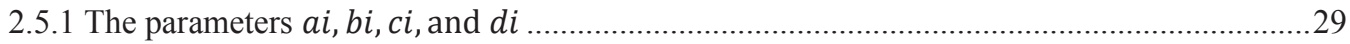

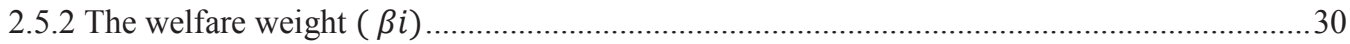

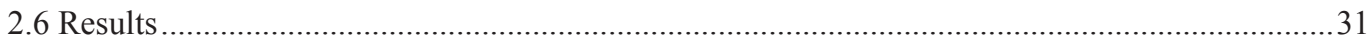

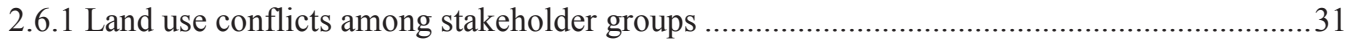

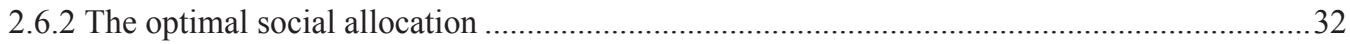

2.6.3 Comparison of individual optimum, social optimum and actual land allocation....................32

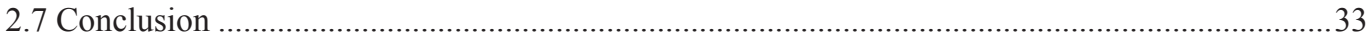

3. LAND TENURE REFORM AND GRASSLAND DEGRADATION IN INNER MONGOLIA,

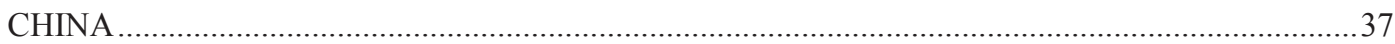

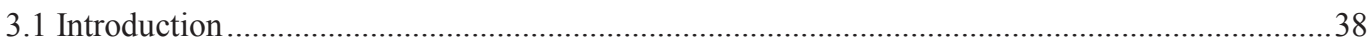


3.2.1 Study area

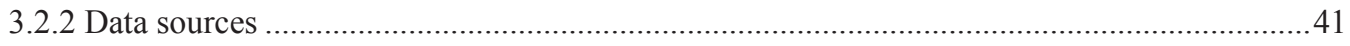

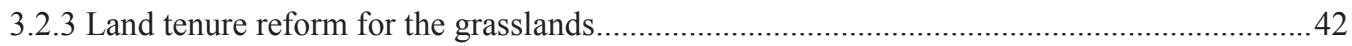

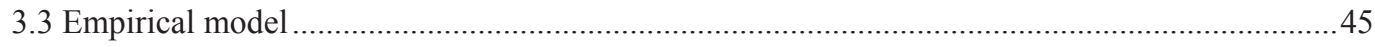

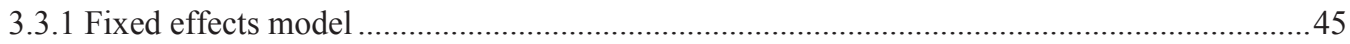

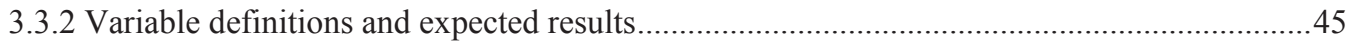

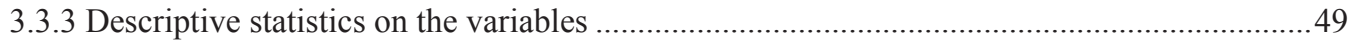

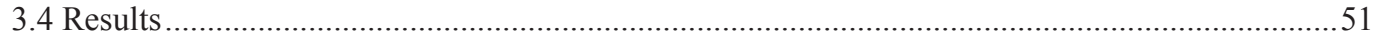

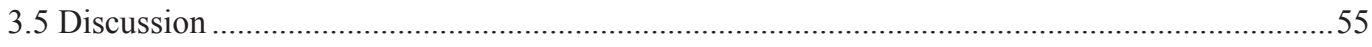

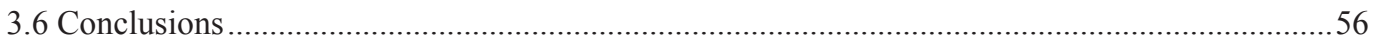

4. HOW DOES LAND TENURE REFORM IMPACT UPON PASTORAL LIVESTOCK PRODUCTION? AN EMPIRICAL STUDY FOR INNER MONGOLIA, CHINA ............................59

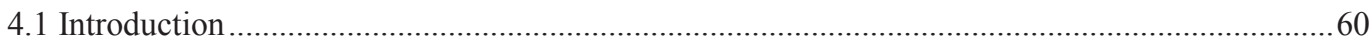

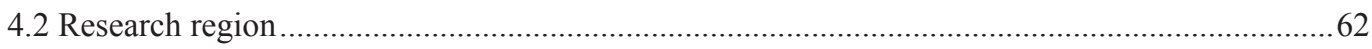

4.2.1 Land tenure reform in the pastoral areas of Inner Mongolia...............................................63

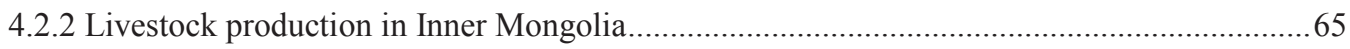

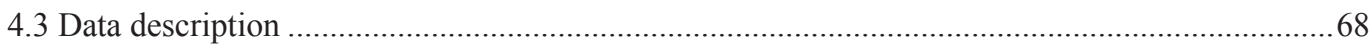

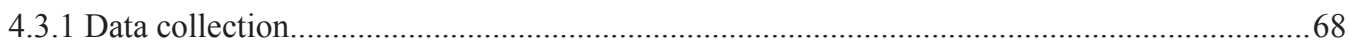

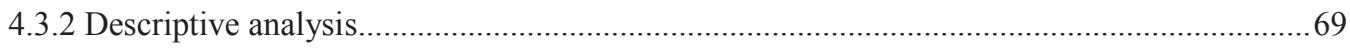

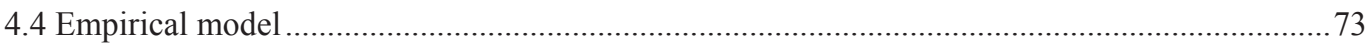

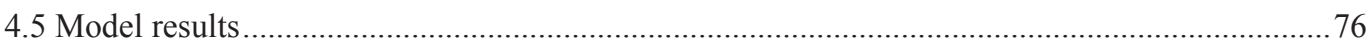

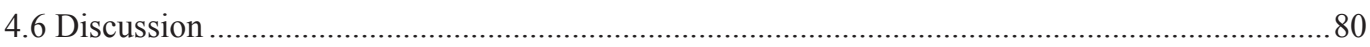

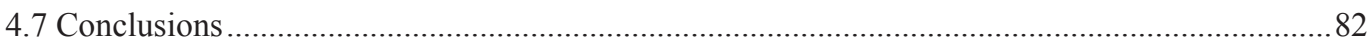

5. THE IMPACT OF ECOLOGICAL CONSTRUCTION PROGRAMS ON GRASSLAND CONSVERVATION IN THE PASTORAL AREAS OF CHINA .................................................... 86

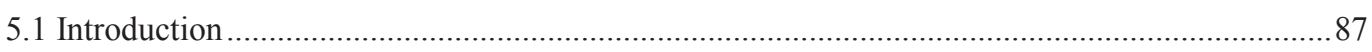

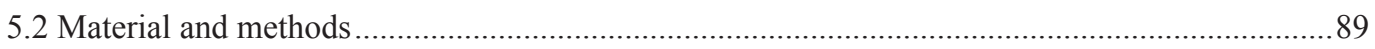

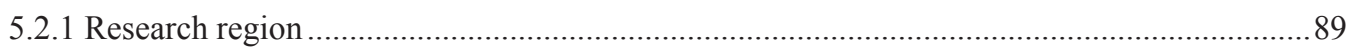

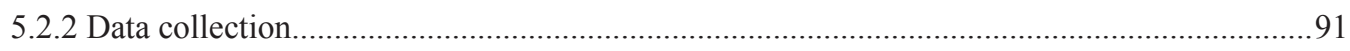

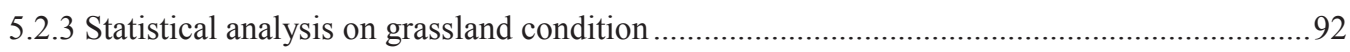

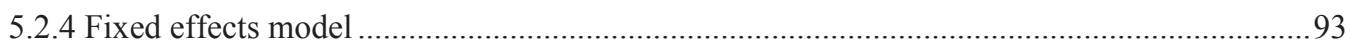

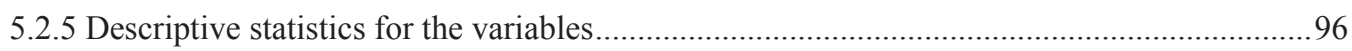

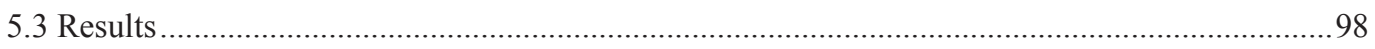

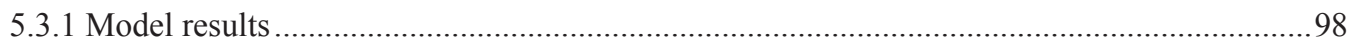




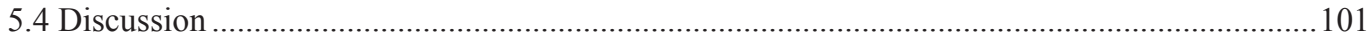

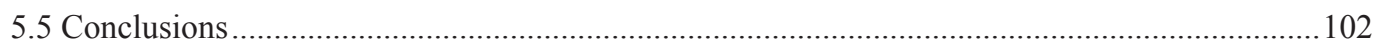

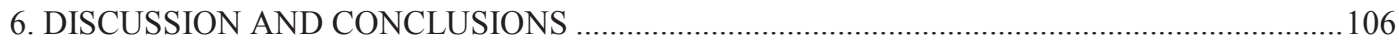

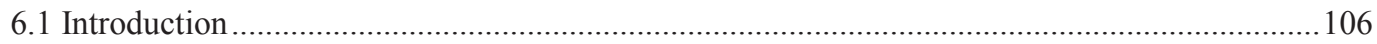

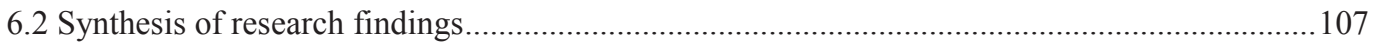

6.2.1 Different preference on grassland use by different stakeholders ........................................107

6.2.2 Grassland privatisation is a significant reason to cause grassland degradation in a long term

6.2.3 Grassland privatisation puts a ceiling on the livestock production of pastoral areas, but it

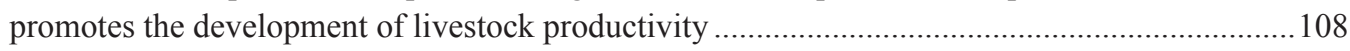

6.2.4 Ecological Construction Programs have significant impacts on preventing grassland

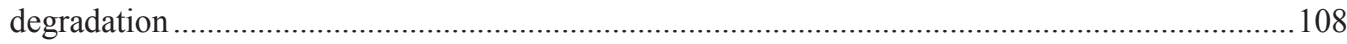

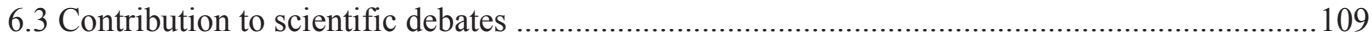

6.3.1 The tragedy of the commons versus the tragedy of privatisation ......................................... 109

6.3.2 Deterministic stocking rates versus stochastic stocking rates ..........................................111

6.3.3 Top-down intervention versus bottom-up intervention...................................................... 112

6.3.4 The one-size-fits-all versus tailor-made policies for resource governance ............................114

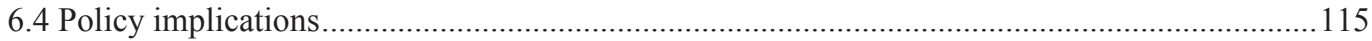

6.5 Limitations and recommendations for future research ........................................................... 118

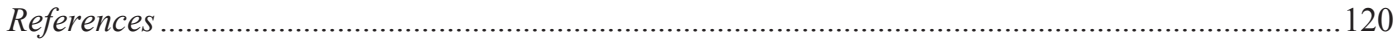

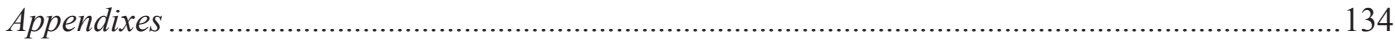

Appendix 2-A: Derivation of the individually optimal allocation of land ....................................... 134

Appendix 2-B: Derivation of the socially optimal allocation of land .............................................. 136

Appendix 2-C: Questionnaires and results of Analytic Hierarchy Process ......................................139

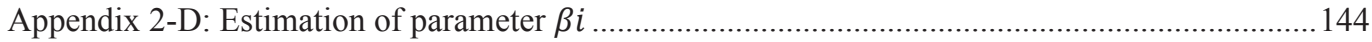

Appendix 4-A: Descriptive statistics of the model variables......................................................... 145

Appendix 4-B: The model specification with quadratic term ..................................................... 146

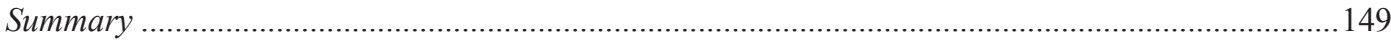

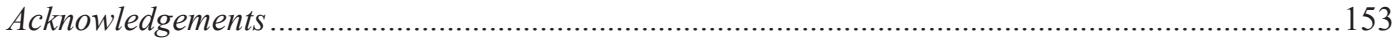

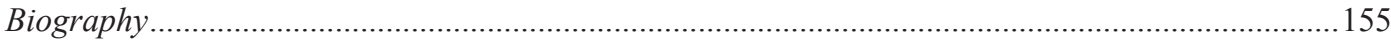


Chapter 1

\section{Introduction}




\section{INTRODUCTION}

\subsection{Problem statement}

According to the FAO (2008), grasslands occupy $26 \%$ of the total land area of the world, and $70 \%$ of the global agricultural area. They are among the largest ecosystems in the world, contribute to the livelihoods of more than 800 million people, and are important as feed sources for livestock, as habitats for wildlife, for environmental protection efforts and for the in situ conservation of plant genetic resources (FAO, 2008). The sustainable use and management of grasslands have been of great concern to academic circles, policy-makers and NGOs, especially in the context of the growing worldwide problem of grassland degradation, rapid increases in demand for livestock products and the high level of poverty among pastoralists (Suttie et al., 2005; FAO, 2015). As defined by Fernandez-Gimenez and Swift (2003), sustainable grassland use and management should maintain the productive and adaptive capacity of grassland ecosystems while providing for the wellbeing of human communities. In practice, various policy interventions have been made, devoted to balancing the conservation of grasslands, production of livestock and the livelihoods of local households in agricultural societies.

However, the validity of existing policy interventions must be examined in terms of sustainable grassland use and management, given that grassland degradation is still ongoing and rural poverty is deepening in some pastoral areas (Hua and Squires, 2015). In this regard, research in multiple disciplines has found that some government policies accelerate resource destruction (Ostrom, 2009). To date, the policy interventions for grassland use and management widely employed by governments around the world aim to transform traditional pastoralism, by developing sedentarisation instead of nomadism, privatisation ${ }^{1}$ of grasslands instead of communal tenure, intensification instead of extensive grazing, commercialisation of livestock systems instead of subsistence, deterministic stocking rates instead of opportunistic strategies with stochastic stocking rates, and so forth (Homewood, 1995; Li and Zhang, 2009). Traditional pastoralism is subsistence-oriented and has been perceived as primarily mobile, manifesting in such diverse forms as nomadism, transhumance, and migration as well as pasture rotation on a large scale (Fernandez-Gimenez and Le Febre, 2006). Widespread sentiments identify traditional pastoralism as an irrational, ecologically destructive and economically inefficient system (Homewood, 1995; Ho and Azadi, 2010). So, what are the actual outcomes of the government-driven

\footnotetext{
${ }^{1}$ Note that privatisation generally refers to the assignment of property rights over an asset or resource from the public (state) to the private sector. In the case of China, formal property rights over grasslands have remained in the public (or collective) sector. Hence, when we use the term privatisation for grasslands in the Chinese context we include the transfer of use rights over grasslands from the public to the private sector rather than the assignment of formal property rights.
} 
transformation of traditional pastoralism? In other words, what are the impacts of the prevailing policy interventions on the grassland system ${ }^{2}$ ?

The global tendency of grassland policy in the twentieth century has been toward privatisation (or individualisation, subdivision, etc.), which transforms the property rights or use rights over grassland resources from communities to individuals (Mwangi, 2007; Li and Zhang, 2009; Li and Huntsinger, 2011). Since then, grassland privatisation has become the most significant transformation of traditional pastoralism, and the result of establishing physical boundaries between grassland parcels has led to a series of considerable changes in traditional modes of livestock production and household livelihoods (Sheehy et al., 2006; Li and Zhang, 2009). In general, land-ownership regimes other than private property are considered by many economists to be inefficient and prone toward the overuse of resources (Mwangi, 2007). Particularly, the conventional wisdom based on the concept of "the tragedy of the commons" (Hardin, 1968) and the theorem of property rights (Coase, 2013), contends that the open access to resources and unclear property rights of traditional pastoralism would inevitably cause overuse and increasing grassland degradation (Li et al., 2014). As such, grassland privatisation has been long embraced as the solution for achieving the sustainable use and management of grasslands (Mwangi, 2007; Ybarra, 2009). The development of grassland privatisation has also been influenced by the changes in the economy, such as technological innovation, changes in relative factor scarcities especially with increasing populations and the creation of new markets (Demsetz, 1967; Mwangi, 2007). However, an increasing number of scholars have explored some of the unintended effects of grassland privatisation, challenging the conventional wisdom of the "the tragedy of the commons".

After the period of implementation of grassland privatisation, various environmental policies and programs have been introduced, influenced by growing attention to grassland ecosystems and worldwide grassland degradation in recent decades. The policy interventions for grassland conservation mainly target at controlling livestock grazing, because overgrazing is believed to be one of the main causes of grassland degradation by most of policy makers, such as in South Africa, South American Campos, China etc. (Suttie et al., 2005; Miao et al., 2015; Liu et. al., 2016). These environmental policies and programs further prompted pastoralists to transform their traditional lifestyles, particularly developing the intensification of animal husbandry, in place of extensive, grazing practices (Cao et al., 2013b).

Nevertheless, traditional pastoralism had prevailed for centuries. Increasing literature has criticised existing policy interventions as impairing the strategies of traditional pastoralism, reducing mobility,

\footnotetext{
${ }^{2}$ The grassland system in this research includes both the grassland condition (grassland area and quality) and livestock production. This is an adaptation of the resource system as defined by Ostrom (2009) in her framework of socialecological systems.
} 
flexibility and reciprocity of grassland use (Fernandez-Gimenez and Le Febre, 2006). It has been advocated that the government-driven transformation of traditional pastoralism broke the balance between the grassland ecosystem and livestock production, increased vulnerability to natural disasters and threatened pastoral livelihoods. In particular, privatisation and enclosure in arid and semi-arid pastoral areas seriously threatens the integrity of ecological systems because these areas are characterised by temporal variability and spatial heterogeneity (Mwangi, 2007). It is necessary to examine whether a tragedy of privatisation may have occurred, rather than the well-known tragedy of the commons. In addition, some scholars have implied that grassland degradation as a result of overgrazing is not possible in traditional pastoralism, because animals would be moved to new places for available forage before the vegetation of one area is significantly impacted by grazing ( $\mathrm{Li}$ and Huntsinger, 2011). Furthermore, the restriction of livestock grazing inevitably causes economic loss to herders, which may impede the implementation of the environmental policies and programs. As such, the environmental policies and programs do not seem to be effective for preventing grassland degradation, especially those focussed on controlling livestock grazing.

What are the outcomes of these prevailing policy interventions, i.e. the outcomes of the governmentdriven transformation of traditional pastoralism? Are they valid in light of the sustainable use and management of grasslands? In this dissertation, these questions will be examined by researching the following issues: what is the impact of grassland privatisation on grassland condition and livestock production? What is the impact of the environmental policies and programs on grassland conservation? Although some academic studies and governmental reports have presented the results of policy interventions on grassland systems, the existing literature lacks quantitative analysis, based on largescale areas and long-term observations, in order to dissect the policy effectiveness, and has thus far fallen short of thorough and systematic discussion on the outcomes of government-driven transformation of traditional pastoralism (Lu et al., 2015). Therefore, this research employs empirical analysis based on panel data involving extensive grasslands of China and spanning several decades, with a focus on the effects of the transformation of pastoralism on both grassland condition and livestock production.

\subsection{Background information}

\subsubsection{Grasslands of China}

China has around 392 million hectares of grasslands, the second largest area in the world after Australia, accounting for $12 \%$ of the world's grasslands and $41.7 \%$ of the national land area (Fan et al., 2008). Nearly $80 \%$ of these grasslands are in arid and semi-arid regions, which are characterised as most vulnerable to degradation, desertification and salinisation (Feng et al., 2008; National Bureau of 
Statistics of China, 2009). Approximately 17 million people maintain their livelihoods on the grasslands of China ( $\mathrm{Li}$ et al., 2014). The extensive grasslands of China are concentrated in six provinces and autonomous regions: Xinjiang, Tibet, Qinghai, Sichuan, Gansu and Inner Mongolia. They account for $75 \%$ of grasslands and accommodate $70 \%$ of the grazing livestock of China (Suttie et al., 2005). These areas maintained traditional pastoralism over hundreds of years, before undergoing thorough land tenure reform since the 1980s and a series of Ecological Construction Programs since 2000. These policy interventions have been implemented widely in favour of transforming traditional pastoral practices.

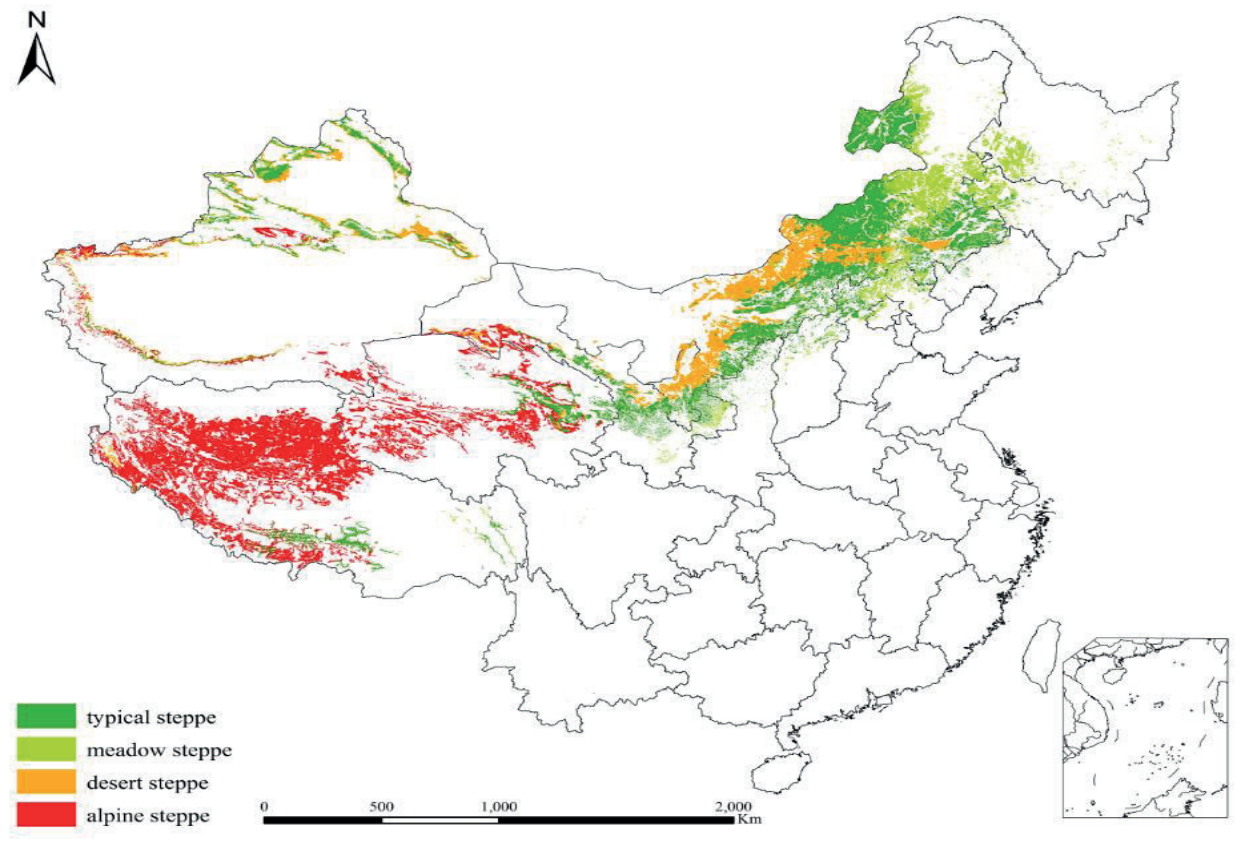

Figure 1.1 The distribution of grasslands in China

As shown in Figure 1.1, the grasslands of China are mainly distributed on the Inner Mongolia Plateau, the Loess Plateau and the Qinghai-Tibetan Plateau. The extensive grasslands are classified into four major types based on the analysis of plant community in phytology (Wu et al., 1980; Kang et al., 2007), including meadow steppes, typical steppes, desert steppes and alpine steppes. These four types of grasslands have a combined distribution ranging from the northeast plain adjacent to Mongolia to south of the Tibetan Plateau (Kang et al., 2007). The meadow steppes and typical steppes are the most commonly used grasslands for grazing and other economic activities related to livestock production, and most of them are located on the Inner Mongolian Plateau (Kang et al., 2007).

China's grasslands play crucial roles in livestock production, household livelihoods and global ecosystems (Kang et al., 2007). Northern China contains over 50\% of China's grasslands, which are 
called the traditional pastoral areas (Ho and Azadi, 2010), and which were home to the world's largest population of sheep and goats and the fourth largest concentration of cattle in the 1990s (Zhang and Yang, 1990; National Research Council, 1992; Ho and Azadi, 2010). They are considered to be the major areas for livestock production in China, with a long history of producing meat, milk, wool and fur. Moreover, local animal husbandry provides livelihoods to millions of people, with a majority existing as traditional self-sufficient enterprises and a few commercial grazing businesses ( $\mathrm{Li}$ et al., 2014). The ecological function of China's grasslands is being emphasized increasingly, such as biodiversity conservation, carbon sequestration, soil retention, soil fertility maintenance, and catchment protection (Suttie et al., 2005). It was shown that the grasslands of northern China significantly impact both regional climates and the global carbon cycle (Ni, 2002). In addition, the majority of pastoral areas are populated by ethnic minorities, such as Mongolians and Ewenkis, thus protecting the grasslands of China also has a social function of maintaining cultural diversity and social stability (Kang et al., 2007). These socio-economic and environmental functions of grasslands have invoked the increasing attention of central and local governments to adopt policy interventions for sustaining the productivity of - in addition to protecting - the grassland ecosystem.

\subsubsection{Grassland degradation in China}

Grassland degradation, a worldwide problem, is particularly severe in China (Ho and Azadi, 2010). Grassland degradation can manifest itself in the lowering of grassland productivity, reduction in soil fertility, soil compaction, increased presence of unpalatable species of grass, or a combination thereof (Li et al., 2013). Although lacking clear documentation and differing in specifics regarding the extent of China's grassland degradation during the last several decades, it is unanimous among herders, scholars and governments that the grasslands of China have experienced degradation, with significant regional variation (Harris, 2010; Waldron et al., 2010). An often-cited figure is that about $90 \%$ of China's grasslands were degraded to various extents by the 2000s (Unkovich and Nan, 2008; Waldron et al., 2010), and that degradation was increasing at a rate of two million hectares per year (Ren et al., 2007; Harris, 2010; Cao et al., 2013b). The grassland areas shrunk significantly by the beginning of the twenty-first century. In particular, the northern grassland boundary had moved about $200 \mathrm{~km}$ southward and the western boundary about $100 \mathrm{~km}$ eastward compared to the previous hundred years (Liu 2008; Cao et al., 2013b).

A series of natural disasters in China in the late 1990s are to some extent responsible for degradation and desertification of the grasslands in northern China (Kang et al., 2007; Wu et al., 2015), for instance, the Yangtze River floods that killed thousands of residents, the Yellow River droughts that cost billions of US dollars in economic losses, and the frequent dust-storms and sand-storms that blanketed the sky of Beijing and affected the health and economic wellbeing of millions of city-dwellers (Harris, 2010). 
It has been noticed that grassland degradation does not only impact herders who rely on the grasslands for survival and their livelihood, but also threatens the ecological security of the whole country (Harris, 2010; Huang et al., 2013).

Plenty of politicians and scholars have raised concerns over the causes of grassland degradation in China. Overgrazing and unsuitable grassland reclamation for cultivation have been accepted as the principal reasons (Ho, 2001). It was indicated that the total number of livestock in China increased by 594 million from 1981 to 2006 (Cao et al., 2013b), and an estimated 67 million hectares of high-quality grasslands have been converted to the cultivation of grains since 1949 (Ho and Azadi, 2010). However, other scholars have suggested that overgrazing only exists and leads to degradation in specific areas, with little evidence from national data to suggest that overgrazing per se has been responsible for widespread grassland degradation across China's pastoral grazing areas (Cao et al., 2013b). As such, one of the most controversial and debated aspects of research about grasslands is the existence and extent of overgrazing and its impact on grassland degradation (Suttie et al., 2005). Other anthropogenic interventions, such as over-excavation of medicinal herbs and mining, are thought to be responsible for at least some of the grassland degradation (Ren et al., 2007). Climate-related factors are an ongoing concern as a significant driver of grassland degradation in arid and semi-arid areas. For example, the distribution of precipitation is discussed as a principle factor of the changes in grassland condition (Harris, 2010; Cao et al., 2013b), while temperature is concluded to be a driver for changes in the biomass production of grasslands (Piao et al., 2006). Last but not least, the policy interventions that attempt to transform traditional pastoralism have been suspected to be significant causes of grassland degradation in China (e.g. Li and Zhang, 2009; Harris, 2010; Cao et al., 2013b).

\subsubsection{Livestock production in the pastoral areas of China}

China's livestock systems can be classified as traditional grazing, industrial production or mixed systems (Cao et al., 2013b). Traditional grazing systems are characterised by the direct consumption of permanent pastures (Waldron et al., 2007). The majority of production in traditional grazing systems provides subsistence to local residents, and therefore their livestock production usually includes several species of multipurpose animals - producing meat, milk, hides, fibre, transport, and manure for fuel (Suttie et al., 2005). These regions are called pastoral areas, which are geographically vast but sparse in population. They are mainly located in the west, north and northwest of China, including the Mongolian and Tibetan plateaus and Xinjiang Uighur Autonomous Region (Cao et al., 2013b). Industrial production systems aim to produce commodities for market sale, such as milk and meat. Their livestock production usually concentrates on one or two species of animals and relies also on crop products and sown pastures. Industrial production systems are mainly located in the southeast (Guangdong Province and Guangxi Zhuang Autonomous Region), north (Shanxi Province, Hebei Province and Beijing and 
Tianjin Municipalities) and northeast (Liaoning Province, Jilin Province and Heilongjiang Province) (Cao et al., 2013b). Mixed systems are the interface between traditional grazing and industrial production.

China is a major player in the international livestock sector and has experienced impressive increases in livestock production ${ }^{3}$ but it has been observed that the increases in livestock production are predominantly associated with industrialised, rather than traditional, grazing systems in China (Cao et al., 2013b). The intensification of livestock production in China started in the late 1980s and has advanced progressively ever since, which resulted in significant changes in livestock production structures as well as the geographical distribution and composition of the livestock commodities of China (FAO, 2016). In addition, with the increasing environmental concerns about the ecosystem of natural grasslands, livestock production increasingly relies on the utilisation of crop stalks, bran, and other byproducts of grain, instead of natural pastures (FAO, 2015). In the 1990s, the central government called for moving cattle and sheep production from the traditional grazing region to the grain-producing provinces, because it was believed that overgrazing of pastoral areas was the main reason for grassland degradation. This policy strategy was strengthened after a series of environmental disasters had occurred in the 2000s. What followed has been a steady increase in the total livestock outputs in China but a decrease in the share of livestock production in the pastoral areas (Li, 2009). In short, the market share of livestock products in China has experienced a geographic shift from pastoral areas to crop-farming areas, in accordance with changes in production technology and national policy strategies in recent years (Li et al., 2008).

Livestock production in the pastoral areas provides livelihoods to millions of people and has considerable capacity to alleviate the increasing stress of livestock product demands that have risen with growing population, urbanisation and rising disposable incomes in China (FAO, 2015). Nevertheless, few studies have discussed the livestock production of the pastoral areas clearly and thoroughly. One important reason is the questionable accuracy of Chinese livestock statistics, especially the data about the pastoral areas (Waldron et al., 2007). Statistical data collection on the livestock population is extremely difficult in China because small rural households raise livestock at a small scale, and supply chains are dominated by countless small traders and processors, unlike the centralised slaughter and auction systems that facilitate statistical data collection in developed countries (Waldron et al., 2007). China's method of collecting these data has been a system of bottom-up reporting, which is vulnerable

\footnotetext{
${ }^{3}$ Based on the FAOSTAT database, China's meat output accounted for $10.8 \%$ of the world total in 1980, and the share rose to $28.7 \%$ in 2004 (Li, 2009). The average growth rate in meat production between 1980 and 2004 was $7 \%$ in China, compared with only $3 \%$ for the world (Waldron et al., 2007).
} 
to misreporting from herders and local officials hoping to respond to the policy orientation of higherlevel governments (Waldron et al., 2007).

\subsubsection{The overview of China's grassland policies}

For a long time, China had no comprehensive long-term policy for grasslands (Ho, 2000). In the past, grasslands were owned by princes, lamaseries, landlords, or clans, and remained in common use by tenant herders. After that, in the collectivist period of New China, the grassland was owned by the production team or People's commune and the grassland was still managed and used communally by all local herders (Hua and Squires, 2015), while local communities had their own institutional structures for the use and management of grasslands (Ho, 2000). When the People's commune was abolished and grassland degradation was impending, there was an urgent need to fill the institutional vacuum for grassland use and management (Ho, 2000). Subsequently, there are two major policies that have been widely employed for the grassland use and management of China, including the land tenure reform during the 1980s-1990s and a series of Ecological Construction Programs after 2000. The former aims at privatising use rights of grasslands to individual households and displacing traditional common use (Banks et al., 2003) and the latter mainly concerns the grassland conservation as well as the maintenance of local household livelihoods (Liu et. al., 2016).

More specifically, land tenure reform started with the Household Production Responsibility System in the cropland areas of China in the late 1970s and spread to the pastoral areas in the early 1980s. The land tenure reform in the pastoral areas was implemented by local governments through local regulations, such as the Double Contracting System ("cao xu shuang cheng bao") in Inner Mongolia. The ownership of livestock was assigned to households on the basis of the size of the household and labour force (Banks et al., 2003). The use rights to grasslands were informally allocated to small groups of households, and use rights to hayfields and croplands were allocated to individual households. Meanwhile, the marketing system for most livestock products was simultaneously liberalised and only wool remained under state monopoly control (Banks et al., 2003). The first Grassland Law of China, initiated in 1985, stipulated that the property rights over grasslands are owned either by the state or the collective but that use rights to the grasslands could be contracted out to either households or collectives. Moreover, the users (individual households) of the grasslands are regulated to control their livestock numbers according to a stocking rate in order to avoid overuse of grasslands (Ho, 2000). Then, the assignment of grassland use rights to individual households was strengthened by Chinese governments in the 1990s, which greatly fuelled the progress of grassland privatisation and was regarded as the second round of grassland privatisation in China (Li and Zhang 2009). In 2002, the revised Grassland Law reaffirmed the shift from state- and collective-oriented land use rights to those of individual households (National People's Congress of the People's Republic of China, 2002). The State Council 
emphasised the specific allocation of the contracted items (e.g. grassland plots, areas, issuing user-right certificates) to households to ensure the long-term stability of contract relations in 2011 (Li, 2012). According to the current Law on the Contracting of Rural Land, grassland use rights can be contracted to individual households for 30 to 50 years.

Since the severe natural disasters of the late 1990s (Harris, 2010), the central government has hastened to engage in ecosystem protection and therefore a series of Ecological Construction Programs have been initiated, especially after 2000 (Wu et al., 2015). For example, the Conversion of Cropland to Forest and Grassland Program (also known as the Grain for Green Program) was mainly implemented between 2001 and 2010, and covered 25 provinces of China with a total budget of 225 billion RMB. It involved returning sloping or deserted cropland to forest or artificial grassland (Wang and Bennett, 2008; Liu, Lu and Yin, 2010). The Returning Grazing to Grassland Program was launched in 2000. It is one of the largest environmental programs on the grasslands of China. This program aimed at grassland conservation by sowing grass on those grasslands experiencing serious degradation, as well as restricting grazing in all program areas, involving grazing bans (either permanently or seasonally), rotational grazing and setting a deterministic stocking rate (Li et al., 2014; Hua and Squires, 2015). Apart from these two major programs in the 2000s, there were other programs that employed similar policy measures for grassland conservation, such as the Program to Combat Desertification around Beijing and Tianjin. These Ecological Construction Programs were implemented at household-level, with or without some compensation in cash, grain or grass seeds for the herders' economic loss (Suttie et al., 2005). Since 2011, another successive Ecological Construction Program, the Subsidy and Incentive System for Grassland Conservation (SISGC), has been initiated in eight pastoral provinces of China, including Inner Mongolia, Xinjiang, Tibet, Qinghai, Sichuan, Gansu, Ningxia and Yunnan. It aims at conserving the condition of grassland and meanwhile improving local herders' livelihoods and livestock production through intensification (State Council of the People's Republic of China, 2010). The central government promised a budget of 13.4 billion RMB per year for its implementation between 2011 and 2015. The major regulations on grazing still include the permanent grazing ban and the deterministic stocking rate, but they are supported with more subsidies or incentives to compensate the herders' economic loss.

\subsubsection{Research region: the pastoral areas of Inner Mongolia}

Inner Mongolia, a province ${ }^{4}$ located in the arid and semi-arid areas of northern China, has 118.3 million hectares of land with a permanent population of 25 million in 2014. It contains $21.7 \%$ of the area of China's natural grasslands. Approximately $67 \%$ of the total land in Inner Mongolia is classified as

\footnotetext{
${ }^{4}$ The full name is Inner Mongolia Autonomous Region.
} 
grassland (Angerer et al., 2008). (Angerer et al., 2008). It has played an important role in the supply of livestock products and the ecosystem of China. Official statistics showed that the animal husbandry of Inner Mongolia accounted for 45\% of the province's gross output value of agriculture in 2013. Inner Mongolia accounted for $18 \%$ of the population of sheep in China in 2013; the mutton output accounted for $22 \%$ of total output in China; $6 \%$ of cattle were raised in Inner Mongolia, and $8 \%$ of beef was produced there.

As a traditionally pastoral region populated by Mongolians, the vast majority of local people maintain their livelihoods by grazing on the grasslands (Angerer et al., 2008). Inner Mongolia has been the major and prior region for implementing the grassland policies in China because of its typical position in China's grassland resource and livestock production ( $\mathrm{Li}$ and Huntsinger, 2011). However, it was reported that $90 \%$ of the natural grasslands of Inner Mongolia had been degraded to some extent by 2000 and grassland degradation remains problematic since (Waldron et al., 2010; Briske et al., 2015). With society's growing attention to the grassland ecosystem and continuing grassland degradation, Inner Mongolia has been increasingly emphasised as an ecological barrier of northern China instead of the previous status it had as the main production area of livestock products (Wu et al., 2015). Moreover, the provincial government of Inner Mongolia has put emphasis on the development of livestock production in crop farming areas, rather than the pastoral areas, since 2001 . For instance, $70 \%$ of livestock production in Inner Mongolia was located in the crop farming area in 2007 (Su, 2010).

According to the current administrative divisions of Inner Mongolia, there are 102 counties, including 33 pastoral counties, 21 semi-pastoral counties and 48 counties dominated by crop farming or urban districts. Pastoral counties are characterised by traditional grazing systems and natural grassland is the dominant land type. In semi-pastoral counties, both natural grassland and cropland are the dominant land types, while traditional grazing systems exist and mixed crop-livestock systems also occur. The pastoral counties and semi-pastoral counties are usually regarded as the pastoral areas of Inner Mongolia and represent a typical region to investigate the grasslands of China (e.g. Taylor, 2006; Li and Zhang, 2009). Figure 1.2 illustrates the location of Inner Mongolia in China and its three types of counties. 


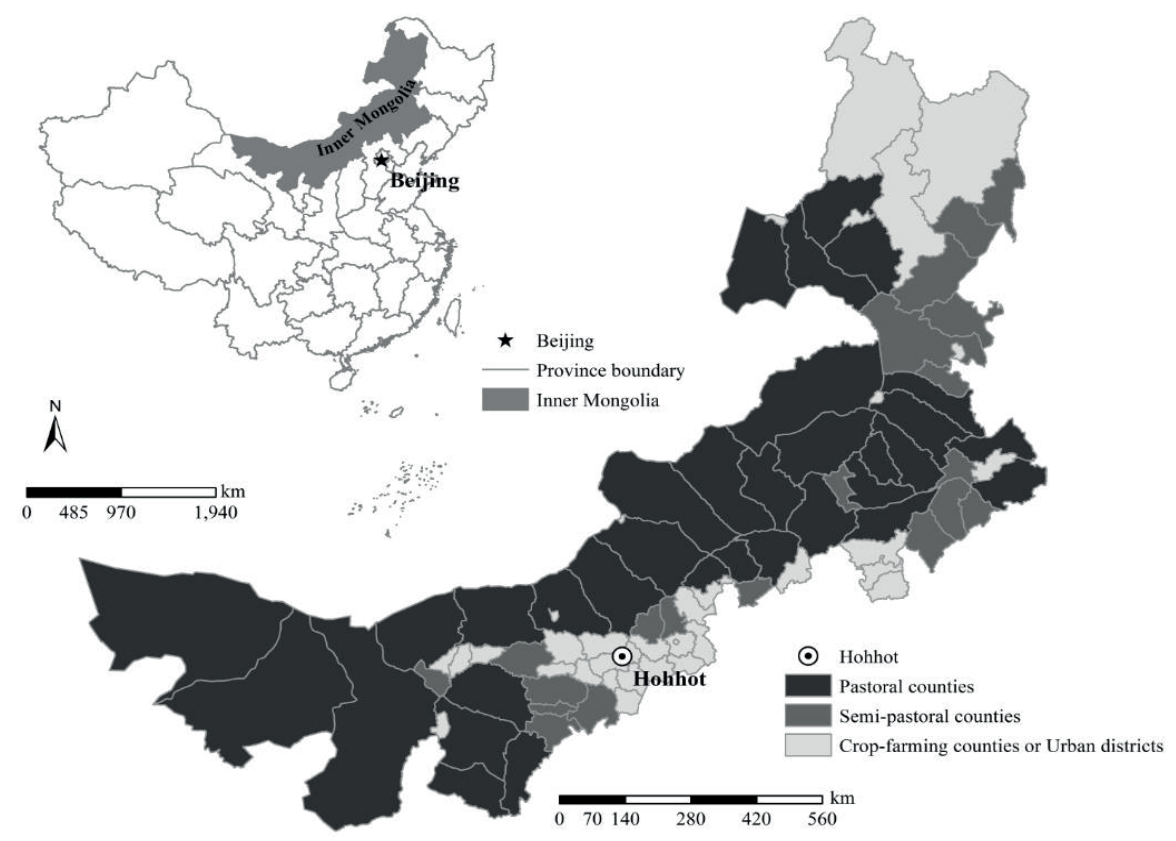

Figure 1.2 Inner Mongolia and its 102 counties

\subsection{Objectives and research questions}

Given that China's grasslands are confronted with the challenge of grassland degradation, the increasing demand for livestock products and the livelihoods of millions of households, an investigation into the sustainability of grassland use and management is urgently needed. Plenty of policies devoted to transforming traditional pastoralism have already been implemented to balance the productive and ecological functions of grasslands. However, grassland degradation and rural poverty in some pastoral areas are still worsening in China and there is no consistency within academic circles regarding how to transform traditional pastoralism under contemporary social, economic and political settings. As such, the objective of this research is to dissect the outcomes of China's policy interventions on its grassland system and further discuss the government-driven transformation of traditional pastoralism.

To fulfil this research objective, four research questions will be addressed in four chapters of this dissertation:

Question 1: What are the individual and social optima of rural land allocation by stakeholders: among cultivated land, grassland, forest and other rural land? This question is answered in Chapter 2. This chapter explores the different desires of stakeholders shaping grassland areas, which mirrors the different perceptions of grassland use under government-driven transformation of traditional pastoralism. 
Question 2: What is the impact of land tenure reform on the grassland condition in the pastoral areas of China? This question is answered in Chapter 3. Chapter 3 investigates the ecological effect of land tenure reform on the grassland system, which presents the ecological outcome of the transformation of pastoralism with the abandonment of communal tenure.

Question 3: What is the impact of land tenure reform on livestock production in the pastoral areas of China? This question is answered in Chapter 4. This chapter explores the economic effect of land tenure reform on the grassland system, and presents the economic outcome of transforming pastoral areas, in terms of livestock changes in population as well as productivity.

Question 4: What is the impact of Ecological Construction Programs on the grassland condition in the pastoral areas of China? This question is answered in Chapter 5. This chapter investigates the effect of Ecological Construction Programs on the grassland system, which mirrors the ecological outcome of the transformation of pastoralism, through the use of deterministic stocking rates and grazing ban.

To summarise, the research objective is specifically addressed by evaluating the ecological and economic effects of the land tenure reform and Ecological Construction Programs that have been employed to intervene in the grassland use and management in China. The aim of this research is to contribute to the approach toward sustainable use and management of grasslands in China or other regions that have similar circumstances to China's, by providing empirical evidence for the academic arguments on the transformation of traditional pastoralism.

\subsection{Materials and methods}

\subsubsection{Conceptual framework}

All resources used by humans are embedded in complex social-ecological systems (SESs). Ostrom (2009) introduced a general framework for analysing sustainability of SESs, which integrates the different frameworks of different disciplines and provides a common method for dissecting the complex SESs. It helps to identify the potentially relevant variables and their subcomponents to design the data collection, to conduct the fieldwork, and to perform the analysis of findings about the sustainability of complex SESs (Ostrom, 2009). As such, this research employs Ostrom's framework as the starting point for conducting our study of linked SESs of grasslands.

Figure 1.3 illustrates the conceptual framework adapted from Ostrom's framework for analysing the SESs of grasslands. It shows the four first-level core subsystems of the SESs of grasslands, the relationships between subsystems and the link to social, economic, and political settings and related ecosystems. The four first-level core subsystems in the SESs of grasslands are identified as: (1) 
grassland system (e.g. grazing area, water systems, and animal husbandry); (2) grassland resource units (e.g. forage, water, and animals); (3) users (e.g. herders, farmers and others); and (4) governance system (e.g. government and policy interventions). These four subsystems are relatively separable but interact to produce outcomes at the SES level, which in turn affect the subsystems (Ostrom, 2009). This thesis aims to reveal the impacts of governance systems upon the grassland systems, resource units and users. One of the broad questions this SES framework is used to solve is what impacts are likely to result from using particular rules for the governance, ownership, and use of a resource system and resource units in a specific technological, socioeconomic, and political environment (Ostrom, 2007). Long-term sustainability depends on rules matching the attributes of the resource system, resource units, and users (Ostrom, 2009). This study is devoted to examining whether the policy interventions of China are beneficial to the grassland system, grassland resource units and users in the long term.

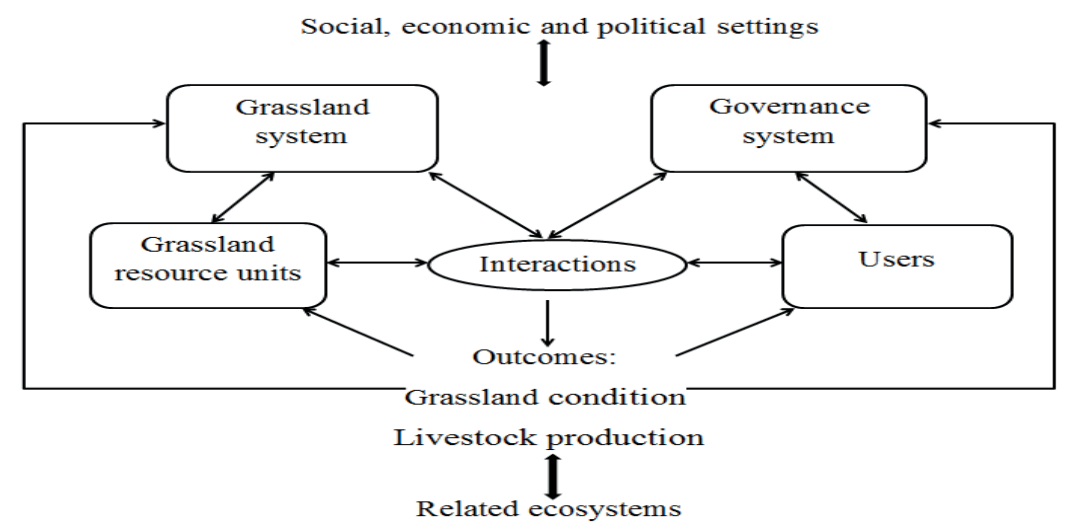

Figure 1.3 Conceptual framework for analysing social-ecological systems of grasslands (Adapted from Ostrom's framework for analysing social-ecological systems (Ostrom, 2009))

More specifically, this study focuses on evaluating the ecological and economic impacts of China's policy interventions on grasslands, which essentially reflects the outcomes of governance systems on grassland systems under the social, economic and political settings in which said systems are embedded. The outcomes for grassland systems are specifically measured by grassland condition and livestock production. The social, economic and political settings considered refer to market forces, technological development and climate changes among other factors. The governance system relates to the specific rules for the use and management of China's grasslands, including the land tenure reform studied in Chapters 3 and 4 and the Ecological Construction Programs studied in Chapter 5. In addition, the conflicts of different users over resource units, specifically the grassland area, are investigated in Chapter 2. 


\subsubsection{Sampling and data collection}

In Chapter 2, the analysis of optimal land allocation is based on a case study. The sample county, Tai Pusi County ${ }^{5}$, is a semi-pastoral county located in the eco-fragile region of Inner Mongolia, which has been characterised by economic backwardness and ecological degradation. The county covers different types of rural land and involves a variety of different stakeholders with divergent interests in rural land use. It is a typical region to investigate the conflicts of rural land allocation in China, reflected in the different preferences for grasslands by different stakeholders. For the data collection, interviews with the representatives of different types of stakeholders were conducted face to face to reveal their preference on land use, involving cultivated land, grassland, forest land and other rural land. The secondary data on socio-economic indicators was collected from statistics and reports from local governments.

Chapters 3, 4 and 5 focus on policy evaluation. Panel data at county-level is used to answer the research questions. Policy interventions have occurred over different years and there are differences in the process of implementation among counties. These differences within and between counties are presented by the panel data. For the analysis of land tenure reform in Chapters 3 and 4 , all of the counties of Inner Mongolia were considered as possible sample counties. After excluding the counties with invalid survey feedback, and after dropping the urbanised counties where changes in the grassland area can be attributed mainly to changes in land use types 60 counties are retained as the research sample, including 29 pastoral counties, 18 semi-pastoral counties and 13 crop farming counties ${ }^{6}$. The research period covers 1985-2008, spanning the main period for implementing land tenure reform on the grasslands of Inner Mongolia. For the analysis of Ecological Construction Programs in Chapter 5, all of the counties in the pastoral areas, including 33 pastoral counties and 21 semi-pastoral counties, were used in the research sample. It should be noted that the crop-farming counties and urban districts are excluded from the research sample because they are not the typical regions included for the Ecological Construction Programs. This research period spans 14 years from 2001 to 2014, involving the years before and after the implementation of the specific Ecological Construction Program studied (i.e. the Subsidy and Incentive System for Grassland Conservation).

In terms of the data collection for the policy evaluation, the required dataset includes four categories of information: the policy interventions, the grassland condition, the livestock production, and the socioeconomic and climate conditions. The information about policy interventions, such as the progress of land tenure reform and Ecological Construction Programs, was gathered based on the statistics and

\footnotetext{
${ }^{5}$ Also named as Tai Pusi Qi in Chinese.

${ }^{6}$ The crop farming counties considered also have grasslands and experienced the same land tenure reform as the pastoral area.
} 
reports from the provincial government as well as through questionnaires. The questionnaires were sent to the Animal Husbandry Bureau of each county and answered by local experts. In the second phase, interviews were conducted by telephone to confirm the answers that were received. Apart from the questionnaires, interviews were conducted with the officers working in the provincial institutes of Animal Husbandry of Inner Mongolia and with local herders to verify the information thoroughly. Remote sensing and GIS (geographic information system) were employed to obtain data about the grassland condition across extensive grasslands over a long period. The data on livestock production and socio-economic and climate factors was collected based on existing statistical data gathered by governments.

\subsubsection{Model selection}

In Chapter 2, the model for investigating the optimal land allocation is based on welfare economics, specifically utilising the utility function and social welfare function. The utility function presents the utilities of different stakeholders for land allocation based on their preference. The Analytic Hierarchy Process (AHP) is used to quantify the preference of stakeholders for different types of land. The social welfare function is derived based on the utility functions and the weights of stakeholders in land allocation, in which three scenarios are employed to estimate the weights. Ultimately, the divergences among individual optima derived from the utility functions, the social optimum derived from the social welfare function, and actual rural land allocation, illustrate the conflicts in preferences of different stakeholders regarding rural land use.

Chapters 3, 4 and 5 employ panel data to dissect the effectiveness of policy interventions. The fixed effects model, which is used to study the causes of changes within an entity over time, is employed to conduct an empirical estimation. The fixed effects model has been widely used in economic research (e.g., Fergusson et al., 2002; Huan et al., 2006). Compared with the multiple regression model, the advantage of the fixed effects model is the control over unobserved fixed factors that could affect the estimation (Liu et al., 2010; Verbeek, 2012). Theoretically, the fixed effects model employs within transformation to remove all time-invariant (fixed) explanatory variables, i.e. the model is performed in deviations from individual means (Verbeek, 2012). As such, it provides a method that takes observable explanatory variables as well as unobservable time-invariant variables into account, but the estimation does not depend on the value of time-invariant (fixed) variables, such as soil nutrient levels, soil depth, slope steepness, geographical positions of grasslands, in the case of this study (Verbeek, 2012). In addition, the feasibility of the fixed effects model has been tested using statistical tests based on the specific dataset used in each chapter. 


\subsection{Contribution of the dissertation}

In general, given the challenge of grassland degradation and increasing demand on livestock production, this research makes a contribution to providing references for improving the policy interventions toward more sustainable use and management of grasslands. Moreover, this study provides an empirical analysis of SESs of grasslands in China based on the common framework introduced by Ostrom. The research findings can be used in other studies that employ the same framework regarding different countries and different disciplines. This research hopes to increase the knowledge needed to enhance the sustainability of complex SESs of grasslands, as well as the understanding of the transformation of traditional pastoralism.

This research systematically discusses the major policy interventions for the use and management of grasslands in China, and further evaluates their effectiveness for the grassland condition and livestock production. The policy evaluation essentially presents the outcomes of government-driven transformation of traditional pastoralism in China. Although the transformation of pastoralism and the specific effects of the policy interventions on grassland systems have been investigated by governments and scholars (e.g. Li and Zhang, 2009; Li et al., 2014; Hua and Squires, 2015), there is a lack of studies providing quantitative and empirical analysis based on large-scale areas and long-term observation. As such, remote sensing and county-level statistics are combined for this research, the dataset of which involves the extensive grasslands of Inner Mongolia and spans decades. Economic models are employed to evaluate changes in grassland systems, targeting the specific policy interventions. This makes it possible to disentangle the policy effectiveness and control for the potential impacts of climate, socioeconomic factors and time trend on the grassland system. This provides an example of the combined use of remote sensing and economics for academic research. In addition, the different preferences of different stakeholders for grassland use under the existing policy intervention is qualified based on utility functions. The specific relevance of each chapter is explained next.

Chapter 2 presents the preference of different stakeholders for land allocation, and thus mirrors the different perceptions on grassland use. The novel contribution is the methodology, which combines welfare economics, the method Analytic Hierarchy Process (AHP) and scenario analysis. Although the outcomes are based on a specific case, the methodology is generic and likely to be valid for measuring conflicts between stakeholders over land use in other regions. The results provide interesting insights that can help to steer future land-use policies considering the different economic and ecological interests of different stakeholders.

Chapter 3 and 4 illustrate the progress of land tenure reform in the pastoral areas of China and investigate the results of privatisation of grasslands on grassland condition and livestock production when other 
factors are controlled for. These chapters provide some references to academic debates over the transformation of pastoralism, or grassland privatisation instead of communal tenure. The policy evaluation is conducted based on panel data which considers the spatial and temporal differences of policy implementation. Moreover, the existing literature about grassland privatisation concentrates on impacts on the grassland ecosystem, but there is a lack of research referring to the impact on local livestock production, examined here in Chapter 4. In this regard, despite the unreliability of official statistics on livestock, these research findings are useful for detecting general trends, if not specific numbers.

Chapter 5 summarises the Ecological Construction Programs in pastoral areas of China, and explains why the actual grassland degradation has not been prevented as effectively as expected. Based on the research results, this chapter points out the potential for improving grassland conservation policies. Moreover, it provides the empirical evidence for the scientific debate about the equilibrium model and the non-equilibrium model regarding deterministic or stochastic stocking rates.

\subsection{Organization of the dissertation}

This dissertation has six chapters, including a general introduction (Chapter 1), four research chapters that focus on the research objective of this dissertation (Chapter 2, 3, 4 and 5), and a general discussion (Chapter 6). The research scheme of the four research chapters is presented in Figure 1.4.

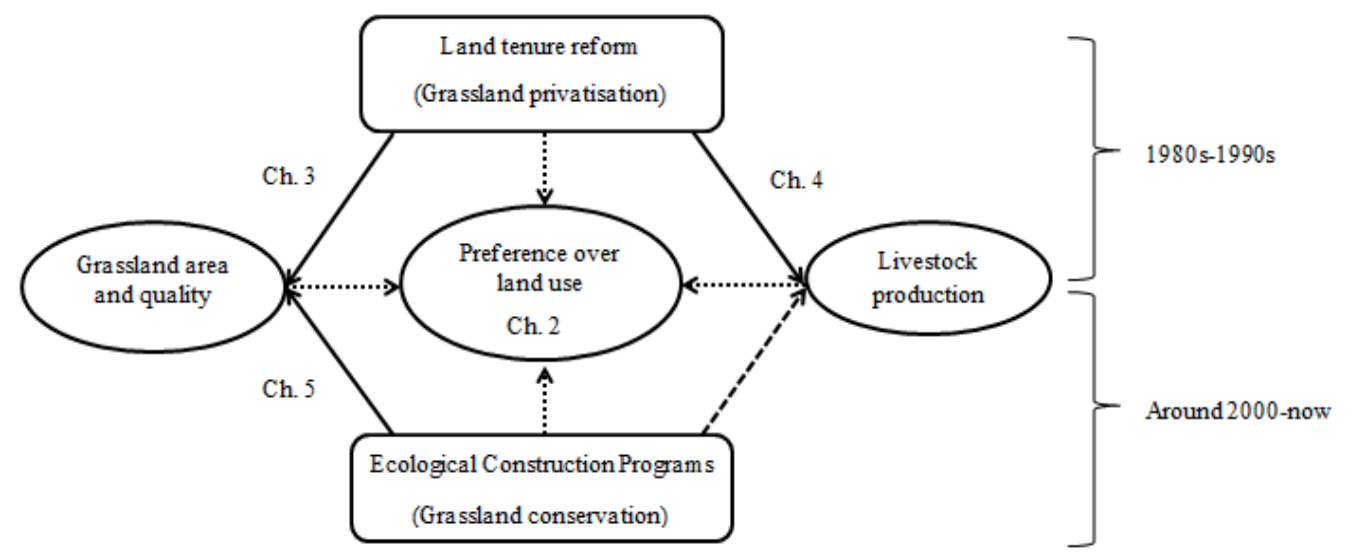

Figure 1.4 The research scheme of the four research chapters

Under the conceptual framework for analysing SESs of grasslands adapted from Ostrom's framework, the four research chapters elaborate on the outcomes of the governance system over the grassland system and its users. Specifically, Chapters 3 and 4 explore the impacts of land tenure reform (grassland privatisation) on grassland degradation and livestock production, which presents the outcomes of policy 
interventions for the grassland system. As previously defined, the grassland system in this research includes grassland conditions as well as livestock production. Grassland degradation is presented by grassland area and quality. Livestock production is indicated by livestock population and meat output. Chapter 5 examines the effectiveness of Ecological Construction Programs on grassland conservation, which presents the outcome of particular rules for the use and management of grassland resource units. In addition, Chapter 2 focuses on investigating the preference over land use by different users under existing social, economic, and political settings. The preference over grassland use is influenced by policies as well as by the outcomes of policy interventions over grassland systems, which is indicated by dashed lines in Figure 1.4. Another significant question marked by the long dashed lines is the effect of Ecological Construction Programs on livestock production, which will not be covered by this research but which is an appropriate candidate for future research. It should be noted that the main period for the implementation of land tenure reform in China is between the 1980s and 1990s, which predates the wide implementation of the Ecological Construction Programs since around 2000. It is assumed that this indication allows us to distinguish these two major policies as well as their main impacts by focusing on different research periods. 
Chapter 2

Rural land allocation in eco-fragile regions

of northern China 


\section{RURAL LAND ALLOCATION IN ECO-FRAGILE REGIONS OF NORTHERN CHINA7}

ABSTRACT: This paper takes a welfare economics perspective to study rural land allocation in ecofragile regions of northern China and explores the trade-off between stakeholder preferences over the economic and ecological benefits of rural land use. The preference of different stakeholder groups for various types of land is quantified by the Analytic Hierarchy Process, and the individual and social optimum of the allocation of land are investigated using stakeholder utility functions and the social welfare function. Our results show the conflicting views of different stakeholder groups and the potential equilibrium in the allocation of rural land under different scenarios.

KEYWORDS: rural land allocation, individual optima, social optima

\footnotetext{
${ }^{7}$ Paper by Min Liu, Wim Heijman, Xueqin Zhu, Liesbeth Dries, and Jikun Huang. Rangeland Journal. doi:
} $10.1071 /$ rj 15069 


\subsection{Introduction}

There is increased pressure on rural land use in many parts of the world (Petit, 2009; Williams and Schirmer, 2012). As a result of economic development, technological progress, environmental change and policy and market forces, the total area of rural land is decreasing worldwide (Liu et al., 2010; Verburg et al., 2008). This raises the question of how to efficiently allocate the decreasing amount of rural land, particularly for a populous country such as China. As a basic production factor, rural land is used for production and subsistence to satisfy immediate human needs for food, fuel, and ecosystem services (DeFries et al., 2007; Millennium Ecosystem Assessment, 2003). On the other hand, its multifunctional role has also triggered land use divergence and conflicts because of differing land use targets among stakeholders (Barker and Selman, 1990; Rambonilaza and Dachary-Bernard, 2007; Yang et al., 2012; Pacione, 2013). This paper investigates the optimal allocation of rural land taking into account the ecological and economic benefits for different stakeholders in society.

Changes in rural land use are not only attributed to micro-level household decisions on land use, but are also affected by national or macro-level land use strategies. For example, in China, several national programs have been introduced since the 1990s that attempt to steer rural land allocation in order to satisfy not only human needs for economic development but also the provision of ecosystem services. One of the main programs is the Sloping Land Conversion Program (SLCP, also known as the 'Grain for Green' program), initiated by the Chinese central government in 2000 in order to convert sloping cropland into forest or grassland (Liu et al., 2010). Such national programs that are directed at ecological conservation, may constrain the economic activities of local residents, while the majority of rural households in China rely on rural land for their livelihoods and economic benefits. As such, rural land use change associated with economic development and ecological conservation inevitably results in land use conflicts among different stakeholders.

These problems are particularly severe in eco-fragile regions where ecological issues and collective impoverishment are causing serious land use conflicts in the process of rural land use change. This is reflected in overgrazing, poor implementation of eco-environmental policies, deforestation, soil erosion and ecosystem deterioration. One fifth of the territory of China is identified as eco-fragile regions facing such problems (Yuan et al., 2011). In this paper, we therefore focus on land use change and conflicts in the farming-grazing transitional zone in the eco-fragile regions in northern China.

Optimal rural land allocation can be studied either from the macro perspective referring to the global or regional social-economic situation, or from the perspective of land use decisions at the rural household level. The scientific research on land use and land cover change has received increased attention since the 1990s because of prominent problems due to population growth, overuse of natural resources and 
environmental deterioration (Turner Ii et al., 1993; Qasim et al., 2013). Most research has focused on analysing the land cover dynamics using remote sensing data (Turner Ii et al., 1994; Zhan et al., 2007) and the driving forces of land use change based on qualitative analysis, econometrics or game theory (Angelsen, 2001). Others have tried to determine an optimal landscape (Heijman and Mouche, 2013). The current paper will add to the existing literature by using a welfare economics perspective to investigate the equilibrium of rural land allocation, taking into account the interplay between ecological and economic demand. In other words, we will study the optimal rural land allocation based on the trade-offs between economic development and ecological conservation as seen by different stakeholders.

The remainder of this paper is structured as follows. First, we present a conceptual framework of stakeholder interaction in rural land use decisions. Different stakeholder groups are identified based on various land use targets. Next, we derive the theoretical model starting with the utility function and preferences over desired rural land allocation for each stakeholder group. The optimisation of rural land allocation in terms of the benefits to society is explored by deriving the welfare function. This approach is in line with other studies that have modelled environmental problems through welfare analysis (Gerlagh and Keyzer, 2004; Gerlagha and Keyzer, 2003; Zhu, 2004). In the empirical part of the paper, we first describe the data collection methodology. The Analytic Hierarchy Process (AHP) is used to quantify the preference of each stakeholder group for different types of land. The optimal land allocation is derived based on these preferences and different scenarios concerning the weights that are assigned to each stakeholder group in the social welfare function. The paper concludes with a discussion on the differences between existing rural land use policies and the socially optimal allocation as studied in this paper.

\subsection{Conceptual framework}

To understand the complex relationships in the process of rural land use allocation, we use the concept of social-ecological systems (SESs). SESs represent complex adaptive systems in which social and biophysical agents are interacting at multiple temporal and spatial scales (Levin et al., 2013). Ostrom (2007; 2010) introduced a diagnostic framework for the study of complex social-ecological systems, considering the resource units, resource system, governance system and users as four core subsystems to link social, economic and regulatory settings and related ecosystems (Ostrom, 2009). This has enabled researchers to develop a common language that crosses social and ecological disciplines to analyse how interactions among a variety of factors affect outcomes. On the basis of Ostrom's framework, this paper focuses attention on the influence of the relationship between the governance system and users on the outcome of rural land use. Figure 2.1 demonstrates the analytical framework in this context. 


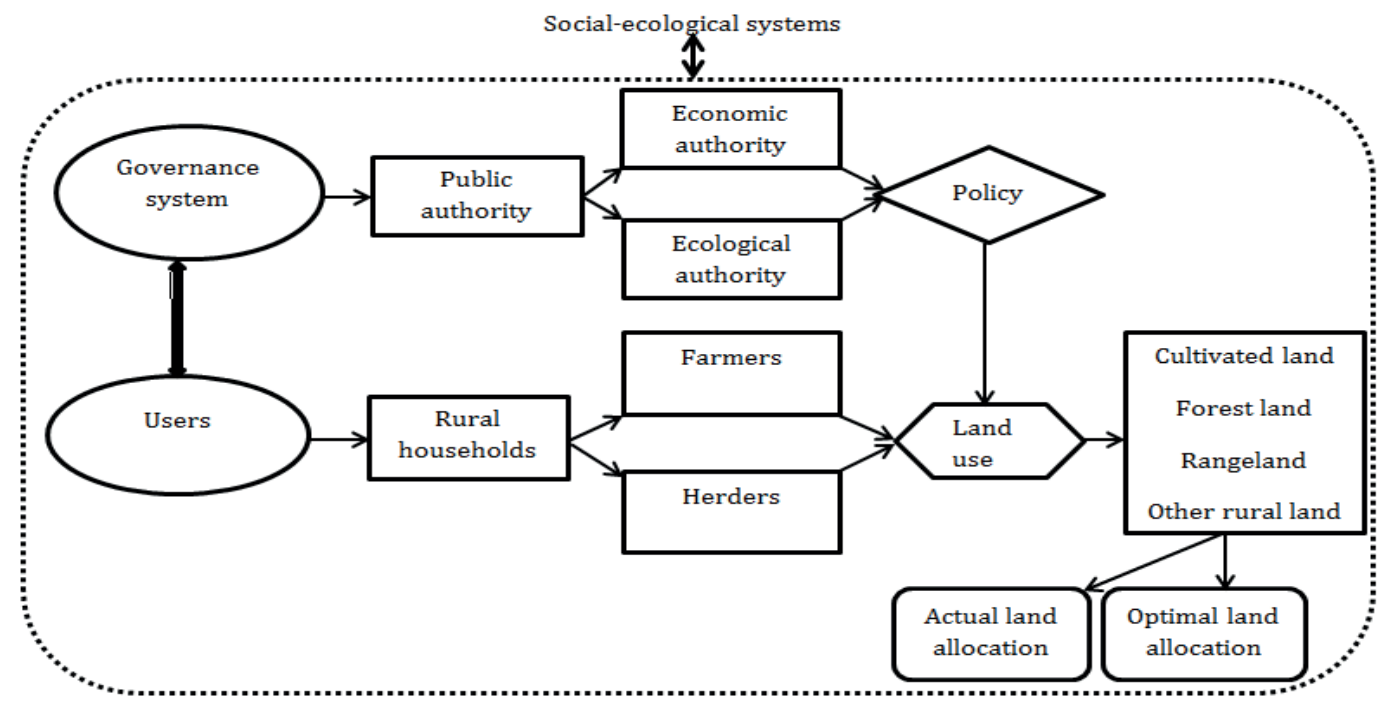

Figure 2.1 The framework for analysing the interaction between different stakeholders ${ }^{8}$

In the process of rural land allocation, the governance system is represented by the rules and regulations set at the level of the government to regulate rural land management for ecological conservation and economic development. Public authorities implement the specific rules related to rural land use. Rural households, as the users of the rural land, are affected directly by these rules in terms of land use decisions for subsistence, production or recreation. In this paper, we assume that public authorities and rural households are the social agents in the social-ecological systems of rural land use. Public authorities are divided into public actors with an economic objective (focusing on economic development) and public actors with an ecological objective (focusing on the conservation of natural resources for current and future generations). This is a simplified representation of reality which assumes that these public objectives can be separated. Among the private stakeholders we distinguish between farmers, who engage in both crop production and animal husbandry, and herders, who are solely dependent on the use of grasslands for livestock production. As such, we divide the social agents into four stakeholder groups, namely herders, farmers, ecological public authority and economic public authority.

In the next sections, we investigate the optimal land allocation based on the trade-offs between ecological conservation and economic development among different stakeholders. Specifically, we analyse the individual and social optimum of rural land allocation. The optimum is based on the different

\footnotetext{
${ }^{8}$ We follow the rural land classification by AQSIQ (General Administration of Quality Supervision, Inspection and Quarantine of the People's Republic of China) whereby rural land is divided into cultivated land, forest land, rangeland and other rural land (such as land used for raising animals, agricultural facilities, agricultural roads, pit-ponds, fishponds, irrigation, drying grains and forming ridges among croplands) according to the functions of land use in 2002.
} 
preferences of each stakeholder group as to the rural land value with a combination of diverse land functions, such as various degrees of economic function, ecological function and social function from the cultivated land, rangeland, forest land and other rural land. We describe the role of each stakeholder group in the allocation of rural land as follows: the local ecological public authority aims at protecting the regional ecosystem on behalf of the national government and social ecological demand, the economic public authority achieves the local government's targets for local economic development, and farmers and herders rely on the land for their agricultural production. The herders graze their animals on the rangeland, while the farmers rely primarily on the cultivated land. Section 3 will present the theoretical model which formalizes the conceptual framework.

\subsection{Model specification}

According to welfare economics, different agents have different demands on the consumption of various goods/services. This has led to the study of individual utility and social welfare optimisation for combinations of different goods characteristics (Heijman and Mouche, 2013; Perman et al., 2011). In our research context, we consider a hypothetical society consisting of four individuals and four goods. More specifically, the four individuals represent the four stakeholder groups (herders, farmers, ecological public authority and economic public authority), and the four sets of goods are cultivated land, rangeland, forest land and other rural land. The four stakeholder groups derive utility from consumption of the four types of land. A Cobb-Douglas form of utility function is used to investigate individual utility and social welfare. The Cobb-Douglas utility function has been applied in previous research to study the optimal consumption, leisure, investment and voluntary retirement problem for an agent (e.g. Koo et al., 2013), the trade-off between goods and leisure (e.g. Train and McFadden, 1978), the ecological discount rate (e.g. Gollier, 2010) and a typical low-rent housing lessees' welfare model (e.g. Wu et al., 2012). It is an appropriate method to investigate the individual and social optimum in utilitarianism, as studied here.

\subsubsection{The utility function of each stakeholder group}

In this section, the individual optimum is derived through the utility function of each stakeholder group. As with any resource, the allocation of land may be considered optimal when the aggregate social returns from its various uses are maximised (Lopez et al., 1994). Here, we will consider the economic and ecological uses of rural land by each stakeholder group in order to investigate their utility. Considering that the target of stakeholder group $i$ is to maximise its utility $\left(U_{i}\right)$ subject to land constraints, the utility function in the Cobb-Douglas form is,

$$
U_{i}=l_{\text {cul(i) }}^{a_{i}} l_{\text {ran(i) }}^{b_{i}} l_{\text {for }(i)}^{c_{i}} l_{\text {oth }(i)}^{d_{i}}
$$


where $\mathrm{i}=1,2,3$ and 4 represent the four stakeholder groups: herders, farmers, ecological public authority and economic public authority, respectively. $l_{c u l(i)}$ is the area of the cultivated land which is allocated by stakeholder group i for crop production. $l_{\text {gra }(i)}$ is the area of the rangeland allocated by stakeholder group $i$ for grazing animals and fulfilling an ecological protection function. $l_{\text {for }(i)}$ is the area of the forest land demanded by stakeholder group $i . l_{\text {oth }(i)}$ is the area of the rest of the rural land arranged by stakeholder group $i . a_{i}, b_{i}, c_{i}$ and $d_{i}$ are the utility elasticities of stakeholder group $i$ on land allocation among the cultivated land, rangeland, forest land and other rural land. The land constraint is as follows:

$$
l_{\text {cul }(i)}+l_{\text {ran }(i)}+l_{\text {for }(i)}+l_{\text {oth }(i)}=L,
$$

with $l_{\text {cul }(i)}, l_{\text {ran }(i)}, l_{\text {for }(i)}, l_{\text {oth }(i)} \geq 0 ; 0 \leq a_{i}, b_{i}, c_{i}, d_{i} \leq 1 ; a_{i}+b_{i}+c_{i}+d_{i}=1$.

where $\mathrm{L}$ is the total area of the rural land in the research region. Equation (2) illustrates that the sum of the cultivated land, rangeland, forest land and other rural land equals the total area of rural land. To find the individual optimum of land allocation, we maximise the utility functions (see Appendix 2-A for the detailed derivation). With the help of the Lagrange optimisation procedure this gives:

$$
\begin{aligned}
& l_{\text {cul(i) }}^{0}=a_{i} \times L, \\
& l_{\text {ran }(i)}^{0}=b_{i} \times L, \\
& l_{\text {for }(i)}^{0}=c_{i} \times L, \\
& l_{\text {oth(i) }}^{0}=d_{i} \times L .
\end{aligned}
$$

$l_{\text {cul }(i)}^{0}, l_{\text {ran (i) }}^{0}, l_{\text {for(i) }}^{0}$ and $l_{\text {oth(i) }}^{0}$ are the resulting individual optima of stakeholder group $i$, indicating the individually rational optimum depending on the preference of stakeholder group i for rural land use and taking into account land constraints.

\subsubsection{The social welfare function}

Bergson and Samuelson introduced the social welfare function, which sums up the utility functions of all the individuals in the society (Pollak, 1979). We assume that the four stakeholder groups represent all of the social agents of land use in the eco-fragile regions, therefore our social welfare function is presented by the configuration of the four stakeholder groups' utilities, subject to land constraints. Based on the utility functions of each stakeholder group, the Cobb-Douglas form of the social welfare function is: 


$$
W=\prod_{i=1}^{4} U_{i}^{\beta_{i}}
$$

subject to:

$$
\begin{gathered}
l_{\text {cul }(s)}+l_{\text {ran }(s)}+l_{\text {for }(s)}+l_{\text {oth }(s)}=L, \\
\text { with } \sum_{i=1}^{4} \beta_{i}=1 \text { and } \beta_{i} \geq 0, l_{\text {cul }(s)}, l_{\text {ran }(s)}, l_{\text {for }(s)}, l_{\text {oth }(s)} \geq 0,
\end{gathered}
$$

where $\mathrm{W}$ is the social welfare, $l_{\operatorname{cul}(s)}, l_{\operatorname{ran}(s)}, l_{\text {for }(s)}, l_{\text {oth(s) }}$ are the areas of cultivated land, rangeland, forestland and other rural land in the society. $U_{1}, U_{2}, U_{3}$ and $U_{4}$ are the utilities of herders, farmers, ecological public authority and economic public authority respectively based on the social land allocation. $\beta_{i}$ is the welfare weight of stakeholder group $i$ in the society.

To find the socially optimal land allocation, we maximise the social welfare function (see Appendix 2$\mathrm{B}$ for the detailed derivation). This gives:

$$
\begin{aligned}
& l_{\text {cul }(s)}^{*}=L \times \sum_{i=1}^{4} \beta_{i} a_{i}, \\
& l_{\text {ran }(s)}^{*}=L \times \sum_{i=1}^{4} \beta_{i} b_{i}, \\
& l_{\text {for }(s)}^{*}=L \times \sum_{i=1}^{4} \beta_{i} c_{i}, \\
& l_{\text {oth }(s)}^{*}=L \times \sum_{i=1}^{4} \beta_{i} d_{i} .
\end{aligned}
$$

$l_{c u l(s)}^{*}, l_{\text {ran }(s)}^{*}, l_{\text {for }(s)}^{*}$ and $l_{\text {oth }(s)}^{*}$ are the resulting socially optimal rural land allocations, which illustrates the optimum for social welfare based on the preferences on land use and welfare weights of each stakeholder group in the society.

\subsection{Research region and data collection}

An empirical application of the above theoretical model was conducted in Tai Pusi County, located in the eco-fragile region in the mixed farming zone in northern China. Tai Pusi faces both economic backwardness and ecological degradation (Chen, 2007) and is on the southern edge of Otindag Sandy Land, the nearest crucial sand source of sandstorms in Beijing. Its ecosystem plays a significant role in preventing sandstorms from reaching Beijing and various eco-environmental policies with restrictive land use are implemented here. Tai Pusi is one of the poverty-stricken counties of China and two thirds 
of local rural households' income is derived from agricultural production. Its total population is 211,146, and there are 171,500 and 39,646 residents living in rural and urban areas, respectively. Rural residents include 168,514 farmers and 2,986 herders. Tai Pusi County's total area measures 341,473 hectares, including 322,100 hectares of rural land, 14,613 hectares of urban and industrial land and 4,760 hectares of unused land. Figure 2.2 presents the 7 townships of Tai Pusi County. The townships are divided into pasture area and agricultural area because of different natural and social factors. In the pasture area, where the herders are living, the local livelihoods depend primarily on grazing and very few herders engage in crop farming. The farmers living in the agricultural area are involved in both crop farming and livestock breeding, but only with pen grazing due to the limitation of a strict policy that bans grazing since 2008. In recent years, with increasing population and eco-environmental policies, conflicts on rural land use among local farmers, herders and the government have intensified.

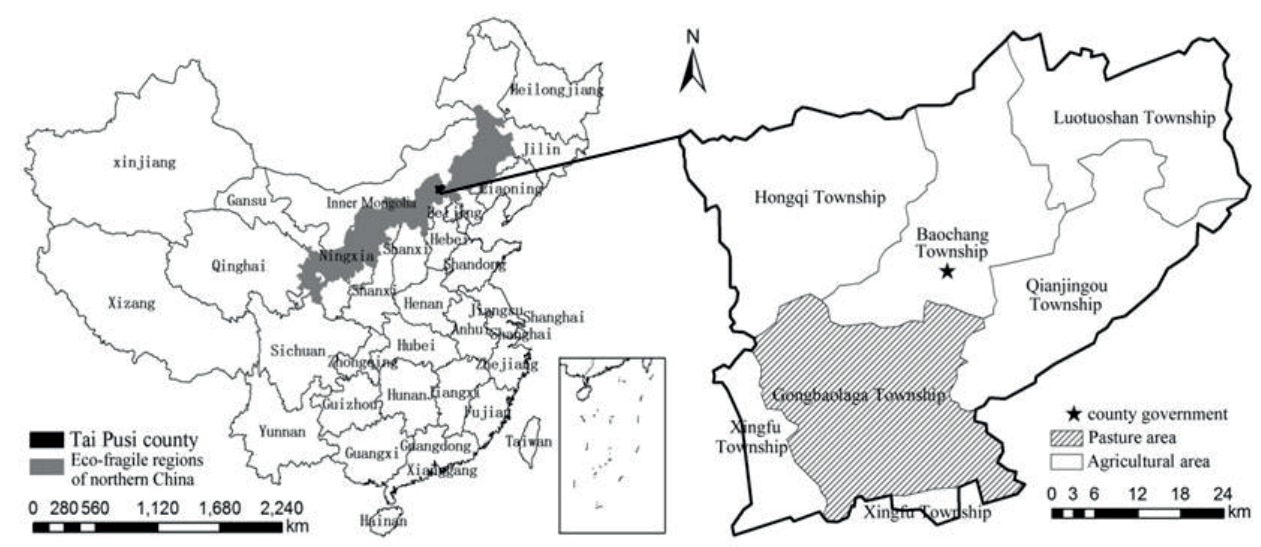

Figure 2.2 The eco-fragile regions in northern China (left) and Tai Pusi County (right) Source: Ouyang (2013) and Farming and Grazing Bureau, Tai Pusi County. 
Figure 2.3 shows the change of the cultivated land, forestland, rangeland and other rural land in Tai Pusi County from 1995 to 2009.

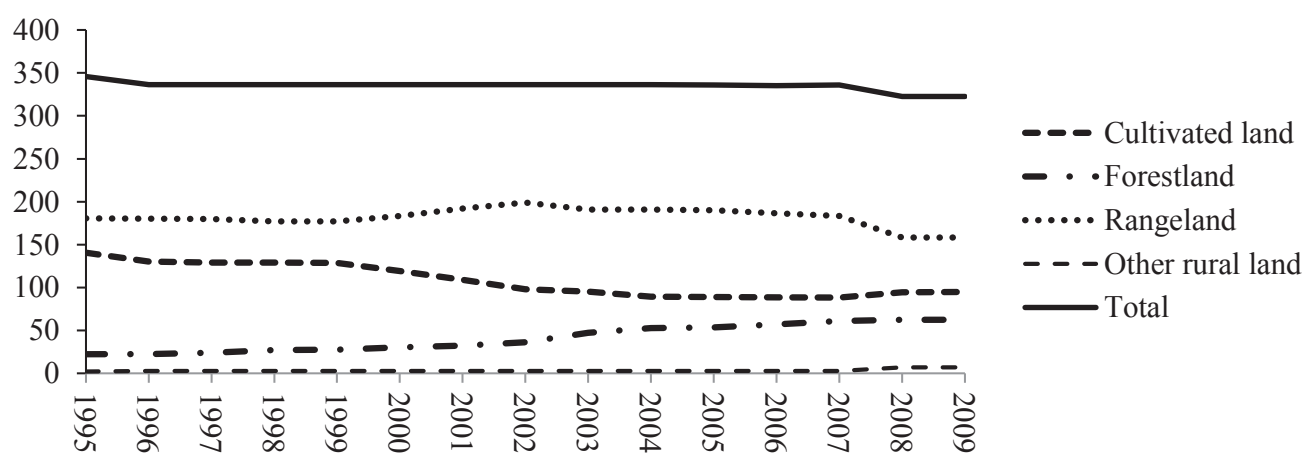

Figure 2.3 The dynamic change of rural land use in Tai Pusi County ${ }^{9}$

Source: Land Resources Bureau, Tai Pusi County.

The largest proportion of rural land has always been represented by rangeland, with cultivated land in second position and other rural land in the last position. In general, rural land use change has occurred, but has had little effect on the order of the dominant land use type. The total area of rural land is decreasing slightly and transitions of land use between cultivated land, rangeland, forest land and other rural land are clearly observable. The area of rangeland decreased rapidly during 2007 and 2008 after a smooth decrease between 2002 and 2006. The area of cultivated land decreased from 1999 until 2008, while conversely, the area of forest land area started increasing from 1999 with a sharp growth in 2002 and 2003.

\subsection{Estimation of the model parameters}

\subsubsection{The parameters $a_{i}, b_{i}, c_{i}$, and $d_{i}$}

Parameters $a_{i}, b_{i}, c_{i}$ and $d_{i}$ are the utility elasticities of stakeholder group $\mathrm{i}$ on cultivated land, rangeland, forest land and other rural land. Interviews with key informants and stakeholder representatives were done to assess their preferences. Interviewees included 15 herders, 15 farmers, 6 representatives for the economic public authority and 6 for the ecological public authority ${ }^{10}$. From 30 public authorities in charge of local affairs in Tai Pusi County, the Local Finance Bureau and the Farming and Grazing bureau were selected as the public authorities for economic affairs, since they pay more attention to local economic development than other departments. Similarly, the Environmental

\footnotetext{
${ }^{9}$ Note that garden plots are included in the category of cultivated land as their area is relatively small in the research region.

${ }^{10}$ We believe that a limited number of interviewees per stakeholder group is sufficient to determine the parameter estimates because the variance in interviewee responses was very small (see Appendix 2-C for details).
} 
Protection Agency and the Forestry Bureau represent the ecological public authorities. Based on the interviews, the Analytic Hierarchy Process (AHP) is employed to evaluate the weight values of $a_{i}, b_{i}, c_{i}$ and $d_{i}$ (see Appendix 2-C for the different steps in the AHP process). AHP, introduced by Thomas Saaty (1980), is one of the most effective tools for dealing with complex decision-making. A large number of studies in different fields have been published based on AHP, such as planning, resource allocation, conflict resolution and optimisation (Vaidya and Kumar, 2006). The values of parameters $a_{i}, b_{i}, c_{i}$ and $d_{i}$ that we derived using AHP are shown in Table 2.1.

Table 2.1 Values of parameters $a_{i}, b_{i}, c_{i}$ and $d_{i}$

\begin{tabular}{llllll}
\hline \hline & Cultivated land & Rangeland & Forest land & Other rural land & Total \\
\hline Herders & 0.2084 & 0.5286 & 0.1606 & 0.1024 & 1 \\
$\begin{array}{l}\text { Farmers } \\
\begin{array}{l}\text { Ecological } \\
\text { public authority }\end{array}\end{array}$ & 0.4317 & 0.2695 & 0.2202 & 0.0786 & 1 \\
$\begin{array}{l}\text { Economic public } \\
\text { authority }\end{array}$ & 0.4304 & 0.3173 & 0.3746 & 0.0960 & 1 \\
\hline \hline
\end{tabular}

\subsubsection{The welfare weight $\left(\beta_{i}\right)$}

The social welfare weight $\beta_{i}$ will be calculated for three scenarios.

Scenario 1: $\beta_{i}$ is considered equal for all four stakeholder groups. The prevailing practice in choosing social welfare weights is to pick the utilitarian weights (Yang and Nordhaus, 2006). Following this approach we assume that each stakeholder group has the same weight in the social welfare function, i.e. $\beta_{1}=\beta_{2}=\beta_{3}=\beta_{4}=1 / 4$. This scenario is considered the scenario of social fairness in land allocation.

Scenario 2: $\beta_{i}$ is considered as the Negishi weight, introduced by Negishi (1972). In this scenario, the social welfare function is maximized using a weighted sum of individual utilities with constant weights that add up to one across the population. In other words, everyone in the equilibrium of Negishi format will be at the maximum level of utility subject to their initial endowments (Stanton, 2011). Furthermore, Manne and Rutherford (1994) interpreted the equilibrium values of the Negishi weights as the shares in the global endowment of economic resources. Zhu and van Ierland (2006) showed that the Negishi weight is the income share of each region in the total economy if the Cobb-Douglas utility function is used. Here, we use the income share of each stakeholder group in the total income as its Negishi weight $\beta_{i}$. Specifically, the total income of the farmers/herders is the population of farmers/herders multiplied by the average net income of farmers/herders in 2012. Similarly, $\beta_{3}$ and $\beta_{4}$ depend on the income of the economic public authority and ecological public authority, respectively. In terms of the income of the public authorities, a proxy income is employed. That is, assuming that the local government balances 
its real income and expenditure, the eco-environmental expenditures on rural land are equivalent to the income of the ecological public authority from the rural land, and the economic expenditures on local rural residents are equivalent to the income of the economic public authority from the rural land.

Scenario 3: $\beta_{i}$ is considered as the working population share of stakeholder group $\mathrm{i}$, which is to investigate the optimal land allocation from the perspective of the employment structure in the society.

Values of $\beta_{i}$ in the three scenarios are shown in Table 2.2 (see Appendix 2-D for more details).

Table 2.2 Values of $\beta_{i}$ in three scenarios

\begin{tabular}{llll}
\hline \hline & $\begin{array}{l}\text { Scenario 1 } \\
\left(\beta_{\mathrm{i}} \text { equal weights }\right)\end{array}$ & $\begin{array}{l}\text { Scenario 2 } \\
\left(\beta_{\mathrm{i}} \text { income share }\right)\end{array}$ & $\begin{array}{l}\text { Scenario 3 } \\
\left(\beta_{\mathrm{i}} \text { population share }\right)\end{array}$ \\
\hline Herders & 0.25 & 0.01 & 0.03 \\
Farmers & 0.25 & 0.53 & 0.86 \\
Ecological public authority & 0.25 & 0.04 & 0.00 \\
Economic public authority & 0.25 & 0.42 & 0.10 \\
\hline Total & 1 & 1 & 1 \\
\hline \hline
\end{tabular}

\subsection{Results}

\subsubsection{Land use conflicts among stakeholder groups}

We find the local optima of each stakeholder group on land allocation according to the individual preferences and stakeholder utility functions. The actual total area of rural land in 2009 was used as the maximum rural land availability in the study region $(322,261$ hectares).

Table 2.3 Optimal rural land allocation according to each stakeholder group and actual allocation in $2009\left(10^{3}\right.$ hectares $)$

\begin{tabular}{llllll}
\hline & Cultivated land & Rangeland & Forest land & Other rural land & Total \\
\hline Herders & 67.2 & 170.3 & 51.8 & 33 & 322.3 \\
Farmers & 139.1 & 86.8 & 71.1 & 25.3 & 322.3 \\
Ecological public authority & 68.4 & 102.3 & 120.7 & 30.9 & 322.3 \\
Economic public authority & 138.7 & 101 & 37.2 & 45.4 & 322.3 \\
\hline Actual allocation in 2009 & 94.7 & 158.1 & 62.4 & 7.1 & 322.3 \\
\hline
\end{tabular}

The results in Table 2.3 present the conflicts among stakeholder groups on rural land use. The herders have a strong preference for rangeland, while farmers have more of an interest in cultivated land and a lesser interest in rangeland. The ecological public authority pays more attention to the rangeland and forest land as they have more of an ecological function. Cultivated land and rangeland are also favoured by the economic public authority. Compared to the actual allocation in 2009 we observe large differences to the local optima. This indicates the differences between the actual allocation and the 
aspirations of stakeholders. In the following section, we explore the equilibrium in land allocation based on social welfare optimisation under three scenarios.

\subsubsection{The optimal social allocation}

According to the three scenarios on welfare weight $\beta_{i}$, we identified the optimal rural land allocation in eco-fragile regions from the social welfare perspective. The results are shown in Table 2.4.

Table 2.4 Socially optimal land allocation under three scenarios and actual allocation in $2009\left(10^{3}\right.$ hectares)

\begin{tabular}{llllll}
\hline Land allocation & $\begin{array}{l}\text { Cultivated } \\
\text { land }\end{array}$ & Rangeland & Forest land & Other rural land & Total \\
\hline $\begin{array}{l}\text { Scenario 1 } \\
\text { ( } \beta_{\mathrm{i}} \text { is equal weight) }\end{array}$ & 103.3 & 115.1 & 70.2 & 33.7 & 322.3 \\
$\begin{array}{l}\text { Scenario 2 } \\
\left(\beta_{\mathrm{i}} \text { is income share }\right)\end{array}$ & 135.4 & 94.3 & 58.5 & 34.1 & 322.3 \\
$\begin{array}{l}\text { Scenario 3 } \\
\left(\beta_{\mathrm{i}} \text { is population share) }\right.\end{array}$ & 136.7 & 90.9 & 67.1 & 27.6 & 322.3 \\
Optimal range & $103.3--136.7$ & $90.9--115.1$ & $58.5--70.2$ & $27.6--34.1$ & \\
\hline Actual allocation in 2009 & 94.7 & 158.1 & 62.4 & 7.1 & 322.3 \\
\hline \hline
\end{tabular}

Considering the welfare weight as the income share of each stakeholder group (scenario 2), cultivated land has much more weight than the other three types of land, a result which is similar to the one in scenario 3. However, the demand for rangeland is higher than for cultivated land if we give equal weight to every stakeholder group (scenario 1), and also the demand for forest land is larger than in the other scenarios. The optimal range is based on the minimum and maximum in the scenarios as the lower and upper bound, in which the highest demand by the society is on the cultivated land and rangeland, followed by forest land, and finally other rural land. Comparing the actual allocation in 2009 with the optimal range, all types of rural land are out of the optimal range except the forest land. In addition, the mean of the optimal range is highest for cultivated land while the actual allocation tends most towards rangeland.

\subsubsection{Comparison of individual optimum, social optimum and actual land allocation}

Table 2.5 presents an overview of the above results. It shows the individual optimum for the four stakeholder groups, the social optimum and the actual situation in rural land allocation, all as the share of each rural land type in total rural land. Comparing the results within each type of land, we see that the individual optimal shares of cultivated land are outside of the socially optimal range. Herders and the ecological public authority wish to allocate less land for cultivation, while farmers and the economic public authority want to allocate more land for cultivation. Preferences for rangeland are largely within the socially optimal range except for farmers who would like to see less rangeland and herders who 
prefer a much larger share of rangeland than what is socially optimal. Unsurprisingly, the ecological public authority would want to allocate much more land for forestry. The actual land allocation in the research region is outside of the socially optimal range for each of the land types except for forest land. Land allocation based on social optimisation would increase the area of cultivated land and decrease the area of rangeland.

Table 2.5 Shares of rural land allocated to cultivated land, rangeland, forest land and other rural land in different situations

\begin{tabular}{|c|c|c|c|c|c|}
\hline & Cultivated land & Rangeland & Forest land & $\begin{array}{l}\text { Other rural } \\
\text { land }\end{array}$ & Total \\
\hline $\begin{array}{l}\text { Herders optimal } \\
\text { allocation }\end{array}$ & $20.9 \%$ & $52.8 \%$ & $16.1 \%$ & $10.2 \%$ & $100 \%$ \\
\hline $\begin{array}{l}\text { Farmers optimal } \\
\text { allocation }\end{array}$ & $43.2 \%$ & $26.9 \%$ & $22.0 \%$ & $7.8 \%$ & $100 \%$ \\
\hline $\begin{array}{l}\text { Ecological public } \\
\text { authority optimal } \\
\text { allocation }\end{array}$ & $21.2 \%$ & $31.7 \%$ & $37.4 \%$ & $9.6 \%$ & $100 \%$ \\
\hline $\begin{array}{l}\text { Economic public } \\
\text { authority optimal } \\
\text { allocation }\end{array}$ & $43.0 \%$ & $31.3 \%$ & $11.5 \%$ & $14.1 \%$ & $100 \%$ \\
\hline $\begin{array}{l}\text { The socially optimal } \\
\text { range }\end{array}$ & $32.1 \%--42.4 \%$ & $28.2 \%--35.7 \%$ & $18.2 \%--21.8 \%$ & $8.6 \%--10.6 \%$ & \\
\hline Actual share in 2009 & $29.4 \%$ & $49.1 \%$ & $19.4 \%$ & $2.2 \%$ & $100 \%$ \\
\hline
\end{tabular}

\subsection{Conclusion}

This paper takes a welfare economics perspective to investigate current land use conflicts and socially optimal land allocation. Optimisation based on individual utility functions and AHP reveals land use conflicts among stakeholders due to heterogeneous preferences for different types of land. By optimising the social welfare function, using different welfare weights, we derive the socially optimal range of land allocation. Comparing our empirical results with current land allocation over different land types, we find that a socially optimal land allocation would require a shift towards more cultivated land and less rangeland.

These results should be put in the Chinese policy context. Since the 1990s, the Chinese government has shown increased interest in extending the area of forest land and rangeland for ecosystem protection purposes. Programs such as the SLCP that aim to convert sloping cropland into forestland or grassland are witness to this policy direction (Liu et al., 2010). However, our results show that the social optimum land allocation requires conversion in the other direction: from grasslands towards cultivated land, while the area of forest land is already within the socially optimal range. The preference for cultivated land over rangeland may be driven by the policy restrictions on rangeland. Farmers can use cultivated land more freely than rangeland. While this insight might seem controversial in view of the current policy 
context, our results could also be driven by the overall pressure on rural land, and cultivated land in particular, in China. This pressure is likely to be especially strong in the eco-fragile regions where most of the local residents depend on farming, but where agricultural productivity falls far behind the national average level. This promotes the demand for more cultivated land and land for agricultural infrastructure. Furthermore, our results may also reflect the misalignment between preferences of the national government - as included in the national policy programs that focus on environmental protection - and preferences of local governments - whose performance evaluation is based primarily on economic growth indicators (Liu and Diamond, 2005). Moreover, it is worth mentioning that a decrease in the area of grasslands in favour of cultivated land does not necessarily conflict with environmental objectives. First, research on the effectiveness of current grassland protection policies has not yet provided conclusive evidence (Zheng et al., 2006; Cao et al., 2013). Second, a conversion to more cultivated land is likely to lead to a more intensified use of the rural land. As a result, this may reduce the pressure on the grasslands as rural residents can sustain their livelihoods through cultivation rather than by increasing the number of animals on the grasslands.

Finally, we would like to point out a number of limitations of our research. While the research method is generic and likely to be valid for other regions facing land use conflicts, the specific outcomes presented in this paper are based on stakeholder interviews in one Chinese county and are therefore not generalizable. Furthermore, the application of the model includes only 4 different categories of land and 4 stakeholder groups which is a simplification of reality. Finally, the analysis only assesses the distribution of land resources and hence abstracts from the allocation of other relevant resources of rural households. 


\section{ACKNOWLEDGEMENTS:}

Funding for this research was supported by the Chinese academy of engineering with the project: Ecological security and food security in the grasslands of China (2012-ZD-7). The authors would like to thank Xiangzheng Deng, Wenhui Kuang and Zeng Tang for their help and suggestions during the field work in China. 


\section{Chapter 3}

\section{Land tenure reform and grassland degradation in Inner Mongolia, China}




\section{LAND TENURE REFORM AND GRASSLAND DEGRADATION IN INNER MONGOLIA, CHINA11}

ABSTRACT: Since the start of the land tenure reform in the pastoral areas of China in the 1980s, grassland use rights have increasingly been assigned to individual households and subsequently more grasslands have been in private use. However, in the same period, most of the grasslands in China have experienced degradation. The question that this paper tries to address is whether the land tenure reform plays a significant role in grassland degradation. It is answered by an empirical analysis of the impact of land tenure reform on the changes in grassland condition, using data from 60 counties in Inner Mongolia between 1985 and 2008. Grassland condition is presented by grassland quantity and quality using spatial information based on remote sensing. The timing of the assignment of grassland use rights and the timing of the actual adoption of private use by households differ among counties. These timing differences and differences in grassland condition among counties allow disentangling the impact of the land tenure reform. A fixed effects model is used to control for climate, agricultural activity and the time-invariant heterogeneity among counties. The model results show that the private use of grasslands following the land tenure reform has had significantly negative effects on grassland quality and quantity in Inner Mongolia. Moreover, the negative effects did not disappear even after several years of experience with private use. In conclusion, our analysis reveals that the land tenure reform, namely privatisation of grassland use rights, is a significant driver of grassland degradation in Inner Mongolia in a long term, which presents "a tragedy of privatisation", as opposed to the well-known "tragedy of the commons".

KEYWORDS: privatisation, formal use rights, private use, grassland degradation, fixed effects model

\footnotetext{
${ }^{11}$ Paper by Min Liu, Liesbeth Dries, Wim Heijman, Jikun Huang, Xueqin Zhu, and Xiangzheng Deng, submitted to $a$
} peer-reviewed journal. 


\subsection{Introduction}

The tragedy of the commons, a concept introduced by Hardin (1968), has long been part of the conventional wisdom in ecology, economics and political science (McEvoy, 1987). Theoretical research contended that resource degradation was inevitable unless the commons were either privatised or maintained as common land with clear rights of entry and use (Hardin, 1968). Similarly, in the theorem of property rights (Coase, 1960), a clear assignment of property rights is proposed as a precondition for economically efficient resource allocation and environmental sustainability. As a consequence, the privatisation of property rights or use rights over resources has been implemented widely by governments around the world (Little, 1992; Lesorogol, 2003; Squires et al., 2009; Ybarra, 2009). The same privatisation trend has been observed in Inner Asia and Africa regarding the reform of grassland tenure (Sneath, 1998; Lesorogol, 2008).

However, Hardin's theory of the tragedy of the commons and Coase's theorem of property rights have been rejected by pastoral specialists, who found that these theoretical findings provided a poor guide to understanding pastoralism (Feeny et al., 1990; Behnke, 1994; Sneath, 1998). They concluded that exclusionary land tenure is counterproductive to protect the grassland condition in arid and semi-arid areas (Turner, 1999; Galvin, 2009). And some scholars (e.g. Ostrom, 1990; Li and Zhang, 2009) found that traditional common use systems of grasslands often met the criteria for sustainable SocialEcological Systems (Ostrom, 2009), namely the exclusion of outsiders and the self-organization of resource users (Ostrom, 1990). Therefore, doubts exist about the likelihood that traditional common use systems would induce a tragedy of the commons. Moreover, a growing number of academic studies question the effects of the prevailing privatisation of grassland property rights or use rights on the grassland condition. For instance, some studies assert that grassland privatisation puts an end to mobile pastoralism by introducing inflexible boundaries and identify this as a main driver for grassland degradation (e.g. Fernandez-Gimenez and Le Febre, 2006; Li and Zhang, 2009). Mobile pastoralism is embraced because mobility maintains ecosystem stability and biological diversity and conforms with the sustainable use of natural resources that are subject to strong spatial and temporal heterogeneity, as is the case in arid and semi-arid areas (Fernandez-Gimenez, 2002; Fernandez-Gimenez and Le Febre, 2006; Tessema et al., 2014; Fan et al., 2015). Empirical evidence was provided by Sneath (1998) who used satellite images to show that grassland degradation was much less severe in Mongolia - which kept the common use system for grasslands - than in the Russian and Chinese parts of Inner Asia where the privatisation of grassland property rights or use rights was implemented. Furthermore, Guelke (2003) showed that grassland degradation in South Africa was primarily due to the introduction of privatisation.

In China, land tenure reform started with the Household Production Responsibility System in the cropland areas in the late 1970 s and spread to the pastoral areas by the early 1980s. The land tenure 
reform in the pastoral areas aims at privatising use rights of grasslands to individual households and displacing traditional common use (Banks et al., 2003). Some differences have been observed in the tenure reform of grasslands among the provinces. For instance, the grasslands tenure reform started in 1984 in Inner Mongolia and Heilongjiang while it had started already in 1983 in Ningxia (Ho, 2000). Furthermore, the privatisation of grassland use rights in some provinces was ahead of the national decision about the tenure reform of grasslands, as the first Grassland Law of China was introduced only in 1985. Moreover, it is reported that most of the grasslands in China have experienced various degrees of degradation since the 1980s ( $\mathrm{Li}$ et al., 2014). The manifestation of the grassland degradation involves a reduction in the extent of grass cover, a reduction in the density of grass cover, a reduction in the output of forage material, an increase in unpalatable grass species, an increase in soil compaction, changes in plant functional group or a combination of all of them (Feng et al., 2009; Li et al., 2013; Lin et al., 2015). According to Chinese governmental reports, $10 \%$ of the total area of grasslands was degraded in the $1970 \mathrm{~s}$, increasing to $30 \%$ in the 1980 s and $50 \%$ in the middle of the 1990 s (Meng and Gao, 2002). By the 2000 s, about $90 \%$ of the grasslands were degraded to various extents, with significant regional variation (Unkovich and Nan, 2008; Waldron et al., 2010). It is widely agreed that grassland degradation is one of the most important environmental issues confronting China presently (Han et al., 2008; Feng et al., 2009). As efficient policy interventions derive from correct understandings about the causes of grassland degradation (Brown et al., 2008), and good management practices are capable of improving the grassland condition significantly (Parras-Alcántara et al. 2015), a relevant question is what role the land tenure reform has played in the process of grassland degradation.

Although some studies exist that discuss the impact of the land tenure reform on the grassland condition in China (e.g. Ho, 2001; Li and Zhang, 2009), there is a lack of empirical analysis based on long-term data on a large-scale (Lu et al., 2015). Therefore, this paper uses information on the changes in grassland condition and progress of the land tenure reform in a typical pastoral area in China over a relatively long period (1985-2008) to estimate the effect of land tenure reform on grassland condition. In the following sections, we first provide some background information about the grassland tenure reform in China, including the progress in the assignment of grassland use rights and the actual use of grasslands. Next, the materials of our empirical research are described and the fixed effects model in our case is presented. We conclude with some remarks about the effects of the land tenure reform on the grassland condition in the research region and implications of our findings for future research. 


\subsection{Materials}

\subsubsection{Study area}

To explore the effect of land tenure reform on the grassland condition in the pastoral areas of China, we selected Inner Mongolia, a province located in northern China, to conduct our empirical study. Inner Mongolia belongs to the arid and semi-arid areas of China that is vulnerable to degradation, desertification and salinization (Feng et al., 2009). It contains $21.7 \%$ of the area of China's natural grasslands. Approximately $67 \%$ of the total land in Inner Mongolia is classified as grassland, the majority of which is temperate grassland (Angerer et al., 2008). As a traditionally pastoral region populated by Mongolians, the vast majority of local people maintain their livelihoods upon the permanent grasslands and the region has a relatively low population density in spite of rapid economic growth and a soaring population growth elsewhere in China (Angerer et al., 2008). The grassland condition in Inner Mongolia has been a major concern because the region is not only one of the main production regions for animal products of China (Li et al., 2016), it also functions as an ecological barrier for northern China. For instance, the colossal dust storms which rumbled through hundreds of cities and villages of northern China and blanketed the sky of Beijing between 1998 and 2001, are said to have originated from dryland areas and degraded grasslands mainly in Inner Mongolia (Wu et al., 2015). In terms of its status as main region for livestock production in China, the mutton output of Inner Mongolia accounted for $22 \%$ of the total output of China in 2013, while $8 \%$ of all Chinese beef was produced here (China Animal Industry Yearbook, 2014). Therefore, continued grassland degradation in Inner Mongolia is supposed to harm economic development as well as cause ecosystem instability in China (Meyer, 2006). By the end of the twentieth century, 90\% of the grassland condition of Inner Mongolia had been degraded to various extents (Mei et al., 2013), which has stimulated growing attention to the protection of grasslands in recent decades.

Inner Mongolia was the first region for implementation of the land tenure reform in the grassland area (Li and Huntsinger, 2011). According to provincial government reports for Inner Mongolia, the privatisation of grassland use rights began officially through the Double Contracts System in 1982 . Because of its limited uptake, the implementation of grassland privatisation was strengthened by the Two Rights and One System policy (Shuang Quan Yi Zhi) in 1996 (Bureau of Animal husbandry of Inner Mongolia, 2000; Li and Zhang, 2009). This is regarded as the second round of privatisation of grassland use rights. To this date, local governments continue to work on clarifying the boundaries of grassland use rights for each household and on issuing certificates (Bureau of Animal husbandry of Inner Mongolia, 2015). In practice, the specific timing and extent of conducting the land tenure reform differed among counties in Inner Mongolia. This paper is therefore based on county-level data with the 
aim of disentangling the effects of privatisation on the grassland condition. Figure 3.1 presents the region of Inner Mongolia and marks the counties that are included in our empirical analysis.

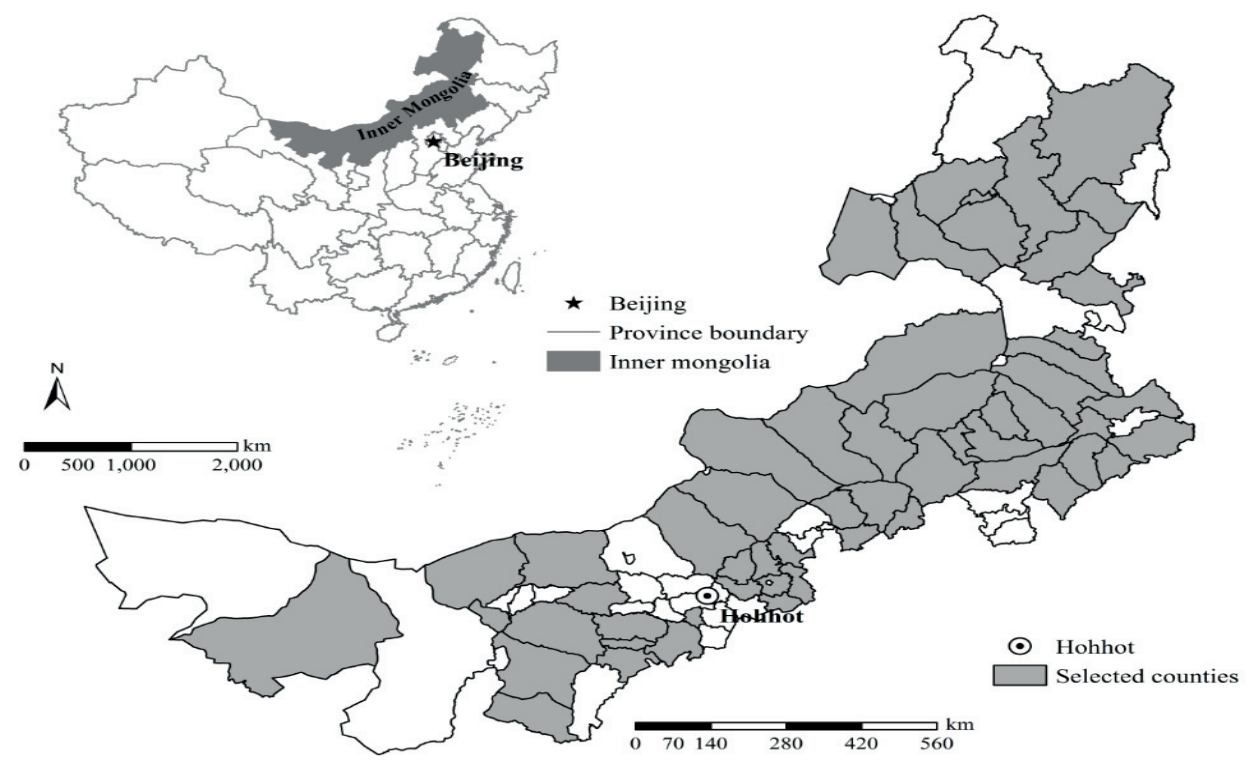

Figure 3.1 Inner Mongolia and the selected counties in this study

\subsubsection{Data sources}

County-level data were collected for the period 1985-2008, the main period during which the land tenure reform was implemented across Inner Mongolia. Information about the land tenure reform was collected through questionnaires. The questionnaires were sent to the Animal Husbandry Bureau of each county and answered by local experts on the grassland tenure reform. In a second phase, interviews were conducted by telephone to confirm the answers that were received. A total of 74 valid questionnaires were obtained out of 102 counties of Inner Mongolia. Besides the questionnaires, we had interviews with the officers who are working in the provincial institutes of Animal Husbandry of Inner Mongolia and with local herders to verify the progress of land tenure reform on local grasslands.

In the existing literature, grassland condition is indicated by grass cover, height, density, biomass production or density of perennial vegetation (Gu and Li, 2013; Yu and Farrell, 2013). Commonly used methods to measure these indicators include small-scale sampling tests in field studies and data analysis with remote sensing and GIS (Geographic Information System) over large areas. The former focuses on measuring the specific indices of grass production and vegetation diversity directly, while the latter estimates the general grassland condition based on satellite images (Gu and Li, 2013). In this study, the method with remote sensing and GIS is more appropriate because we aim to quantify the spatial and 
temporal differences in grassland condition across extensive grasslands during a long period. In this regard, our information on grasslands and climate conditions relies on a land use database developed by the Chinese Academy of Sciences with original data from Landsat Thematic Mapper / Enhanced Thematic Mapper (Plus) (TM/ETM+) images which have a spatial resolution of $30 * 30 \mathrm{~m}$ (Deng et al. 2011). Visual interpretation and digitization of Landsat TM/ETM+ images were conducted to generate land use maps for the years 1985, 1995, 2000, 2005 and 2008. Land cover classification system was applied to distinguish grasslands from cultivated land, forestry area, water area, built-up area, and unused land. According to the grass cover, grasslands were further classified into three subclasses which were adopted from the research by Feng et al. (2009) and Deng et al. (2011), including dense grassland, moderate grassland and sparse grassland. In addition, socio-economic information was derived from statistical data collected by local governments. After dropping the urbanised counties - where changes in the grassland area can be attributed mainly to changes in land use types - and those counties that experienced changes in administrative regions, 60 counties out of 74 counties with valid questionnaires are retained as the research sample for this study, as marked in Figure 3.1.

\subsubsection{Land tenure reform for the grasslands}

\subsubsection{A review of the legislation on grassland tenure of China}

In the collectivist period of China, grasslands were assigned to production teams or People's communes and the grasslands were managed and used communally by all households in the same production team (Hua and Squires, 2015; Taylor, 2006). After that period, given the successful experience of privatising land use rights to individual households in the cropland regions in the late 1970s, the Chinese central government introduced the household-based privatisation of land use rights into the pastoral areas in the early 1980s. Since then, the management of grasslands has increasingly become the responsibility of individual households (Banks et al., 2003).

The first Grassland Law of China was initiated in 1985 and stipulated that the property rights over grasslands are owned either by the state or the collective but that use rights to the grasslands can be contracted out to either households or collectives (Ho, 2000). According to the current Law on the Contracting of Rural Land, the grassland use rights can be contracted to individual households for a duration of 30 to 50 years. In practice, local governments started to assign grassland use rights to households through a Double Contracting System ("cao xu shuang cheng bao") in the 1980s. In 2002, the revised Grassland Law reaffirmed the devolution of land use rights from the state and collectives to individual households (National People's Congress of the People's Republic of China, 2002). The State Council emphasised the specific allocation of the contracted items (e.g. grassland plots, areas, issuing user-right certificates etc.) to households to ensure the long-term stability of contract relations in a 
government report in 2011 (Li, 2012). With these legislative efforts, the privatisation of the grasslands has been conducted gradually in the extensive pastoral areas of China, and increasingly private use by households has replaced traditional open access to land (Hua and Squires, 2015; Yang et al., 2004). By 2014, the total area of grasslands that have been assigned to individual households reached 223 million hectares, out of 400 million hectares of grasslands in China (Ministry of Agriculture of China, 2015).

\subsubsection{The implementation of the land tenure reform on grasslands}

Table 3.1 provides a typology of the assignment of use rights and the actual ways of grassland use in the pastoral areas of China since the start of the land tenure reform. This typology is in line with the investigation of land tenure reform on the Tibetan plateau by Banks (2003). Three types of assignment of grassland use rights existed during the last three decades, namely, formal use rights assigned to individual households, to a group of households or to a collective. Correspondingly, there were three ways of grassland use, including private use, joint use and common use. Private use indicates that a certain area of grasslands is managed and used by an individual household, while other users are excluded. Joint use means that a group of households manage and use an area of grasslands together, in which group members are often neighbours or relatives that have small parcels of grasslands and wish to make their land larger and contiguous. Finally, common use means that the grasslands within a collective or administrative village are used by all of the members of the collective or the villagers.

Table 3.1 The assignment of formal use rights of grasslands and the actual ways of grassland use

\begin{tabular}{llll}
\hline \hline \multirow{2}{*}{ Formal use rights assigned to } & \multicolumn{4}{l}{ Actual use of grasslands } \\
\cline { 2 - 4 } & Private use & Joint use & Common use \\
\hline Individual households & + & + & + \\
Group of households & na & + & + \\
Collective/administrative village & na & na & + \\
\hline \hline
\end{tabular}

Source: adapted from "formal and de facto grassland management units" (Banks et al., 2003) na indicates not available.

When the use rights are assigned to a collective or an administrative village, the actual way of grassland use is always common use. If use rights are assigned to a group of households, actual use can be common use or joint use. Private use, joint use and common use can all occur when the use rights are assigned to individual households. The intention of the land tenure reform in the pastoral areas is, however, to achieve full private use when use rights are assigned to households. This has spurred criticisms and claims of failure of the privatisation process in China's extensive grasslands, compared to the case of the cropland areas where household-based use rights were assigned overnight and private use was established simultaneously (Ho, 2000; Banks et al., 2003). Scholars (e.g. Richard et al, 2006; Li and 
Zhang, 2009; Li, 2012) have identified a number of possible barriers to the completion of the land tenure reform in the pastoral areas of China: (1) the inflexible boundaries stemming from the privatisation of grassland use rights is incompatible with the need for livestock mobility due to the heterogeneity of resources in arid and semi-arid areas (Li and Zhang, 2009); (2) there is a lack of financial resources for protecting private property rights, e.g. to build fences (Ho, 1996; Li et al., 2007); (3) individual household ownership is inconsistent with local or traditional knowledge about property or use rights (Richard et al, 2006); and (4) private use by individual households destroys the traditional institutions of grassland use and management (Li, 2012). In what follows, we will investigate another possible explanation for why the adoption of private use is lagging, namely that privatisation negatively affects the grassland condition.

\subsubsection{Land tenure reform in sample counties}

Table 3.2 gives indications of the land tenure reform progress of grasslands in the selected counties between 1985 and 2008. In 1985, only $6.67 \%$ of the 60 counties had assigned grassland use rights to individual households. By 2008, this proportion had increased to $81.67 \%$, and the average number of years since formal use rights had been contracted to individual households was 11.55. Meanwhile, actual changes in the use of the grasslands followed this institutional evolution. In 1985 , only $5 \%$ of the selected counties had adopted the practice of private use. In 2008, this percentage had reached to $63.33 \%$ and the average number of years since private use had been adopted was 8.72. These observations about the land tenure reform in the sample counties demonstrate that the adoption of private use lagged behind the privatisation of formal use rights.

Table 3.2 Land tenure reform progress in the selected counties, 1985-2008

\begin{tabular}{lllllll}
\hline \hline & Unit & 1985 & 1995 & 2000 & 2005 & 2008 \\
\hline $\begin{array}{l}\text { The proportion of counties in which } \\
\text { grassland use rights have been assigned to } \\
\text { individual households }\end{array}$ & Percent & 6.67 & 23.33 & 76.67 & 80.00 & 81.67 \\
$\begin{array}{l}\text { The average number of years since the use } \\
\text { rights have been assigned to households }\end{array}$ & Years & 0.18 & 1.92 & 5.17 & 9.13 & 11.55 \\
$\begin{array}{l}\text { The proportion of counties with actual } \\
\text { private use of grasslands }\end{array}$ & Percent & 5.00 & 15.00 & 58.33 & 63.33 & 63.33 \\
$\begin{array}{l}\text { The average number of years since actual } \\
\text { private use has been adopted }\end{array}$ & Years & 0.13 & 1.22 & 3.68 & 6.82 & 8.72 \\
\hline \hline
\end{tabular}




\subsection{Empirical model}

\subsubsection{Fixed effects model}

The fixed effects model has been widely used in economic research (e.g., Fergusson et al., 2002; Huang et al., 2006). It is used primarily to study the causes of changes within entities over time. The general model is presented as follows:

$$
Y_{i t}=\beta X_{i \mathrm{t}}+U_{i}+\varphi_{i t}
$$

where $i$ and t present entity $i$ and year t, respectively. $Y_{i t}$ is the dependent variable. $X_{i t}$ denotes the vector of independent variables. $U_{i}$ is the specific intercept for each entity and represents all time-invariant (fixed) characteristics of entity $i$ that influence the dependent variable, including both observable and unobservable factors. $\varphi_{i t}$ is the random error term. The difficulty in estimating the parameters of $\beta$ is that $U_{i}$ involves unobserved factors. In this regard, a within transformation is used to remove all timeinvariant (fixed) explanatory variables, i.e. a model is performed using deviations from individual means (Verbeek, 2012). Therefore, the fixed effects model is a method of estimating the parameter of $\beta$ that takes the observable as well as unobservable time-invariant explanatory variables $\left(U_{i}\right)$ into account, but the estimation does not dependent on the value of $U_{i}$ (Fergusson et al., 2002).

The fixed effects model is appropriate to solve our research question considering that the results of the land tenure reform within each county can be studied effectively by controlling for the unmeasured heterogeneity among counties. As shown in table 3.2, the progress in land tenure reform changes substantially across our research period and for a considerable proportion of the counties in our dataset, which satisfies the basic requirement of the fixed effects model (Daun-Barnett, 2011). Moreover, our research sample attempts to include all of the relevant counties in Inner Mongolia, rather than random draws, which preliminarily indicates the fixed effects model more appropriate than the random effects model (Verbeek, 2012). Nevertheless, the appropriateness of the fixed effects model will be further examined through statistical testing in section 5 .

\subsubsection{Variable definitions and expected results}

The dependent variable in the empirical analysis is the grassland condition. The grassland condition includes the situations of both quantity and quality of grasslands, which are quantified considering the extent and density of grass cover that are suggested as the crucial manifestation of grassland degradation (Feng et al., 2009; Li et al., 2013). Specifically, the quantity of grasslands is measured by the total area of grasslands in hectares, while the areas with less than 5 percent of grass cover are not counted as grasslands. And the quality of grasslands is presented through the areas of grasslands of different subclasses that are classified according to the different density of grass cover, including dense grassland, 
moderate grassland and sparse grassland. According to the research by Feng et al. (2009) and Deng et al. (2011), dense grassland has the highest quality and its grass cover is more than 50 percent. Moderate grassland has grass covering 20-50 percent of the land, and sparse grassland with 5-20 percent. In our case, it is supposed that the grassland degradation is manifested by the decrease of total, dense and moderate grassland areas, as well as the increase of sparse grassland area when total grassland area with decrease or no changes. The latter considers that the dense and moderate grasslands may degrade into sparse grassland, which was observed by the research about the moving direction of grassland centre of gravity in China during 1976-1996 by Feng et al. (2009). Hence, four dependent variables are included in the empirical analysis to indicate the grassland condition: total grassland area, dense grassland area, moderate grassland area, and sparse grassland area. The following equations for estimation are derived from the general fixed effects model (see equation (1)):

$$
\begin{aligned}
& G_{i t}=g_{i}+a_{1} L_{i t}+a_{2} L_{i t}^{2}+a_{3} T_{i t}+a_{4} T_{i t}^{2}+a_{5} F_{i t}+a_{6} F_{i t}^{2}+a_{7} T F_{i t}+a_{8} C_{i t}+a_{9} C_{i t}^{2}+\varepsilon_{i t} \\
& D_{i t}=d_{i}+b_{1} L_{i t}+b_{2} L_{i t}^{2}+b_{3} T_{i t}+b_{4} T_{i t}^{2}+b_{5} F_{i t}+b_{6} F_{i t}^{2}+b_{7} T F_{i t}+b_{8} C_{i t}+b_{9} C_{i t}^{2}+\mu_{i t} \\
& M_{i t}=m_{i}+c_{1} L_{i t}+c_{2} L_{i t}^{2}+c_{3} T_{i t}+c_{4} T_{i t}^{2}+c_{5} F_{i t}+c_{6} F_{i t}^{2}+c_{7} T F_{i t}+c_{8} C_{i t}+c_{9} C_{i t}^{2}+\gamma_{i t} \\
& S_{i t}=s_{i}+d_{1} L_{i t}+d_{2} L_{i t}^{2}+d_{3} T_{i t}+d_{4} T_{i t}^{2}+d_{5} F_{i t}+d_{6} F_{i t}^{2}+d_{7} T F_{i t}+d_{8} C_{i t}+d_{9} C_{i t}^{2}+\sigma_{i t}
\end{aligned}
$$

where $\mathrm{i}$ and $\mathrm{t}$ present the $\mathrm{i}^{\text {th }}$ county and year t. Total grassland area $\left(G_{i t}\right)$, dense grassland area $\left(D_{i t}\right)$, moderate grassland area $\left(M_{i t}\right)$ and sparse grassland area $\left(S_{i t}\right)$ are the dependent variables. Equations (2), (3), (4) and (5) will be referred to as the total, the dense, the moderate and the sparse grassland model, respectively.

$L_{i t}$ indicates our main variable of interest, the progress of the land tenure reform in county i until year $t$. It is measured as the number of years until year $t$ that private use has been adopted in county $i$. We focus on the years of actual private use of the grasslands rather than the years of the assignment of formal use rights to households because it is considered that the actual use will affect the grassland condition. As was shown in table 3.2, the adoption of actual private use lags behind the assignment of formal use rights, and the correlation value between the years of assigning formal use rights and actually adopting private use is 0.825 . In this regard, including both the years of formal use rights assignment and the years of actual private use as variables in the model would cause multicollinearity. The quadratic term of $L_{i t}, L_{i t}^{2}$, is included in the model because a non-linear relationship is expected between the land tenure reform and the grassland condition.

To correctly estimate the effect of the land tenure reform, we control for other factors that may affect the condition of the grasslands, namely, the factors related to climate (Gao et al., 2010; Li et al., 2012; 
Lu et al., 2015), agricultural activities (He et al., 2014; Hua and Squires, 2015) and heterogeneity among counties (Deng et al. 2011; He et al., 2014). Climate factors are presented by temperature $\left(T_{i t}\right)$ and precipitation $\left(F_{i t}\right)$ (Gong et al., 2015). Their quadratic terms $\left(T_{i t}^{2}\right.$ and $\left.F_{i t}^{2}\right)$ and cross term $\left(T F_{i t}\right)$ are considered (Li et al., 2013). $C_{i t}$ is the percentage change in cultivated land in county $\mathrm{i}$ in the five years preceding year $\mathrm{t}$ and $C_{i t}^{2}$ is its quadratic term. $C_{i t}$ and $C_{i t}^{2}$ are considered as controls for the switch of land between grassland and arable land which was shown to have a significant and direct effect on grassland quantity in China (Feng et al., 2009; Li et al., 2013). Finally, the factors about the heterogeneity among counties such as elevation, slope, soil type and distance to the provincial capital do not change significantly over time and are therefore treated as time-invariant (fixed) factors in the model, denoted by $g_{i}, d_{i}, m_{i}$ and $s_{i}$ in equations (2) to (5). Variable definitions and the expected impact of independent variables on the grassland condition are listed in table 3.3. 


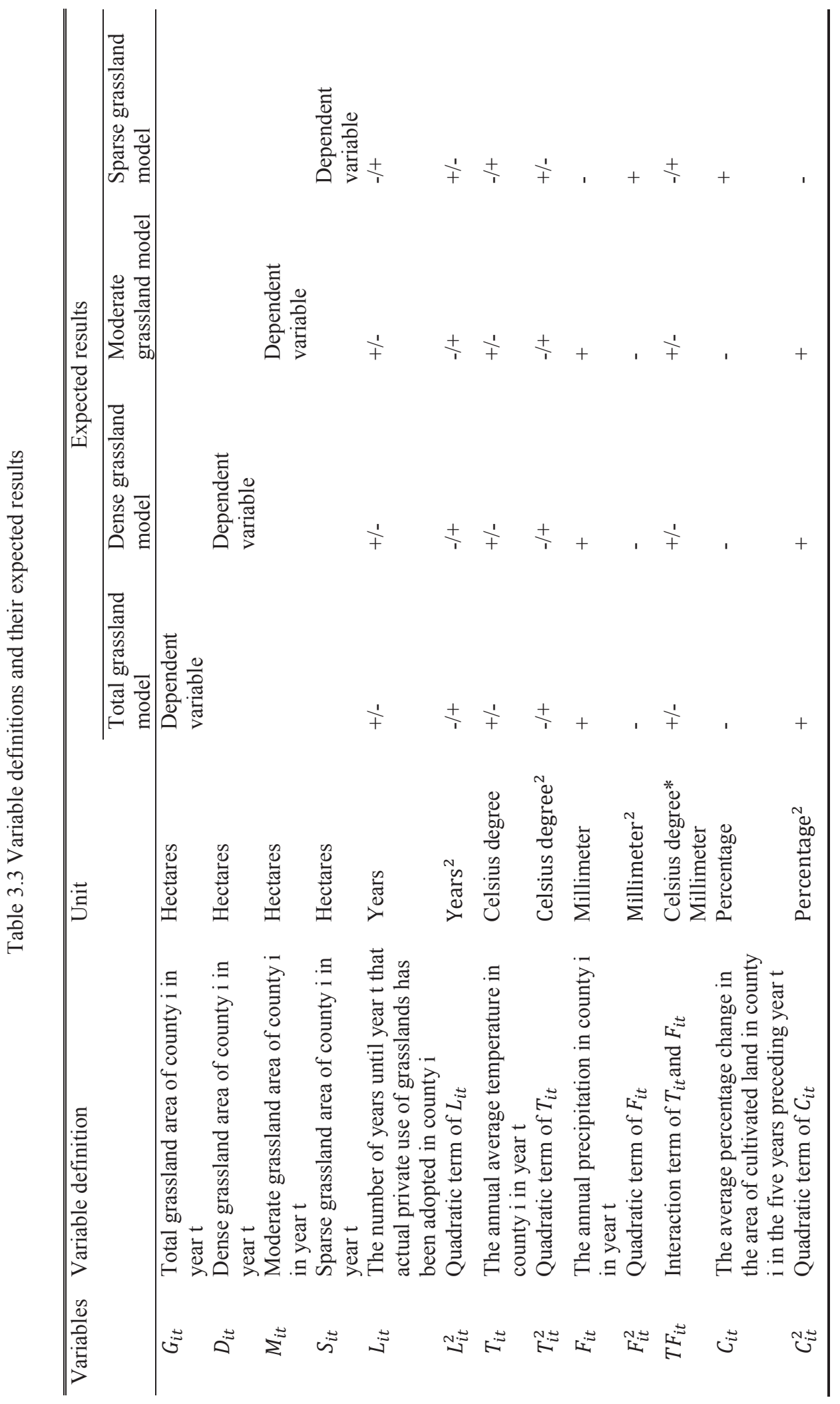


Given the contradicting views in the literature about the effect of privatisation on grassland quality, the expected effect of $L_{i t}$ in our estimations is ambiguous (e.g. Hardin, 1968; Guelke, 2003; Galvin, 2009). However, we expect that the effects of the land tenure reform will be strong at the beginning and reduce in intensity over the years. Hence an opposite sign to that of $L_{i t}$ is expected for the coefficients of $L_{i t}^{2}$ in the four models. It is noted that the expected effects of all explanatory variables in the sparse grassland model are the opposite of the expectations in the other three models because grassland degradation involves a decrease in total, dense and moderate grassland areas, but an increase in sparse grassland area. Additionally, the expected sign of temperature $\left(T_{i t}\right)$ is ambiguous because higher temperatures facilitate plant growth, but also cause fast evaporation from ground surfaces and stimulate the development of pests (Deng et al., 2013; Li et al., 2013). Precipitation $\left(F_{i t}\right)$ improves the grassland condition in the arid and semi-arid areas (Li and Zhang, 2009). Both temperature and precipitation are expected to have nonlinear relationships with the grassland condition (Li et al., 2012; Zhou et al., 2002), and therefore the opposite signs to those of $T_{i t}$ and $F_{i t}$ are expected for the coefficients of $T_{i t}^{2}$ and $F_{i t}^{2}$ in the four models. The interaction term of $T_{i t}$ and $F_{i t}$ is also included because the effect of temperature depends on the amount of precipitation. Finally, the intensive agricultural activities were suggested to cause grassland degradation (Zhang et al., 2007; Feng et al., 2009). We therefore expect negative coefficients for $C_{i t}$ in the total, dense and moderate grassland models, and a positive coefficient in the sparse grassland model. Again a nonlinear relationship is expected for this variable.

\subsubsection{Descriptive statistics on the variables}

Table 3.4 shows the mean value and standard deviation of our main variables for the research sample. In general, the areas of total grassland $\left(G_{i t}\right)$, dense grassland $\left(D_{i t}\right)$ and moderate grassland $\left(M_{i t}\right)$ decreased, and the area of sparse grassland $\left(S_{i t}\right)$ presented fluctuant increases between 1985 and 2008 . The areas of total, dense and moderate grasslands experienced their highest points in 1985, and in 2000 for sparse grassland area. Specifically comparing 1985 and 2008, the total grassland area decreased which indicates the degradation of grassland quantity. Furthermore, given the decrease in total grassland area, the decrease in dense and moderate grassland areas and increase in sparse grassland area demonstrate the degradation of grasslands with higher grass cover into lower quality grasslands. Moreover, the average number of years with actual private use in the 60 sample counties was increasing from 0.13 in 1985 to 8.72 in 2008 . And the standard deviations of $L_{i t}$ indicate that the differences in adopting private use among the 60 sample counties were increasing from 1985 to 2008. The average temperature reached its highest point in 2008, while annual precipitation was the highest in 1985 and the lowest in 2000. The average percentage change in cultivated land increased from 1985 to 2000 then decreased to become even negative in 2005 . 


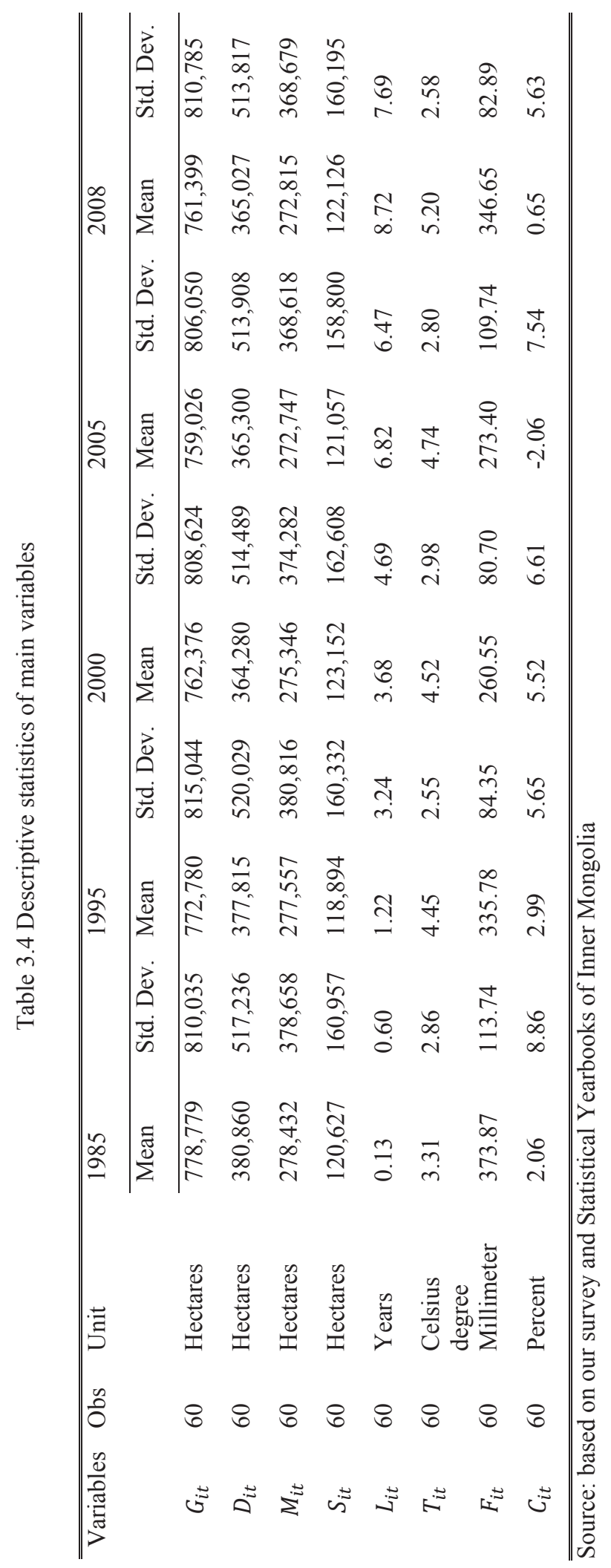




\subsection{Results}

In this section, we first examine whether our data are appropriate for using the fixed effects model through statistical tests, involving the choice of the fixed effects or random effects model and a test for cross-sectional dependence. Moreover, we examine whether the variable of private use $\left(L_{i t}\right)$ and its quadratic term $\left(L_{i t}^{2}\right)$ are endogenous variables. This may be the case because the moment at which actual private use was adopted in a county could be decided by local households rather than by the (exogenous) formal government policy.

Specifically, the Hausman test is employed to determine whether a fixed or a random effects model is more appropriate. The test results for all four models reject the null hypothesis at $p<0.05$, indicating that the fixed effects model is more appropriate. Cross-sectional dependence in panel-data models (also called contemporaneous correlation) is then tested using the Pasaran CD test considering that our panel data includes many more cross-sectional units (60) than time periods (5). Test results show that residuals are not correlated across entities and hence no cross-sectional dependence occurs in any of the four models. Ultimately, the Durbin-Wu-Hausman test is employed to examine endogeneity of the variables of $L_{i t}$ and $L_{i t}^{2}$. The test results reject the null hypothesis of exogeneity of $L_{i t}$ in the total and dense grassland models. The null hypothesis of exogeneity of $L_{i t}^{2}$ is rejected in the total, dense and moderate grassland models. It indicates that endogeneity is found in the total, dense and moderate grassland models, which therefore require the instrumental variables approach. In this regard, the number of years for which formal use rights have been assigned to households is strongly correlated with the number of years for which actual private use has been adopted (the correlation coefficient is 0.825 ). Moreover, the implementation of this formal policy was not decided by the local government or households, but it followed the policy guidelines from higher level governments, which means the variable about formal use rights can be supposed to be exogenous. We therefore consider the number of years with formal use rights and its quadratic term as the instrumental variables of $L_{i t}$ and $L_{i t}^{2}$. The instrumental variables tests further prove that they are valid and strong instrumental variables for $L_{i t}$ and $L_{i t}^{2}$. After these tests, our four models are run using fixed effects and based on instrumental variables in the models with endogeneity. The results are shown in table 3.5. 


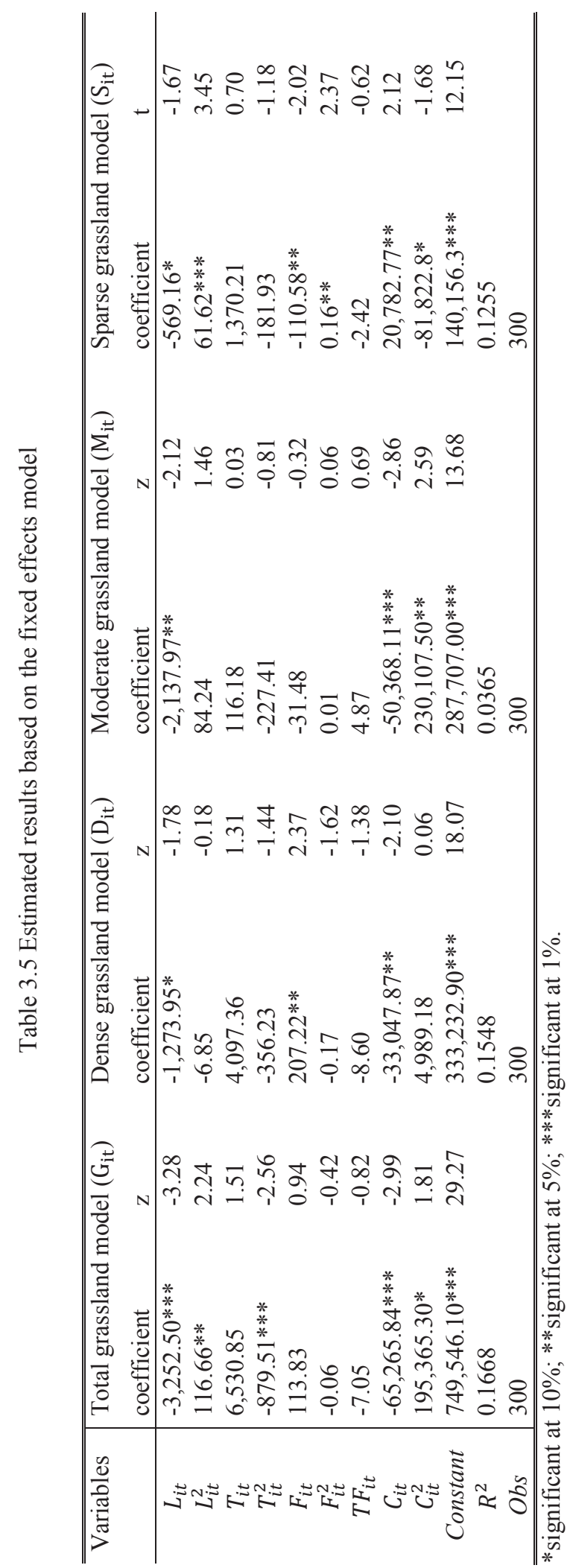


As listed in table 3.5, the coefficient of $L_{i t}$ is significant and negative and the coefficient of $L_{i t}^{2}$ is significant and positive in the total grassland model. It indicates that a possible turning point exists at which the decrease in total grassland area may be reversed as the increase in the number of years with private use. Similarly in the sparse grassland model, the coefficient of $L_{i t}$ is significant and negative, and the coefficient of $L_{i t}^{2}$ is significant and positive as well. Again the possibility of a turning point exists at which the decrease in sparse grassland area will reverse. It is noted that the coefficients of $L_{i t}$ are significant and negative in the dense and the moderate grassland models, but the coefficients of $L_{i t}^{2}$ are not significant. It indicates that when other variables remain constant, the dense (moderate) grassland area decreases by 1274 (2138) hectares if the period with private use increases by one year. In addition, the significant and negative coefficient of $T_{i t}^{2}$ indicates that temperature has a nonlinear relationship with the total grassland area. The significant coefficients of $F_{i t}$ show that precipitation is able to increase the dense grassland area significantly, but conversely reduce the sparse grassland area. And sparse grassland area has a nonlinear relationship with precipitation as presented by its significant coefficient of $F_{i t}^{2}$. Ultimately, the growth of cultivated land $\left(C_{i t}\right)$ has significant and negative effects on the total, dense and moderate grassland areas, and a significant and positive effect on the sparse grassland area. Nonlinear relationships are present in the total, moderate and sparse grassland models as shown by their significant coefficients of $C_{i t}^{2}$.

Comparing the above estimated model results with our expected results in table 3.3, the coefficients of significant variables in the models are almost consistent with our expectations, but the coefficients of $L_{i t}$ and $L_{i t}^{2}$ in the sparse grassland model did not present opposite signs with that in the other three models. This difference indicates that the private use results in the decrease of sparse grassland area firstly and then increase, rather than increase from the beginning as we expected. A possible explanation could be that some sparse grassland degrades to such a degree that the grass cover drops from 5-20\% to less than 5\%. Such severe levels of degradation would however not be picked up by the variable of sparse grassland because land areas with less than 5\% grass cover are no longer counted as grassland areas. And then the decrease of spares grassland area per se is offset by its increase caused by the degradation of grassland quality that the dense and moderate grasslands degrade into sparse grassland after several years of private use. 


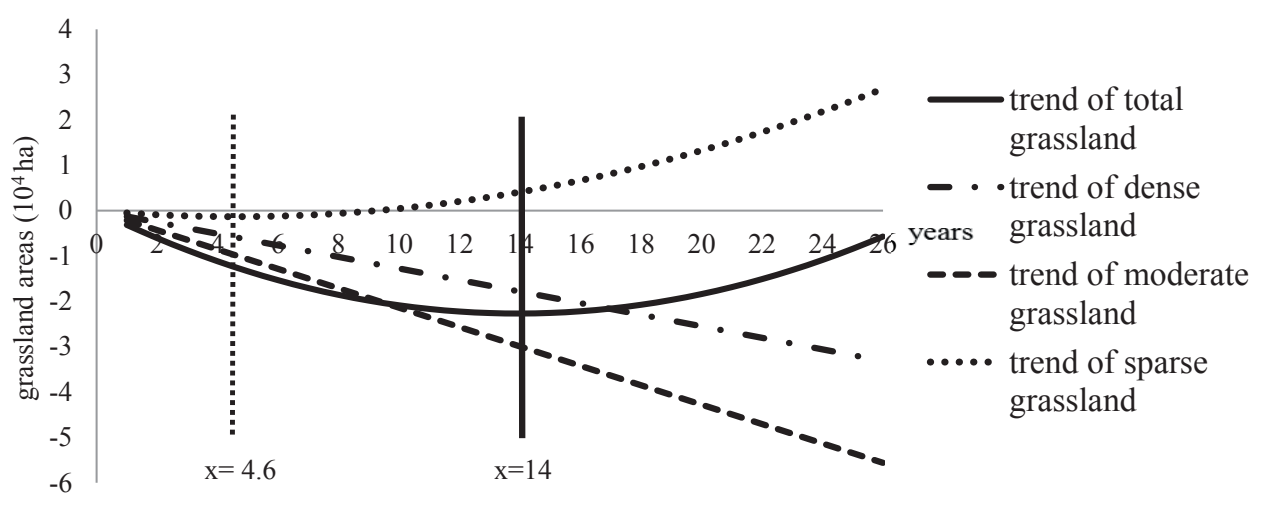

Figure 3.2 Estimated changes in the areas of different grasslands as the increase in the number of years with private use

In figure 3.2, we employ the significant regression coefficients of $L_{i t}$ and $L_{i \mathrm{t}}^{2}$ to particularly depict the changes in the areas of different grasslands as the number of years with private use increases. It is interpreted as the estimated effects of the land tenure reform on grassland condition while all of the other factors are controlled for. Specifically, the $\mathrm{x}$-axis indicates the number of years with private use and the $y$-axis presents the areas of different grasslands. Considering the longest duration with private use till 2008 was 26 years in our original dataset, we drawn the maximum year of the $\mathrm{x}$-axis at 26 . The figure shows that the dense and moderate grassland areas present continuous decreases without reversion as their coefficients for $L_{i t}^{2}$ are not significant in the model. And the moderate grassland area decreases more quickly than dense grassland. However, both sparse and total grassland areas demonstrate the predicted upward trends after the initial decreases as their coefficients for $L_{i t}$ and $L_{i t}^{2}$ are significant. That is, sparse and total grassland areas decrease at first but then start to increase after a certain number of years with private use. The turning point is 4.6 years for the sparse grassland area and 14 years for the total grassland area in our case.

As such, the figure indicates that the total grassland area decreases and is not able to recover to the initial level until several decades after the start of the land tenure reform. Moreover, the continuing decrease in dense and moderate grassland areas indicates that the grasslands with higher grass cover will sustain degradation over time under privatisation. This trend is confirmed by the increase in the sparse grassland area while the reduction in the total grassland area. Subsequently, the increase in the total grassland area may stem from the increase in the sparse grassland area, rather than the improvement of grassland quantity. In short, the empirical 
analysis confirms the negative effects of privatisation on grassland quantity and quality in the long term.

\subsection{Discussion}

In line with the results of Sneath (1998), Li et al. (2007) and Li and Huntsinger (2011), we find a negative impact of privatisation on the grassland condition. This may have discouraged herders to adopt private use, which could be an inherent explanation for the slow progress in the implementation of the land tenure reform on the grasslands of China in recent decades. But conversely, some scholars (see e.g. Li et al., 2007) have argued that the observed negative impacts of the privatisation of grassland use rights result from constraints in the supporting conditions for a successful privatisation process, rather than from the privatisation per se. Specifically, they point to a lack of resources for pastoral herders for instance to build fences and to effectively protect privatised grasslands from overuse by outsiders. An interesting avenue for further research would be to explore in more detail whether the so-called tragedy of privatisation has its roots in privatised use rights per se or in its failed implementation in practice.

Another challenge for future empirical research is to take into account the specific effects of overgrazing and the impacts of ecological reconstruction projects that have been initiated to protect the grassland condition in China since the 2000s ( $\mathrm{Li}$ et al., 2014). The existing evidence on the relationship between livestock production and grassland degradation is vague and controversial (Harris, 2010; Cao et al., 2013b). Moreover, Liu et al. (2016) has shown that the impact of ecological projects on grassland condition was offset to some extent by socioeconomic and climate factors. While these elements were not directly investigated in this paper because of limitations in the data, they were approximated by including the variables of agricultural activities in the model.

Concerning the governance of China's grasslands, instead of the private use by households, the community-based governance is fiercely advocated by pastoral specialists (e.g. FernandezGimenez et al., 2012). They claim that community-based governance can facilitate the reciprocity of resource use among households, including capital investment and labour force use (e.g. Vetter, 2005; Li and Zhang, 2009; Cao et al., 2013b). Some empirical evidence exists to support community-based governance as well. For instance, Cao et al. (2013a) observed that the biomass, vegetation cover and species richness of grasslands are significantly higher under multi-household management than under single-household management in Maqu county, Gansu province. Ho (2001) showed that grasslands can be successfully managed by a village 
community on the basis of a community-based arrangement at low transaction costs. However, more empirical evidence is needed on a large-scale to allow assessing the benefits of community-based governance over private use, taking into account the conditions of current social, economic and policy incentives in the pastoral areas.

\subsection{Conclusions}

This paper used quantitative analysis to investigate the relationship between grassland privatisation and grassland degradation. First, a review was made of the controversial views on the impact of privatisation on the grassland condition. Next, we summarized the progress in the land tenure reform in the pastoral areas of China. The evolution of grassland degradation was demonstrated in a typical pastoral area, using data for 60 counties in Inner Mongolia between 1985 and 2008. A fixed effects model was employed to disentangle the effect of the land tenure reform on the grassland condition while controlling for factors related to climate, agricultural activity and heterogeneity among counties. The model results show that private use causes the reduction of the total grassland area and the degradation of dense and moderate grasslands into sparse grassland in the long run. In conclusion, our analysis suggests that the land tenure reform, namely the privatisation of grassland use rights, plays a significant role in the degradation of grassland quantity and quality in Inner Mongolia. In other words, we observe "a tragedy of privatisation" (Guelke, 2003; Li and Huntsinger, 2011), as opposed to the well-known "tragedy of the commons". 


\section{ACKNOWLEDGEMENTS:}

Funding for this research was supported by grant from National Natural Sciences Foundation of China (71333013). The authors would like to thank Xiaoyi Wang, Dan Wang, Yulan Bu, Jiliang $\mathrm{Hu}$, Yangjie Wang and Jie Zhou for their useful suggestions and help. We are also grateful to the anonymous reviewers for their good comments that contributed to improve the quality of this paper. 


\section{Chapter 4}

How does land tenure reform impact upon pastoral livestock production? An empirical study for Inner Mongolia, China 


\section{HOW DOES LAND TENURE REFORM IMPACT UPON PASTORAL LIVESTOCK PRODUCTION? AN EMPIRICAL STUDY FOR INNER MONGOLIA, CHINA ${ }^{12}$}

ABSTRACT: How has land tenure reform affected livestock production in pastoral areas of China? This question is explored by estimating what impact assigning grassland use rights has on livestock production based on county-level data for Inner Mongolia between 1985 and 2008. The timing of the introduction of the household-based assignment of grassland use rights differed between counties, enabling a comparison of the effects of the land tenure reform. The changes in livestock production over time are examined by analysing data on changes in livestock population and meat output. The descriptive analysis shows that livestock production increased at a higher speed in the crop farming areas, but that the development of livestock productivity was faster in the pastoral areas. In the empirical analysis, we employed a fixed effects model to disentangle the effects of land tenure reform on livestock production from factors related to market forces, grassland condition, technological development and environmental heterogeneity. The model results reveal that the implementation of land tenure reform had significant and negative effects on the increase in livestock production, although total livestock production actually increased. It therefore appears that land reform is in itself unable to offset the impact of other factors that accelerate the increase in livestock production. Moreover, the constraining effect of land tenure reform on the increase in livestock production decreases with the number of years for which land tenure reform has been implemented, and ultimately disappears. Remarkably, the constraining effect of land tenure reform is stronger on the increase of livestock population than on that of meat output. This indicates that land tenure reform is beneficial in that it improves livestock productivity. In conclusion, land tenure reform, namely the privatisation of grassland use rights, puts a ceiling on livestock production, which could be a possible reason as to why it has been difficult to implement the reform on grasslands. However, the reform does prove to be beneficial in improving the livestock productivity of pastoral areas.

KEYWORDS: assignment of property rights, use rights, pastoral area, livestock population, meat output, fixed effects model

\footnotetext{
${ }^{12}$ Paper by Min Liu, Jikun Huang, Liesbeth Dries, Wim Heijman, and Xueqin Zhu, submitted to a peer-reviewed journal.
} 


\subsection{Introduction}

Land tenure reform in China is characterised by assigning long-term land use rights to individual households, involving cropland, grassland, and forest land (see e.g. Hu, 1997; Banks, 2003; Zhang et al., 2012a). According to the current Law of the People's Republic of China on the Contracting of Rural Land, use rights of grassland are contracted to individual households for a duration of 30-50 years. At the end of the 1970s, land tenure reform was first implemented through the Household Production Responsibility System in the crop farming areas of China and was completed rapidly and successfully. Research showed that the assignment of individual cropland use rights gave farmer the incentive of improved agricultural production and spurred the marketing of agricultural goods (see e.g. Ho, 1996; Hu, 1997; Krusekopf, 2002; Banks, 2003). Based on this outcome, the central government of China continued land tenure reform in pastoral areas in the early 1980s and assigned grassland use rights as well as livestock property rights that had been owned by the communes to individual households. However, the assignment of grassland use rights has not been completed as successfully as that of cropland in China (Liu et al., 2015). For instance, compared with the cropland in China, where household-based use rights were assigned overnight, the assignment of grassland use rights is still incomplete despite efforts for 30 years. By 2014, around $84 \%$ of grasslands had been allocated to individual households in China, and the central government continues to emphasise the need for clarifying grassland use rights for individual households (Ministry of Agriculture of China, 2015). In practice, in some areas of Inner Mongolia, only the grasslands for mowing forages have been allocated to individual households while the grazing grasslands are still owned and used by all of the local households (Li et al., 2007). Scholars (e.g. Richard et al, 2006; Li and Zhang, 2009; Li, 2012) have identified a number of possible barriers to the completion of the land tenure reform in the pastoral areas of China. This paper will explore possible reasons by focussing on the aspect of pastoral livestock production.

Land tenure has been the concern of academia for a long time. The privatisation of grassland property rights or use rights has been regarded as a panacea to avoid overgrazing and protect the grassland ecosystem, in order to avoid the situation termed 'the tragedy of the commons' (Hardin, 1968; McEvoy, 1987; Ybarra, 2009). Coase's (1960) theorem of property rights also argued that a clear assignment of property rights is a precondition for economically efficient resource allocation and environmental sustainability. The followers of the 'tragedy of the commons' and property rights theories advocate that the grassland resource should be either privatised or maintained as common land whilst clearly assigning rights of entry and use to 
promote the sustainable use of grassland through exclusiveness. Following this conventional wisdom, most governments in the world have assigned grassland property rights or use rights in an attempt to ensure the sustainable development of grasslands (Li et al., 2014). In line with observations about the effects of privatisation of cropland, the central government of China believes that the assignment of grassland use rights provides land users with incentives to graze animals within the carrying capacity of the land, as well as to increase land investment in order to conserve their own grasslands (Banks, 2003).

However, the findings on the effects of privatising grassland resources are complex (e.g. see Li and Zhang, 2009). During recent years, some scholars have expressed concern that the traditional common-use system and nomadism have been replaced by private use and settlement due to grassland privatisation (Banks et al., 2003). This transformation of traditional pastoralism has impeded mobility and flexible grazing (Fernandez-Gimenez, 2000; Wang et al., 2013) and limited herders' access to emergency pastures and other key productive resources (Niamir-Fuller and Turner, 1999; Fernandez-Gimenez, 2002). This, in turn, has increased feeding costs and reduced herders' ability to withstand natural risks (e.g. Li et al., 2007), causing constraints on the development of animal husbandry in pastoral areas. Some voices have also stated that grassland privatisation reduces the amount of land available for livestock grazing, further leading to a reduction in the number of livestock that an individual can potentially own, ultimately resulting in poverty (Mwangi, 2007). In addition, research has shown that the carrying capacity of grassland is reduced due to decreased access to heterogeneous landscapes (Boone and Hobbs, 2004; Hobbs et al., 2008; Boone et al., 2005). As such, the total population of livestock that could be supported by a grassland ecosystem is predicted to decline as a result of the spatial and social boundaries stemming from privatisation.

In fact, much of the growth in animal supply has been coming from rapidly expanding intensive breeding systems rather than through traditional grazing systems in pastoral areas (FAO, 2015). Similarly, the main production areas for livestock products in China have experienced a geographic shift from being pastoral areas to being crop farming areas (Li et al., 2008). The market share of livestock products from grazing systems is decreasing compared to that of croplivestock mixed or industrialised systems (Squires et al., 2009). This trend is suggested to be attributed to the reduction in grass yields due to grassland degradation, and raises environmental concern about the ecosystem of permanent grassland (Li et al., 2008; Squires et al., 2009). Besides these possible factors, we wish to ascertain whether the privatisation of grasslands has played a role in the changes in livestock production of pastoral areas. Despite an abundance of 
academic arguments and government reports on the results of the privatisation of grassland, there is a lack of quantitative studies, especially based on large-scale areas and long-term observations (e.g. Li and Huntsinger, 2011; Yu and Farrell, 2013; Conte, 2015). Moreover, the existing literature is short of empirical analysis targeting the impact of grassland privatisation on livestock production, although some studies are concerned with ecological effectiveness. Nevertheless, animal husbandry provides livelihoods to millions of people in pastoral areas and has the potential capacity to meet the rapidly increasing global demand for livestock products which is stimulated by growing populations, urbanisation and rising disposable incomes (FAO, 2015). In this regard, livestock production in pastoral areas is a very significant area and one which deserves being paid close attention to.

In the following section, we first describe the land tenure reform and the current livestock production in the research region. Next, in section 3, the data collection method is illustrated and a descriptive analysis based on the collected data is used to elaborate on the changes in livestock production in the pastoral areas compared to crop farming areas. In sections 4 and 5 , we present the empirical model used in the study and the model results on how land tenure reform and other potential factors affect livestock production in the pastoral areas. In section 6 , we discuss the model results and their underlying reasons. We conclude this paper with remarks on the effects of grassland privatisation on livestock production in pastoral areas.

\subsection{Research region}

China has around 400 million hectares of grassland, accounting for nearly $40 \%$ of its total territory, this being the second largest area of grassland in the world after Australia (Hua and Squires, 2015). Inner Mongolia, a province located in the arid and semi-arid areas of northern China, has 118.3 million hectares of land; in 2014, its permanent population was 25 million. It accounts for $21.7 \%$ of China's permanent area of grasslands. Approximately $67 \%$ of the total land area in Inner Mongolia is classified as grassland, the majority of which can be subclassified as temperate grassland (Angerer et al., 2008). Inner Mongolia plays an important role in the supply of animal products as well as in the ecosystem of China due to its extensive grasslands. In the pastoral areas populated by Mongolians, the vast majority of local people maintain their livelihoods through grazing their livestock on the grasslands (Angerer et al., 2008). Inner Mongolia was one of the first regions in which land tenure reform was implemented on grasslands in China because of its crucial position in China's grassland resource and livestock production (Li and Huntsinger, 2011). 
According to the current administrative divisions of Inner Mongolia, there are 102 counties, including 33 pastoral counties and 21 semi-pastoral counties. The remaining 48 counties are dominated by crop farming or urban districts. Pastoral counties are characterised by traditional grazing systems and permanent grassland is the dominant land type. In semi-pastoral counties, both permanent grassland and cropland are the dominant land types. Mixed crop-livestock systems also exist, where intensive animal husbandry and cropping both occur (Waldron et al., 2010). The majority of the pastoral areas of Inner Mongolia are found in the pastoral counties as well as semi-pastoral counties. Figure 4.1 presents the location of Inner Mongolia in China and its three types of counties.

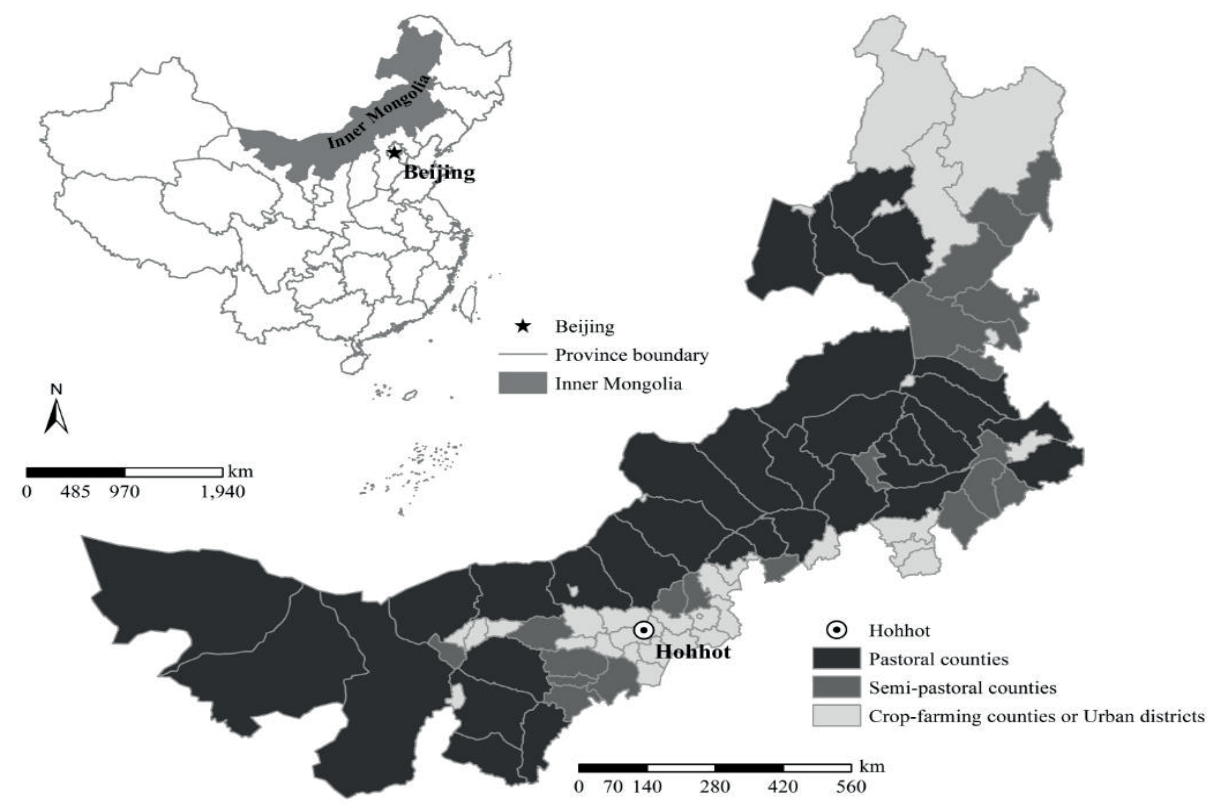

Figure 4.1 Inner Mongolia and its 102 counties

\subsubsection{Land tenure reform in the pastoral areas of Inner Mongolia}

Land tenure reform started in Inner Mongolia with the Double Contracts System (Cao Xu Shuang Cheng Bao) in 1982. This system aimed at assigning to individual households the livestock and grasslands that were managed by the communes during the collectivist period of China. Meanwhile, the users (individual households) of the grasslands are regulated in order to control their livestock numbers according to a determinant stocking rate with the aim of avoiding overuse of grasslands (Ho, 2000). The assignment of property rights over livestock was completed promptly but grasslands were not strictly assigned to individual households in 
the majority of the pastoral areas in the 1980s. Particularly, the use of grasslands merely indicated a rough direction and position to herders, but local herders and their animals still roamed wherever they preferred. Hinton (1990) called this phenomenon privately controlled stock of animals on publicly owned lands in Inner Mongolia. The result was an uncontrolled scramble for wherever forage existed, which amounted to a general attack on a range of vegetation (Hu, 1997). Subsequently, the assignment of grassland use rights to individual households was strengthened by the Two Rights and One System policy (Shuang Quan Yi Zhi) in 1996 (Bureau of Animal husbandry of Inner Mongolia, 2000; Li and Zhang, 2009). This stimulated the progress of grassland privatisation greatly and is regarded as the second round of land tenure reform in the pastoral areas of Inner Mongolia (Yang, 2007). In recent years, growing attention has been paid to ensure the long-term stability of grassland use rights to individual households, such as confirming grassland plots, areas and contracts (Li, 2012). In 2015, local governments in Inner Mongolia are still working on clarifying the boundaries of grassland use rights for each household and issuing certificates (Bureau of Animal husbandry of Inner Mongolia, 2015).

Compared with crop farming areas, the implementation of the land tenure reform on grasslands is relatively complex and has taken a long time. More specifically, the grasslands have been subject to several different types of ownership (Yu and Farrell, 2013) and correspondingly, various types of land use have arisen since the start of the land tenure reform in Inner Mongolia. Table 4.1 provides a typology of the land tenure reform on the changes in formal use rights and actual types of grassland use, which is in line with the investigation of the Tibetan plateau by Banks et al. (2003). 
Table 4.1 Typology of land tenure reform on grasslands of Inner Mongolia

\begin{tabular}{llll}
\hline \hline \multirow{2}{*}{ Formal use rights owned by } & \multicolumn{3}{c}{ Actual grassland use } \\
\cline { 2 - 4 } & Private use & Joint use & Common use \\
\hline Individual households & + & + & + \\
A group of households & na & + & + \\
Collective/administrative village & na & na & + \\
\hline \hline
\end{tabular}

Source: adapted from "formal and de facto grassland management units" (Banks et al., 2003) na indicates not available

As presented in Table 4.1, with the implementation of land tenure reform, three types of ownership of formal grassland use rights have arisen, namely individual household ownership, ownership by a group of households and collective ownership. There are also three types of actual grassland use, these being private use by individual households, joint use by a group of households and common use by all of the villagers. When formal use rights are owned by an administrative or natural village, the only type of grassland use is common use. This arose primarily before or at the beginning of the implementation of the land tenure reform when the grassland rights had not yet been assigned. If the formal use rights are owned by a group of households, the land use is either common or joint. This situation mostly occurs in areas where the grassland resource is too scarce to be assigned to individual households, or where grassland use rights have not been assigned. Private use, joint use and common use exist simultaneously when the formal use rights are owned by individual households. The intention of the land tenure reform in the pastoral areas, however, is to achieve full private use when use rights are assigned to households. This reflects the gap between the household-based assignment of formal use rights and the actual adoption of private use. In practice, the specific timing and extent of conducting the land tenure reform ${ }^{13}$, including the changes in formal use rights and use patterns, differed among counties in Inner Mongolia.

\subsubsection{Livestock production in Inner Mongolia}

Inner Mongolia is one of the main production regions for animal products in China. In 2013, it accounted for $18 \%$ of the population of sheep ${ }^{14}$ of China, ranking first out of all Chinese provinces. The mutton output accounted for $22 \%$ of the total meat output in China. Six per cent

\footnotetext{
${ }^{13}$ In the reminder of the paper, the land tenure reform means the grassland use rights are assigned to individual households.

${ }^{14}$ The term 'sheep' in this paper includes both sheep and goats, in accordance with the China Statistical Yearbook.
} 
of cattle were raised in Inner Mongolia, and 8\% of China's total beef output was produced there, in both cases ranking second in China. Figures 4.2 and 4.3 present the livestock production of Inner Mongolia from 1979 to 2013, based on data from the China Statistical Yearbook (Zhong Guo Tong Ji Nian Jian). Livestock production is interpreted by the livestock population and meat output. Sheep and cattle are the dominant animals being raised in Inner Mongolia (Zhang et al., 2012b). We therefore employ the population of sheep and cattle to represent the livestock population, and the outputs of mutton and beef for meat output.

Figure 4.2 shows that the population of sheep decreased in 1982 and then generally presented an increasing trend until 1999, apart from a decrease during 1991-1993. It experienced a sharp increase from 2001 to 2004 after a decrease from 1999 to 2001, and remained relatively steady between 2005 and 2013. The population of cattle saw slight fluctuations but remained almost unchanged between 1979 and 2000. It reached the lowest point in 2001 after a slight decrease from 1999 and then experienced an increase between 2002 and 2010, followed by a slight decrease until 2013. It is evident that the number of sheep exceeded cattle numbers by a wide margin during the whole period.

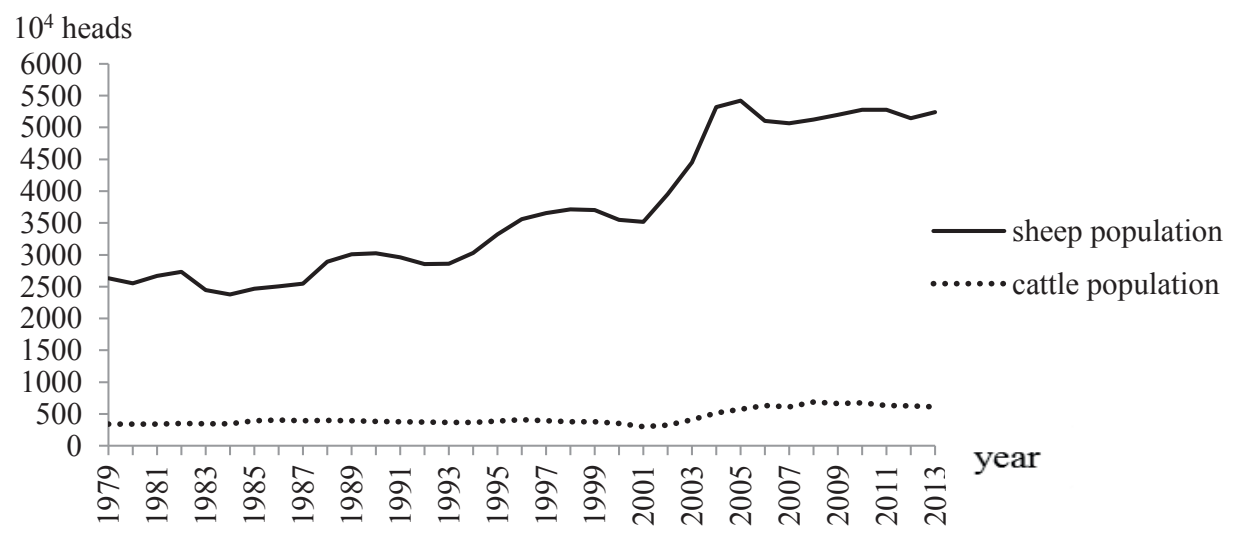

Figure 4.2 Livestock population of Inner Mongolian from 1979 to 2013

Figure 4.3 depicts Inner Mongolia's mutton and beef outputs from 1979 to 2013. Until 2002, the outputs of mutton and beef experienced fluctuating and slow increases. The output of mutton and beef increased sharply between 2002 and 2005, after which the output of mutton remained relatively steady, while beef continued to increase slightly between 2006 and 2013. In general, mutton output exceeded beef output during the whole period. Mutton output in 2013 
was around 14 times higher than in 1979, while beef output was 19 times higher in 2013 than in 1979.

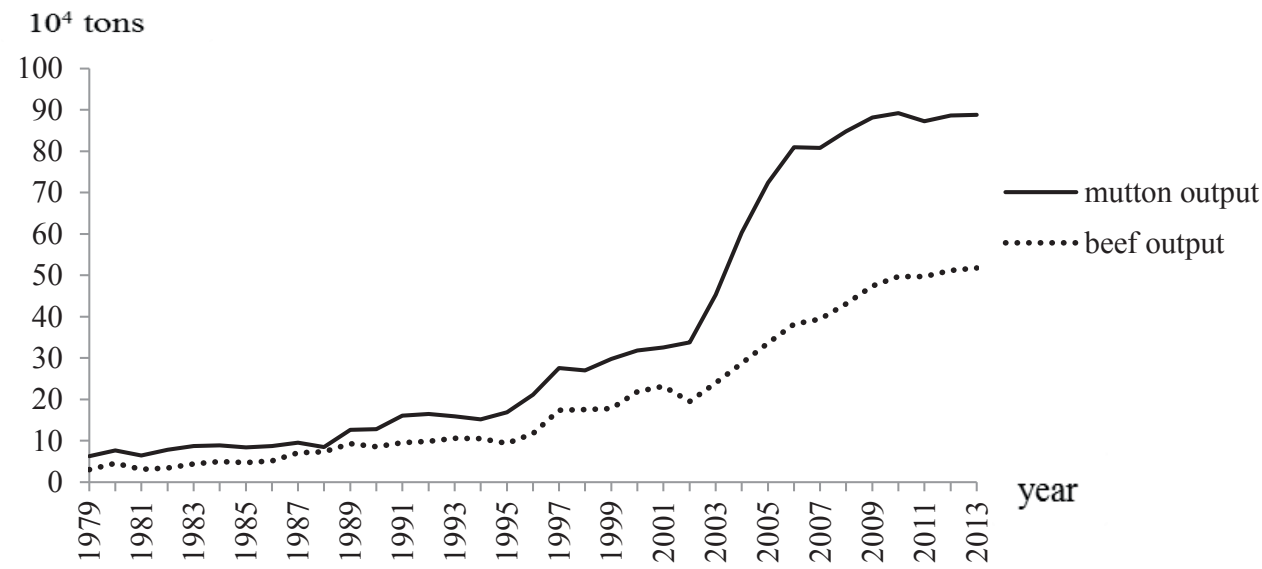

Figure 4.3 Mutton and beef outputs of Inner Mongolia from 1979 to 2013

Figure 4.4 illustrates the development of livestock productivity in Inner Mongolia from 1979 to 2013. The livestock productivity for both sheep and cattle has increased. The increase of productivity for cattle experienced obvious fluctuations, while the productivity for sheep saw a slight and steady increase. It is evident that the output per cattle increased faster than the output per sheep.

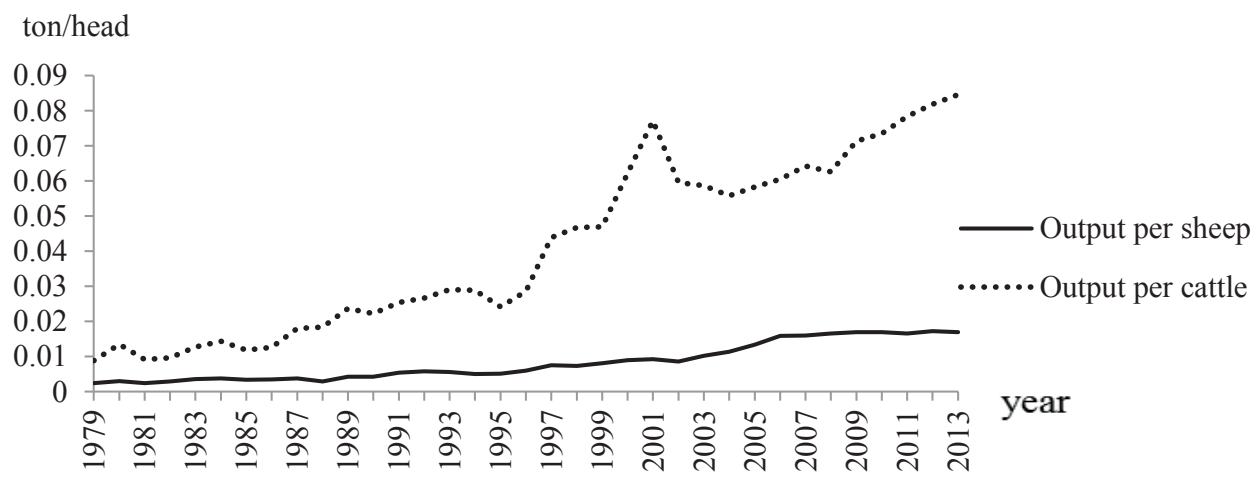

Figure 4.4 Livestock productivity of Inner Mongolia from 1979 to 2013

Although livestock population, meat output and livestock productivity have generally increased in Inner Mongolia over time, the importance and competitiveness of its livestock production 
within China have been threatened by Henan and Shandong provinces, which are the dominant crop farming areas of China where intensive animal husbandry systems have developed in recent years (Su, 2010). Furthermore, a number of ecological projects for grassland conservation and the promotion of non-farming industries have been introduced in Inner Mongolia and have impacted upon the development of animal husbandry in the region (Squires et al., 2009). As a result, the share represented by animal husbandry in the gross domestic product of Inner Mongolia has decreased. Moreover, since 2001, the provincial government of Inner Mongolia has laid emphasis on the development of livestock production in its crop farming areas instead of in the pastoral areas. In 2007, 70\% of livestock production in Inner Mongolia was located in crop farming areas (Su, 2010). This geographic shift from pastoral areas to the crop farming areas is discussed in the following section.

\subsection{Data description}

\subsubsection{Data collection}

We aim to estimate the impact of land tenure reform on pastoral livestock production. The pastoral areas are therefore distinguished from the crop farming areas for the purposes of data collection. Given that the timing and extent of the implementation of land tenure reform differed between counties, our empirical study of the effects of the reform on livestock production is conducted based on county-level data. The other factors that are controlled for their potential impacts on the pastoral livestock production are grassland condition, market forces, technological development and environmental heterogeneity ( $\mathrm{Li}$ et al., 2008; Tessema et al., 2014). We therefore collected three types of data at the county-level in Inner Mongolia: survey data on land tenure reform of each county, observational data on grassland conditions and statistical data on socio-economic indicators.

First, the data on land tenure reform was collected via questionnaires in each county in Inner Mongolia. Based on the typology shown in Table 4.1, the questionnaire focused on when formal use rights were owned by collectives, groups and individual households respectively, and when grassland was actually in common use, joint use or private use. Questionnaires were sent to the Animal Husbandry Bureau of each county and were answered by key informants on local land tenure reform. Interviews were conducted by telephone to confirm the answers after receiving feedback from each county. We ultimately obtained valid feedback from 74 out of 102 counties. In addition, we conducted interviews with the officers who are working in the provincial institutes of Animal Husbandry of Inner Mongolia as well as with local herders to verify the 
progress of land tenure reform on local grasslands. Second, information about grassland conditions was obtained based on remote sensing and an analysis of Geographic Information Systems. This relies on a database developed by the Chinese Academy of Sciences with original data from Landsat Thematic Mapper / Enhanced Thematic Mapper (Plus) (TM/ETM+) images (Deng et al., 2011). GIS satellite images were only collected in 1985, 1995, 2000, 2005 and 2008. We therefore use the average growth rate of grassland areas between the years of observation to estimate the grassland condition for each year. Third, the data on socio-economic indicators is based on existing statistical data collected by local governments. Specifically, the data about livestock production was gathered from the Statistical Yearbooks of Inner Mongolia. Market forces are represented by the real producer price of mutton and beef. This information was collected based on the Annual Compilation of Cost-benefit Data of Chinese Agricultural products (Zhong Guo Nong Chan Pin Cheng Ben Shou Yi Hui Bian) and deflated by a producer price index. Specific data on technological development is lacking, and is thus proxied by a time variable. The factor of environmental heterogeneity among counties is removed by the fixed effects model as a time-invariant variable.

The research period covers 1985-2008, which includes the main period when land tenure reform was implemented on the grasslands of Inner Mongolia. After excluding the urbanised counties and counties that underwent changes in administrative regions during the research period, 60 counties are retained in the research sample. They include 27 pastoral counties, 18 semi-pastoral counties and 15 crop farming counties. In fact, the crop farming counties only have a few permanent grasslands and their livestock production relies mainly on cropping rather than grazing. Furthermore, household-based assignment of grassland use rights was barely implemented because the areas of grasslands in most crop farming counties are too small to be subdivided. Therefore, the information from crop farming counties is only used in the descriptive analysis to compare the relative changes in livestock production between crop farming areas (crop farming counties) and pastoral areas (pastoral and semi-pastoral counties).

\subsubsection{Descriptive analysis}

Based on the collected data, we first illustrate the progress of the land tenure reform ${ }^{15}$ in the pastoral areas of Inner Mongolia from 1985 to 2008. In Figure 4.5, the proportion of counties

\footnotetext{
${ }^{15}$ Considering that some counties did not complete the land tenure reform fully, we denote a county as having implemented the land tenure reform if at least $50 \%$ of the grassland area of this county has been assigned to individual households.
} 
in which formal use rights were assigned to households increased from $9 \%$ in 1985 to $91 \%$ in 2008; the proportion of counties that adopted actual private use rose from $7 \%$ in 1985 to $71 \%$ in 2008. A sharp increase in formal and actual use rights adoption is observed between 1995 and 1998. This is consistent with the second round of land tenure reform implemented in this period. It can be seen that the adoption of actual private use lagged behind the assignment of formal use rights; neither were fully completed until 2008.

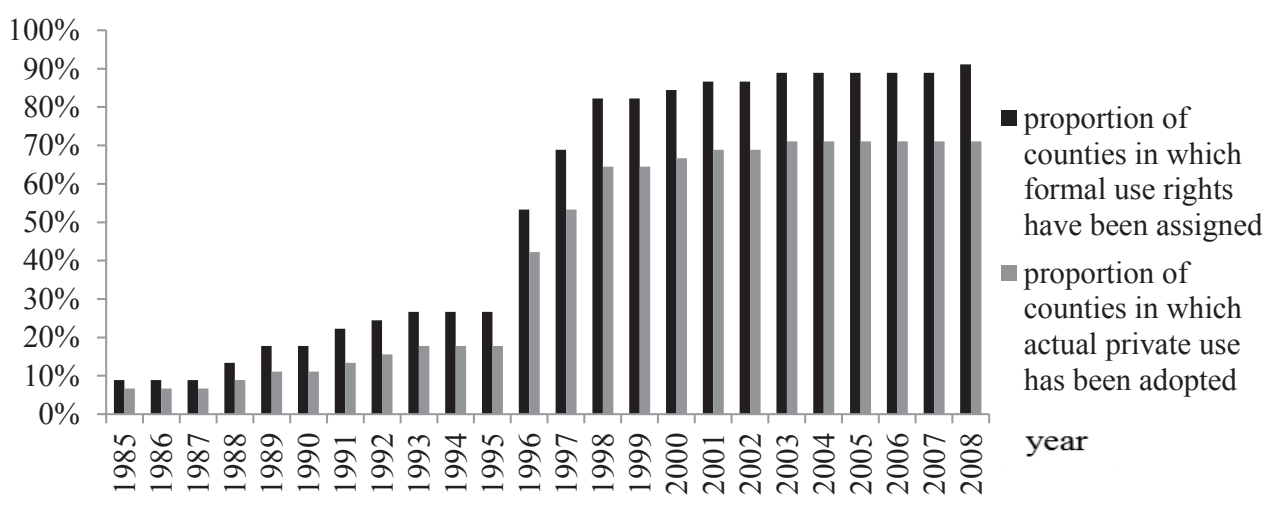

Figure 4.5 Progress of the land tenure reform in the pastoral areas of Inner Mongolia from 1985 to 2008

Figures 4.6, 4.7 and 4.8 demonstrate the changes in livestock production and productivity of the pastoral areas relative to the crop farming areas from 1985 to 2008. The changes are represented as an index where the level in 1985 is set equal to 100. Figure 4.6 indicates that both sheep population and mutton output increased in pastoral areas as well as in crop farming areas from 1985 to 2008, and that the increase of sheep population was slower than that mutton output, especially after 1995. In addition, after 2001, the growth rate of the sheep population in crop farming areas significantly exceeded that in pastoral areas. And the growth rate of mutton output of crop farming areas exceeded that of pastoral areas from 1999 onwards. 


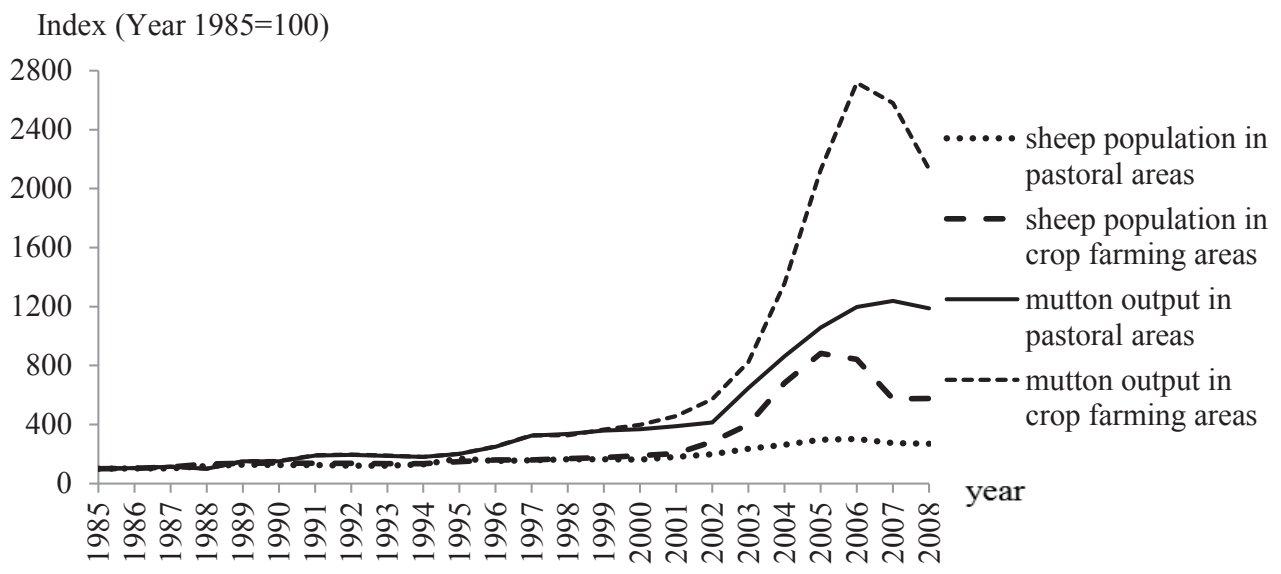

Figure 4.6 Comparison of sheep population and mutton output between pastoral and crop farming areas of Inner Mongolia from 1985 to 2008

Figure 4.7 shows that the cattle population increased slightly compared with 1985, and that the output of beef has increased significantly in both pastoral and crop farming areas over the past 24 years. The increase of beef output was more obvious than that of cattle population. Moreover, the growth rate of the cattle population in pastoral areas was exceeded by that in crop farming areas from 2001 onwards. Also, the growth rate of the beef output in pastoral areas was exceeded by the beef output in crop farming areas after 2000 .

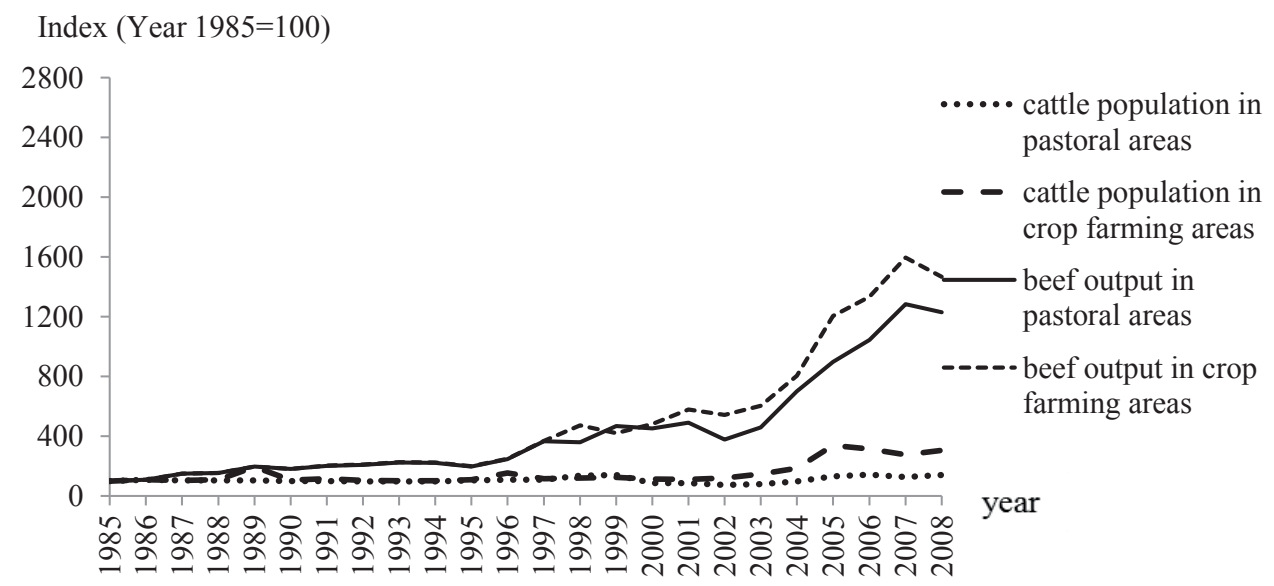

Figure 4.7 Comparison of cattle population and beef output between pastoral and crop farming areas of Inner Mongolia from 1985 to 2008 
Figure 4.8 compares the development of livestock productivity between pastoral and crop farming areas from 1985 to 2008. It is evident that the increment of output per sheep in pastoral areas proved to be larger than that of crop farming areas after 2002. The increment of output per cattle in pastoral areas was larger than that of crop farming areas since 1999. The development of output per cattle was faster than per sheep in both areas.

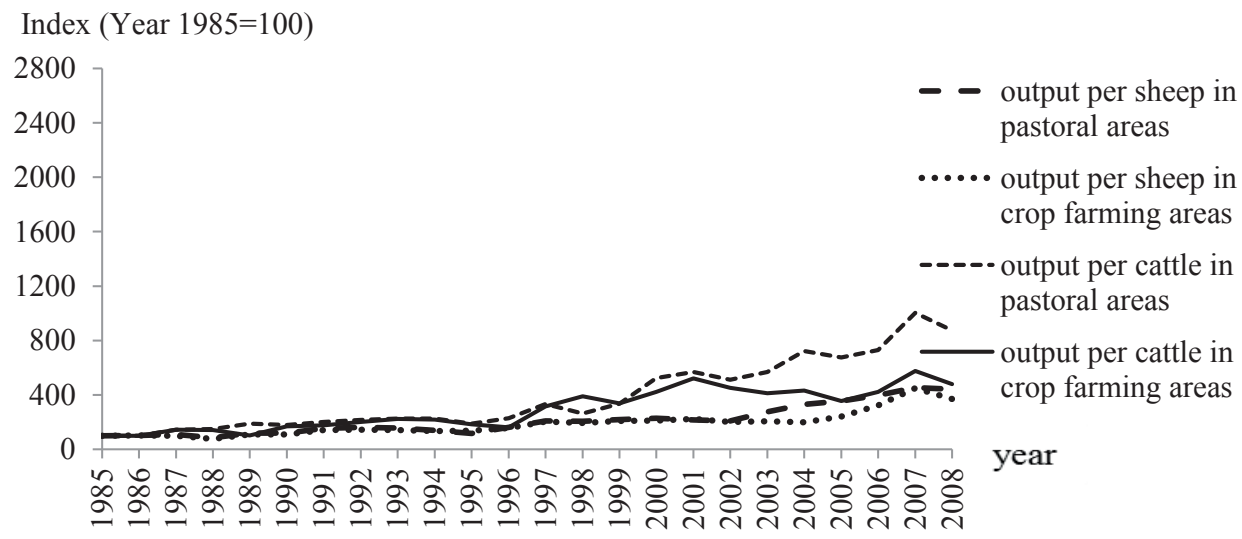

Figure 4.8 Comparison of livestock productivity between pastoral and crop farming areas of Inner Mongolia from 1985 to 2008

In short, land tenure reform was implemented progressively in the pastoral areas in the period 1985-2008. Meanwhile, it appears that the increase of livestock production was faster in crop farming areas than in pastoral areas, but conversely the development of livestock productivity was slower in crop farming areas. It can be seen that the competitiveness of animal husbandry in pastoral areas has been threatened by crop farming areas in recent decades as the livestock population and meat output has grown faster in crop farming areas since around 2000. This is consistent with the fact that in China, the main producing areas of livestock products have experienced an adjustment, moving from a grazing system to a crop-livestock mixed system and from pastoral areas to crop farming areas (Li et al., 2008). Interestingly, the development of livestock productivity was faster in pastoral areas than in crop farming areas, which may be attributed to the transformation of traditional pastoralism in the pastoral areas of Inner Mongolia. As such, we assume that land tenure reform constrained the increase of livestock production, but spurred the development of livestock productivity of pastoral areas. We will assess this assumption with an empirical model based on the data from 45 sample counties of pastoral areas in Inner Mongolia. 


\subsection{Empirical model}

A fixed effects model is widely used in economic research, primarily to study the causes of changes within entities over time (e.g., Fergusson et al., 2002; Huang et al., 2006). The model employs within transformation to remove all time-invariant (fixed) explanatory variables, i.e. the model is performed in deviations from individual means (Verbeek, 2012). As such, the fixed effects model provides a method that takes observable as well as unobservable time-invariant explanatory variables into account, but the estimation is not dependent on the value of timeinvariant (fixed) variables (Verbeek, 2012). Such an approach is appropriate in this study considering that the results of land tenure reform within each county over time can be studied effectively by controlling for the unmeasured heterogeneity among counties. On the other hand, the explanatory variables of land tenure reform we are interested in show changes in value across our research period for a substantial proportion of counties in our data (see Figure 4.5), which satisfies the basic requirement of the fixed effects model (Daun-Barnett, 2011). In addition, our research sample attempts to include all counties in the pastoral areas of Inner Mongolia, rather than random draws, which preliminarily indicates that a fixed effects model is more appropriate than a random effects model (Verbeek, 2012).

Based on the theoretical framework of the fixed effects model, we formulate the effects of the land tenure reform and other potential factors on livestock production into the following equations:

$$
\begin{aligned}
\log \left(S_{i t}\right)=s_{i}+ & a_{1} \log \left(R_{i t-1}\right)+a_{2}\left(1 /\left(R_{i t-1}\right)\right)+a_{3} \log \left(M_{i t-1}\right)+a_{4} \log \left(T_{i t-1}\right)+a_{5} \log \left(G_{i t-1}\right) \\
& +a_{6} Y_{t}+a_{7} P_{i} * Y_{t}+\varepsilon_{i t} \\
\log \left(C_{i t}\right)=g_{i}+ & b_{1} \log \left(R_{i t-1}\right)+b_{2}\left(1 /\left(R_{i t-1}\right)\right)+b_{3} \log \left(B_{i t-1}\right)+b_{4} \log \left(T_{i t-1}\right)+b_{5} \log \left(G_{i t-1}\right) \\
& +b_{6} Y_{t}+b_{7} P_{i} * Y_{t}+\mu_{i t} \\
\log \left(U_{i t}\right)=u_{i}+ & c_{1} \log \left(R_{i t-1}\right)+c_{2}\left(1 /\left(R_{i t-1}\right)\right)+c_{3} \log \left(M_{i t-1}\right)+c_{4} \log \left(T_{i t-1}\right)+c_{5} \log \left(G_{i t-1}\right) \\
& +c_{6} Y_{t}+c_{7} P_{i} * Y_{t}+\lambda_{i t} \\
\log \left(F_{i t}\right)=f_{i}+ & d_{1} \log \left(R_{i t-1}\right)+d_{2}\left(1 /\left(R_{i t-1}\right)\right)+d_{3} \log \left(B_{i t-1}\right)+d_{4} \log \left(T_{i t-1}\right)+d_{5} \log \left(G_{i t-1}\right) \\
& +d_{6} Y_{t}+d_{7} P_{i} * Y_{t}+\delta_{i t}
\end{aligned}
$$

where $i$ and $t$ present the $i^{\text {th }}$ county and year $t$. Variables are defined in Table 4.2 and summary statistics are provided. 

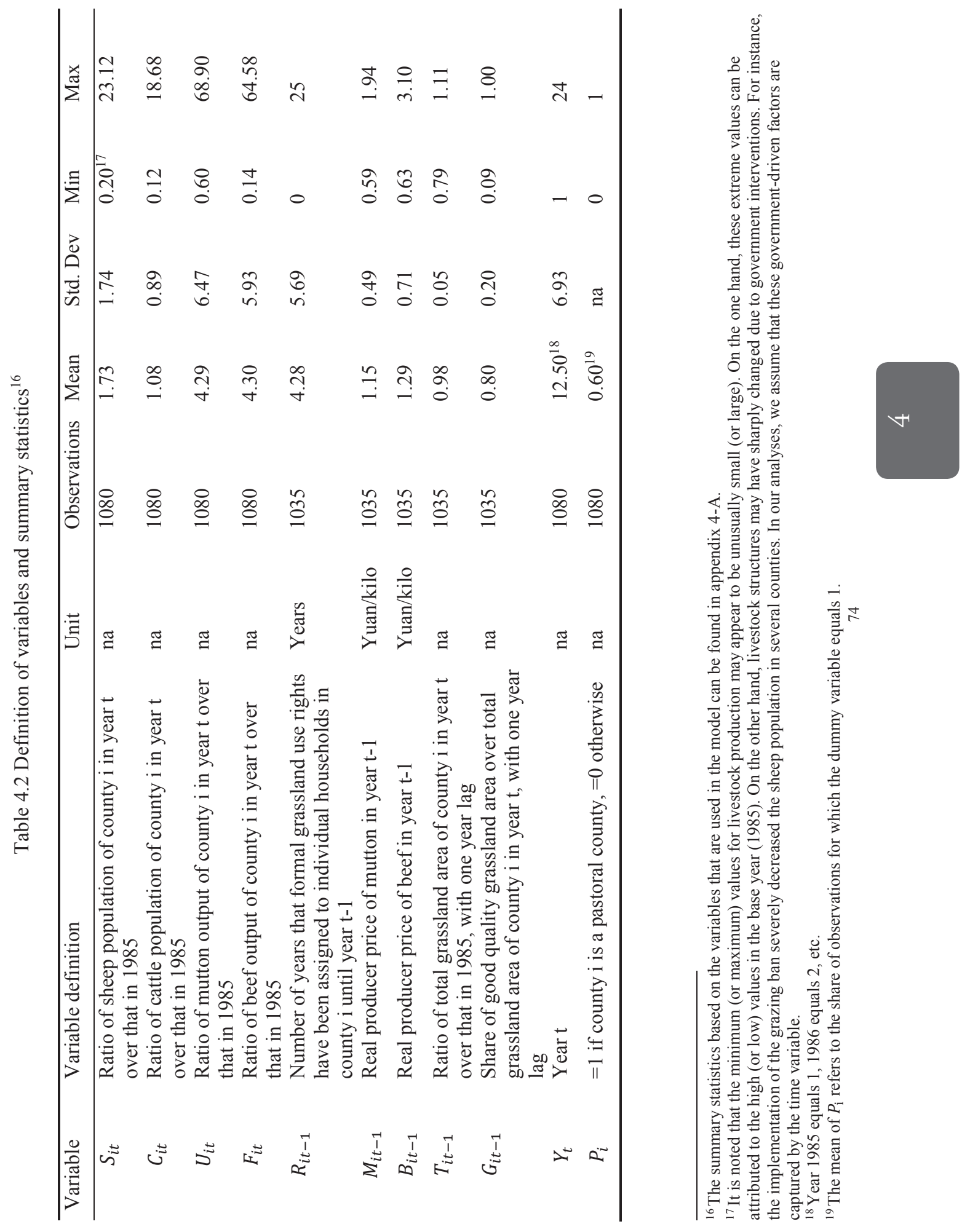

仿齐言

局哥焉

远远

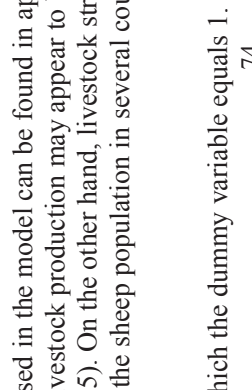

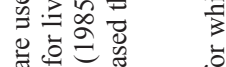

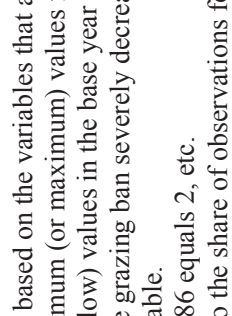

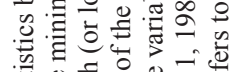

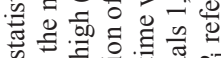

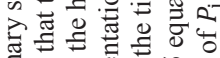

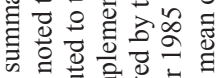
क 
Sheep and cattle population and mutton and beef output are used to represent the livestock production. The ratios of these four indicators in year $t$ compared with the base year 1985 $\left(S_{i t}, C_{i t}, U_{i t}\right.$ and $\left.F_{i t}\right)$, expressed in logarithms, are employed as the four dependent variables in equations (1)-(4). The four equations are denoted as the sheep population, cattle population, mutton output and beef output models, respectively. Variable $R_{i t}$ indicates the land tenure reform of county $i$ in year $t$, which is presented by the number of years in which the formal use rights of grassland have been owned by individual households in county $i$ by year $t$. We assume that land tenure reform has a non-linear relationship with livestock production. Plenty of scholars have proved the existence of a nonlinear relationship between access to land and agricultural production (e.g. Finan et al., 2005). Ostrom (2007) claimed that the problems linked with social-ecological systems require serious study which take account of complex, multivariable, nonlinear, cross-scale, and changing systems. Our functions attempt to explore the trend of livestock production under the land tenure reform over time based on the assumption of their non-linear relationship, which can be concave, convex, quasi-concave or quasi-convex. The logarithm and reciprocal of the variable of land tenure reform are employed to present the non-linear relationships ${ }^{20}$. Considering that the value of the land tenure reform variable is zero for some counties as they had not implemented the reform by 2008 , we add a small original value (e.g., 0.01$)^{21}$ to $R_{i t}$ when $R_{i t}$ is specified in $\log \left(R_{i t}\right)$ or $1 /\left(R_{i t}\right)$.

Based on the existing academic research, the factors of market forces, grassland condition, technology development and environmental heterogeneity are widely suggested to impact the pastoral livestock production (Li et al., 2008; Squires et al., 2009; Tessema et al., 2014). As such, they are considered as control variables in our functions for disentangling the impact of land tenure reform. Market forces are proxied by the local mutton price $\left(M_{i t}\right)$ and the beef price $\left(B_{i t}\right)$ which are expected to affect supply decisions of livestock producers (Komarek et al., 2012). The grassland condition refers to the quantity and quality of grasslands. It indicates the carrying capacity for livestock, reflecting grassland degradation and climate change factors such as temperature and water availability (Henry et al., 2012). Specifically in our model, the ratio of total grassland area in year $t$ over that in 1985 is used to present the changes in quantity

\footnotetext{
${ }^{20} \mathrm{We}$ have also tested a model with a quadratic term instead of the reciprocal to specify the non-linear relationship. The results of both model specifications were comparable, which indicates the model specification is reliable and the model results are robust (see appendix 4-B for details of the specification with the quadratic form).

${ }^{21} 0.01$ is small enough to be regarded as the original value because we tried smaller values (such as 0.001 , and 0.0001 ) and obtained consistent model results.
} 
of grassland $\left(T_{i t}\right)$. The grassland quality is presented by the share of the area of good quality grassland $^{22}$ in the total grassland area in year $\mathrm{t}\left(G_{i t}\right)$.

Technological development is presented by the time variable $Y_{t}$. It should be noted that the development of technology in pastoral areas is mostly government-driven, mainly as a result of the growing interest of the central government in the ecological benefits of grasslands in recent years. For instance, a series of Ecological Construction Programs for grassland conservation have been implemented since 2000 to develop intensive animal husbandry through improving the technology of animal husbandry (Li et al., 2014). These have stimulated the improvement of forage production, feeding and fattening techniques and the use of improved breeds (Liao, 2009). The time variable $Y_{t}$ is therefore used to interpret the impact of these ecological programs as well. $P_{i}$ is a dummy variable that is one for pastoral counties and zero otherwise. The interaction term of $Y_{t}$ and $P_{i}$ is included in the equations to recognise the differences between pastoral counties and semi-pastoral counties in terms of technological development and ecological policies. Apart from the time and dummy variables, we treat all independent variables with a one year lag because market forces, grassland condition and land tenure reform are all considered to affect livestock production with a time delay. Moreover, market forces and grassland condition are used in logarithmic form.

Finally, other factors such as elevation, terrain slope and distance to the provincial capital, which are not expected to change significantly over time, are treated as time-invariant (fixed) factors. They are represented by the terms $s_{i}, g_{i}, u_{i}$ and $f_{i}$ in the models. The coefficients of the independent variables are $a_{n}, b_{n}, c_{n}$ and $d_{n}(\mathrm{n}=1,2, \ldots 7)$ and the random error terms are $\varepsilon_{i t}, \mu_{i t}, \lambda_{i t}$ and $\delta_{i t}$. There are 1035 observations used in the fixed effects model, covering 45 counties and 23 years.

\subsection{Model results}

Before the estimation, we first conduct a Hausman test to choose between the fixed effects or random effects regression as the estimation technique. The test results for the models of sheep population, mutton output and beef output reject the null hypothesis at $\mathrm{p}<0.01$, indicating that the fixed effects regression is more appropriate. Only the test result for the model of cattle

\footnotetext{
22 'Good quality grassland' denotes grassland where the canopy cover of grass is more than $20 \%$. Grasslands are divided into three categories according to the canopy cover, namely dense grassland, moderate grassland and sparse grassland (Deng et al., 2011). In this paper, good quality grassland includes dense grassland and moderate grassland.
} 
population does not reject the null hypothesis at $\mathrm{p}<0.01$. We conducted the random effects and fixed effects regression for the model of cattle population. The results are comparable, with the exception of the coefficient of the constant term. To compare the results of the four models consistently, we use the fixed effects regression for all of them.

Furthermore, we discuss the exogeneity of the variable of land tenure reform $\left(R_{i t}\right) . R_{i t}$ indicates the number of years for which formal grassland use rights have been assigned. In practice, the assignment of formal grassland use rights was implemented by the county-level government based on top-down executive orders. According to our survey, the differences in the assignment of formal grassland use rights among counties resulted mainly from the implementation efficiency of each county government and the county's geographical location. For instance, a county that is located in a remote area was less motivated to assign formal use rights. In this regard, the speed of implementation of the land tenure reform by local governments was not related to local livestock production, grassland condition, or other factors that we include in the model. Hence, we treat $R_{i t}$ as an exogenous variable. In contrast, the decision by local households to actually adopt private use is likely to have taken into account the grassland condition, living customs, production pattern etc., and would therefore have created a potential problem of endogeneity. The exogeneity of policy implementation in China was also supported by Liu et al. (2010) based on their research about the implementation of the Sloping Land Conversion Program (SLCP).

The fixed effects model is used to estimate our four models based on the panel data set. The model results about how the factors impacted upon livestock production in the pastoral areas are listed in Table 4.3. 

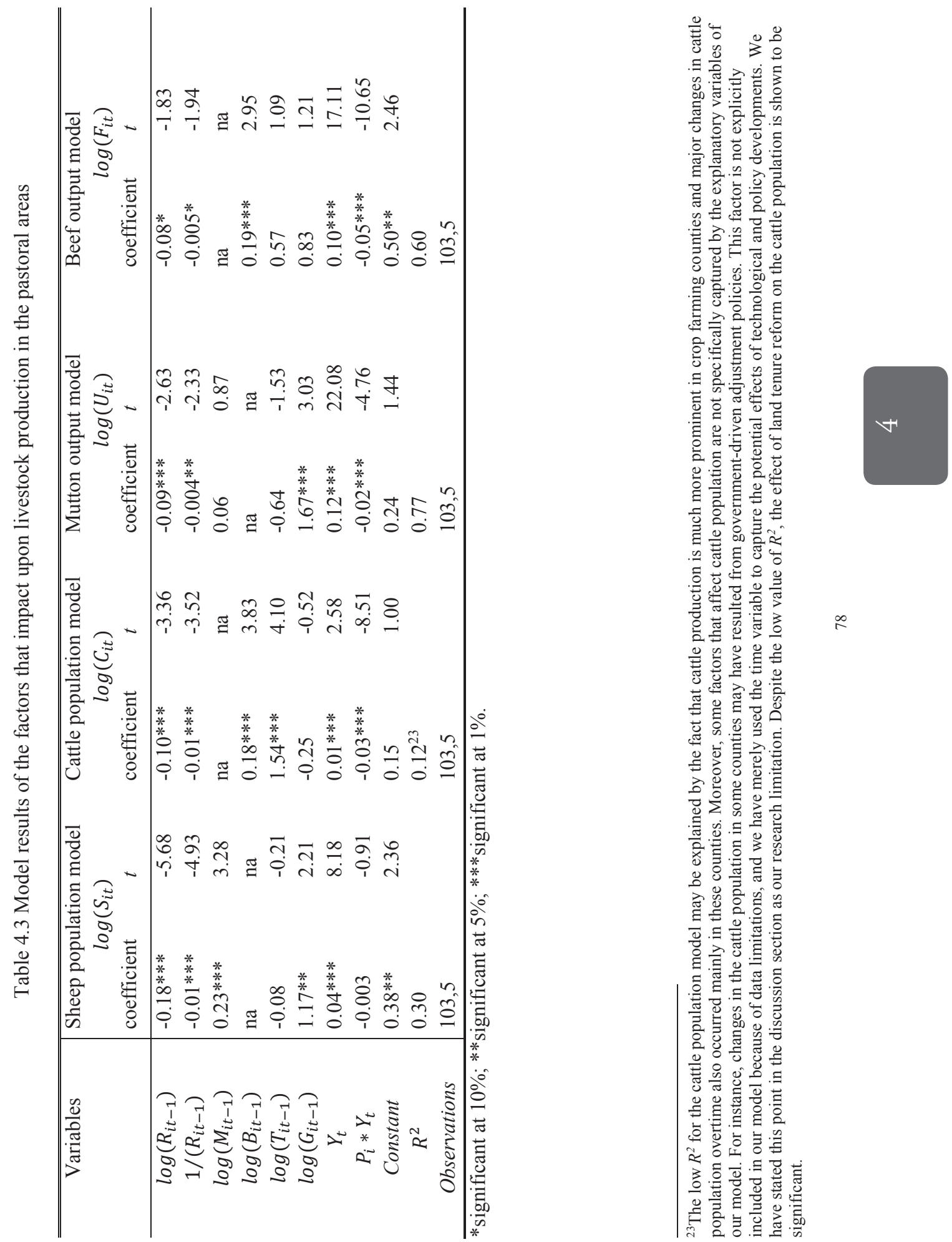

궁

当 品 률

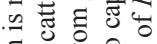

호웡

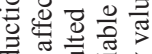

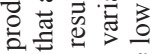

品品品

巡

踏

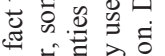

过

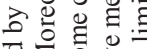

议

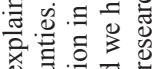

শั

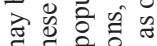

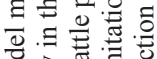

긍 自

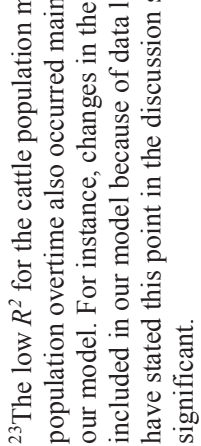

$\stackrel{\infty}{\sim}$ 
First, we focus on the coefficients of $\log \left(R_{i t-1}\right)$ and $1 /\left(R_{i t-1}\right)$, indicating the effects of the land tenure reform on livestock production over time. All of these coefficients are significant and negative in the four models. Based on the coefficients of $\log \left(R_{i t-1}\right)$ and $1 /\left(R_{i t-1}\right)$, quasi-concave curves are obtained as depicted in Fig. 9. The horizontal axis presents the number of years that the land tenure reform has been implemented and the vertical axis shows the livestock production index (livestock production in the first year of land tenure reform equals 100). Considering the longest duration for formal use rights privatised until 2008 was 26 years in our research sample, we determined the maximum year of the horizontal-axis as 26.

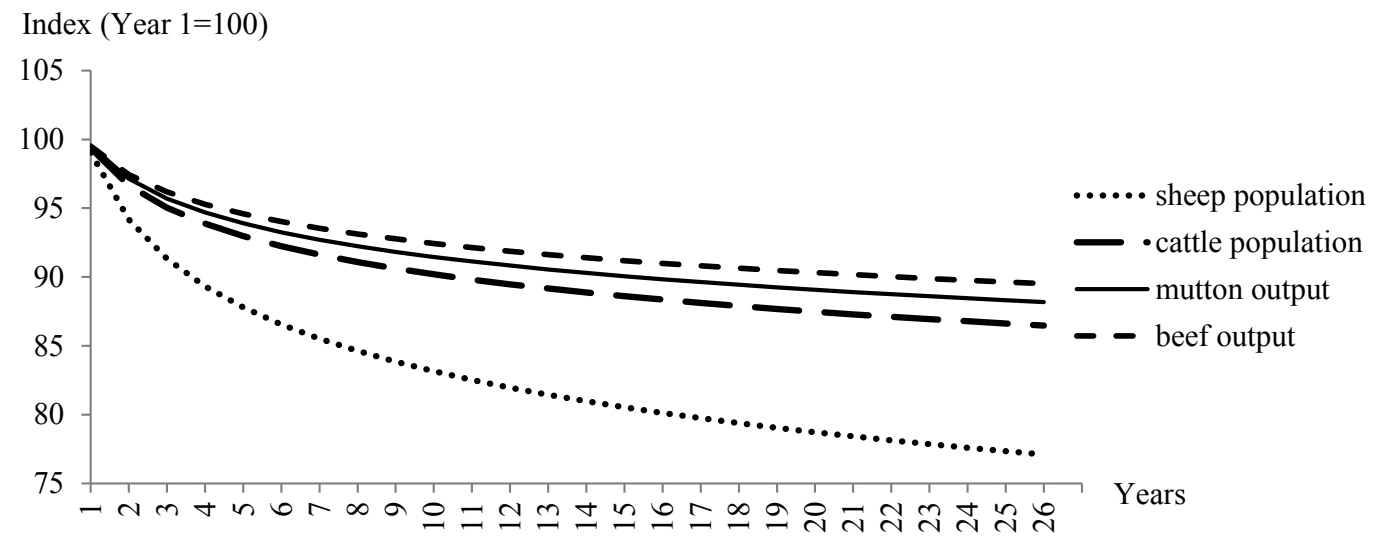

Figure 4.9 Relationship between land tenure reform and livestock production

In Figure 4.9, the indexes of sheep population, cattle population, mutton output and beef output are all decreasing with the number of years that the land tenure reform is implemented, and the reduction is fastest in the first years of the reform while it slows down in later years. Moreover, the decrease in sheep population is faster than that of mutton output, indicating that land tenure reform had a more negative impact on the sheep population than on mutton output. Similarly, land tenure reform has affected the cattle population more than beef output as the decrease in cattle population is faster than that of beef output. These results indicate that the implementation of land tenure reform promotes the development of livestock productivity in pastoral areas although it constrains the increase in livestock population. Moreover, the mutton output (sheep population) decreases faster than beef output (cattle population).

It is interesting to compare Figure 4.9 with Figures 4.6 and 4.7 - which present the increasing trends in the sheep population, mutton output and beef output after 1985. The seemingly contradicting trends of livestock production in these figures can be explained by the effects of the other factors considered in our models. For instance, the producer price has a significant and positive effect on livestock production. The mutton price elasticity indicates that the sheep population in year $t$ will increase by $0.23 \%$ when 
the mutton price in year t-1 increases by $1 \%$. Similarly, cattle population (beef output) in year $\mathrm{t}$ will increase by $0.18 \%(0.19 \%)$ when the beef price in year $\mathrm{t}-1$ increases by $1 \%$. The better grassland condition also has a significant and positive effect on livestock production. Cattle population in year $\mathrm{t}$ will increase by $1.54 \%$ if the total grassland area in year $\mathrm{t}-1$ increases by $1 \%$. Sheep population (mutton output) in year t will increase by $1.17 \%(1.67 \%)$ if the good quality grassland area in year t-1 increases by $1 \%$. In an attempt to improve grassland condition, China has implemented various ecological projects. However, in reality, $90 \%$ of the grasslands are still degraded to various degrees (Mei et al., 2013). For example, between 1991 and 2002,3.1\% of the available natural grassland was lost, either through its being degraded into unused land, or being transformed into other purposes. During the same period, 1.68 million hectares of land was rehabilitated into natural grassland through eco-environmental projects. This resulted in a net decline of 6.38 million hectares (around $2.4 \%$ of the available natural grassland) (Qu et al., 2011). In this regard, the deteriorating grasslands could have impeded the livestock production.

The coefficients of the time variable are significant and positive in four models. It indicates that the technology development affects livestock production positively, and it can be seen that the positive effects are stronger with respect to meat output than for the livestock population. The interaction term of the time variable and the dummy variable of pastoral counties is also significant, but negative, in the cattle population, mutton output and beef output models. It indicates that cattle population, mutton output and beef output increase less in the pastoral counties than in the semi-pastoral counties with technology development. Sheep population increases significantly without a distinction between pastoral or semi-pastoral counties. In general, it appears that the development of livestock production is slower in the pastoral counties than in the semi-pastoral counties over time, with the exception of the development of the sheep population which does not differ between county types. Notably, Figures 4.6 and 4.7 showed that livestock production experienced a geographic shift from pastoral areas to the crop farming areas. Our results extended this finding to the specific comparison between pastoral counties and semi-pastoral counties. That is, livestock production, with exception of the sheep population, has experienced a geographic shift from semi-pastoral counties to pastoral counties in the pastoral areas.

\subsection{Discussion}

The model results demonstrate that the implementation of land tenure reform has significantly constrained the increase of livestock population and meat output in the pastoral areas of Inner Mongolia. This finding can be explained in various ways. On the one hand, the implementation of land tenure reform may have effectively controlled the increase in livestock population, as was the aim of land tenure reform, which expected to internalise the social costs of overgrazing by privatisation and thereby avoid the tragedy of the commons. The increase in meat output is correspondingly restricted due to the 
constraints on livestock population. On the other hand, the spatial and social boundaries stemming from land tenure reform have impeded livestock production because fragmentation and loss in mobility increase the costs of feeding and reduce herders' ability to withstand natural risks (e.g. Li et al., 2007). These results are in line with findings from Mongolia where livestock production declined and poverty rose sharply after grassland privatisation in the 1990s (Griffin, 1995). The model results also illustrate that the decrease in livestock numbers and meat output occurred especially in the early years of the land reform and that this effect weakened over time, which may be attributed to the gradual adaptation of production patterns to the privatised grasslands. Moreover, the constraining effects on the increase of livestock production could be a potential reason to explain why land tenure reform was so slow to be implemented and is still in progress after 30 years. This raises doubts about the adaptability of extending policy measures designed for crop farming areas to the pastoral areas. Although the land tenure reform promoted agricultural production successfully in the crop farming areas of China, the pastoral areas may have produced different results.

Compared with the constraining effects of the land tenure reform, market forces have a strong positive effect on livestock production. The passing of time implies technological development, and also promotes the increase in livestock production, although more slowly in pastoral counties than in semipastoral counties. This points towards potential approaches for stimulating livestock production in pastoral areas. In addition, improved grassland conditions also have positive effects on livestock production, which suggests that grassland conservation is necessary not only to improve the ecosystem, but also to develop sustainable livestock production.

Given the controlling effects of land tenure reform on the increase in livestock population and the facilitating effects on improving livestock productivity, it is recommended that the government supervises the implementation of assigning grassland use rights to individual households and clarifies fuzzy grassland boundaries between households. However, pastoralism that embraces common use may also have benefits for the sustainable development of animal husbandry in pastoral areas due to the advantages of the mobility, flexibility and reciprocity (e.g. Fernandez-Gimenez, 2002). In this regard, the privatisation of grassland property rights or use rights may be a precondition to ensuring cooperative use based on stable property rights or use rights in practice. In fact, recent institutional innovations in pastoral areas of China has followed two distinct pathways: the strict implementation of clarifying grassland use rights to individual households on the one hand, and the encouragement of comanagement and cooperative use of grasslands based on substantive community participation on the other hand (Banks, 2003).

As a final note, we would like to mention a number of limitations of our analysis that present challenges for future research. Our use of the time variable is a simplified way to capture the effect of technological 
development and ecological policy. One challenge for future work is therefore to ascertain the specific effects of technological improvements and ecological policies on livestock production in pastoral areas. Moreover, the data on the grassland quality only represents the canopy cover, but does not indicate its edibility by animals, which is a serious limitation related to the measurement of the grassland conditions. Furthermore, the accuracy of Chinese livestock statistics is questionable (Waldron et al., 2007). The statistical collection of data on the livestock population is extremely difficult in China because small rural households raise livestock on a small scale and supply chains are dominated by countless small traders and processors, unlike the centralised slaughter and auction systems that facilitate statistical collection in developed countries (Waldron et al., 2007). In this regard, our research findings should be useful for detecting general trends if not specific numbers.

\subsection{Conclusions}

This paper explores the period during which the household-based assignment of grassland use rights has been implemented in order to describe the progress of land tenure reform and its impact on the grasslands of China. We focus on comparing the development of livestock production between pastoral areas and crop farming areas under the land tenure reform and evaluating the effect of land tenure reform on livestock production. Livestock production was presented by sheep population, cattle population, mutton output and beef output. The descriptive analysis shows that land tenure reform was implemented progressively in the pastoral areas, rather than the case of the cropland areas where household-based use rights were completed overnight (Banks et al., 2003; Ho, 2000). It appears that the increase of livestock production was faster in crop farming areas than in pastoral areas, while conversely the development of livestock productivity was slower in crop farming areas. A fixed effects model is employed to estimate the impacts of the land tenure reform on livestock production based on a dataset of 45 counties in the pastoral areas of Inner Mongolia from 1985 to 2008. The model controls for factors that obscure the relationship between livestock production and land tenure reform, such as market forces, grassland condition, technological development and environmental heterogeneity among counties. The model results provide quantitative evidence that land tenure reform has put a ceiling on livestock production, but this constraining effect is unable to offset the impact of other factors that accelerate the increase in livestock production, which explains the actual increase in livestock production. Moreover, the constraining effect of land tenure reform on the increase in livestock production decreases with the number of years since the implementation of land tenure reform and ultimately disappears. Remarkably, the constraining effect is stronger on the increase in livestock population than on that of meat output, which indicates that land tenure reform stimulates the development of livestock productivity. With respect to the other factors, it appears that the cattle population tends to be affected by the quantity of grassland, while the sheep population and mutton output are more affected by the quality of grassland. 
The factor of technological development impacts on the increase in meat output more than that on the increase in livestock population, and the influence is more evident in the semi-pastoral counties than in the pastoral counties. It can be seen that technological development also prompts the development of livestock productivity.

The development of livestock productivity that is caused by the implementation of land tenure reform is different from that due to technological development. More specifically, land tenure reform in pastoral areas has transformed the production patterns of pastoralists through the privatisation of grasslands (Ho, 2000). For instance, the indigenous people in Inner Mongolia employed nomadic management and seasonal transhumance to graze animals in areas where pastures and water were available (Wang et al., 2013). Since the spread of the land tenure reform on the grasslands, a growing number of households have built physical boundaries (such as fences) in order to prevent others from using their grasslands, which implies that mobile grazing is no longer possible and most areas of grassland are in small-scale private use (Hua and Squires, 2015). The traditional nomadic production pattern has therefore gradually been displaced by a sedentary pattern. Our research results essentially indicate that this transformation, resulting from land tenure reform, has prompted livestock productivity in the pastoral areas of Inner Mongolia. In other words, land tenure reform entailing grassland privatisation probably stimulates herders to put more effort into improving the output per animal, instead of increasing the amount of animals, which is beneficial to the development of livestock production systems in pastoral areas. However, the constraining effects of grassland privatisation on the increase in livestock production could also be a possible reason to explain why land tenure reform was implemented with difficulty on grasslands, especially in terms of the lag between the reform and the actual adoption of private use. 


\section{ACKNOWLEDGEMENTS:}

The funding for this research was supported by a grant from the National Natural Sciences Foundation of China (71333013). The authors would like to thank Xiangzheng Deng, Fujiang Hou, Dan Wang, Yangjie Wang and Jie Zhou for their useful suggestions and help. We are also grateful to Nico Heerink and Xiaoping Shi for their helpful comments that contributed to improve the quality of this paper. 


\section{Chapter 5}

The impact of Ecological Construction Programs on grassland conservation in the pastoral areas

$$
\text { of China }
$$




\section{THE IMPACT OF ECOLOGICAL CONSTRUCTION PROGRAMS ON GRASSLAND CONSVERVATION IN THE PASTORAL AREAS OF CHINA ${ }^{24}$}

ABSTRACT: A series of Ecological Construction Programs have been initiated to protect the condition of grasslands in China during recent decades. However, grassland degradation is still severe and conditions have not been restored as intended. This paper aims to empirically examine the effectiveness of Ecological Construction Programs for protecting the grassland condition in the extensive pastoral areas of China. We focus on one Ecological Construction Program that has been implemented widely on the grasslands, the Subsidy and Incentive System for Grassland Conservation (SISGC). The Normalized Difference Vegetation Index (NDVI), measured with remote sensing technology, is used to quantify the grassland condition between 2001 and 2014. With data from 54 counties in the pastoral areas of Inner Mongolia, we estimate the impact of SISGC on the grassland condition. A fixed effects model is employed to control for livestock production, climate, time trends and time-invariant heterogeneity between counties. The model results provide quantitative evidence that the condition of the grasslands has improved significantly due to SISGC, but that the effectiveness of SISGC was offset to some extent by other socio-economic and climate factors, such as increased producer prices and high temperature. This may explain why the actual grassland degradation has not been prevented as effectively as was expected. In addition, the impact of SISGC was stronger in counties with a worse initial grassland condition. Furthermore, the effects of producer prices and climate changes were also more pronounced in these counties.

KEYWORDS: Ecological Construction Programs, grassland degradation, NDVI, fixed effects model, Inner Mongolia

\footnotetext{
${ }^{24}$ Paper by Min Liu, Liesbeth Dries, Wim Heijman, Jikun Huang, Xueqin Zhu, Yuanning Hu, and Haibin Chen, has been accepted by Land Degradation and Development.
} 


\subsection{Introduction}

Grasslands are important as a feed source for livestock, as a habitat for wildlife, for environmental protection and for the in situ conservation of plant genetic resources (FAO, 2008). However, rapid increases in livestock populations have increased pressures on the world's grasslands, leading to widespread deterioration, particularly in arid and semi-arid environments (Suttie et al., 2005). China has around 392 million hectares of grasslands, accounting for $12 \%$ of the world's grasslands and $41.7 \%$ of the national land area (Fan et al., 2008). Nearly $80 \%$ of these grasslands are in arid and semi-arid regions (National Bureau of Statistics of China, 2009). Approximately 17 million herders and agroherders maintain their livelihoods on the grasslands in China (Li et al., 2014). According to Chinese governmental reports, $10 \%$ of the total area of grasslands was degraded in the 1970 s, increasing to $30 \%$ in the $1980 \mathrm{~s}$ and $50 \%$ in the middle of the $1990 \mathrm{~s}$. By the $2000 \mathrm{~s}$, about $90 \%$ of the grasslands were degraded to various extent, with significant regional variation (Unkovich and Nan, 2008; Waldron et al., 2010). The manifestation of grassland degradation includes initial lowering of grassland productivity, fragmentation of grass cover, reduction in soil fertility, soil compaction, an increase in unpalatable grass species or a combination of all of them (Feng et al., 2009; Li et al., 2013). Grassland degradation, especially in northern China, is considered to be the cause of serious environmental and ecological problems, such as Yangtze River floods, Yellow River droughts and sand storms of Beijing (Harris, 2010). Grassland degradation therefore threatens not only animal husbandry on the grasslands but also the livelihoods of millions of people and the ecological security of China (Huang et al., 2013). To address these problems, national and local governments have initiated an ambitious series of Ecological Construction Programs for grassland protection in recent decades.

In 1985, China passed the first national Grassland Law which explicitly stipulated the protection and improvement of grasslands (Ho, 2000). The Law devolved grassland use rights from the state and collectives to individual households through long-term contracts, and introduced maximum stocking rates for livestock on the grassland areas. Since the serious drought in China in 1997 and the massive floods of 1998, additional Ecological Construction Programs have been introduced, for example, the Conversion of Cropland to Forest and Grassland Program (also known as the Grain for Green Program), the Returning Grazing to Grassland Program, and the Program to Combat Desertification around Beijing and Tianjin, which aimed at preventing grasslands from degradation and were actively implemented in the 2000s (Liu et al., 2010; Hua and Squires, 2015). Since 2011, another major Ecological Construction Program, the Subsidy and Incentive System for Grassland Conservation (SISGC), has been initiated in eight pastoral provinces of China, including Inner Mongolia, Xinjiang, Tibet, Qinghai, Sichuan, Gansu,

Ningxia and Yunnan (State Council of the People's Republic of China, 2010). Compared to the Ecological Construction Programs for grassland conservation before 2011, the SISGC includes much 
wider areas that involve most of the available natural grasslands of China and provides herders with more ecological compensations. Moreover, its monitoring system for policy implementation has been improved with the use of more targeted monitoring staffs (Guan Hu Yuan) that are employed by local governments.

In general, China's Ecological Construction Programs include two categories of measures for grassland conservation, namely sowing grass or planting trees in the eco-fragile areas to restore the degraded grasslands and reducing livestock grazing to prevent grassland degradation (Ho and Azadi, 2010; Kou et al., 2016). This coincides with the measures for preventing desertification in China: controlling desertification by plantation and combating desertification by natural recovery through isolating the degraded area from external human influences (Miao et al., 2015). In practice, these two measures cover a vast array of regulations (Waldron et al., 2010). Particularly, the reduction in grazing is targeted by regulations determining stocking rate and grazing bans (either permanently, temporarily or seasonally) (Qu et al., 2011). The stocking rate is based on the theoretical maximum of the available biomass production from grasslands that can be consumed by grazing herds without impairing the capacity of the pasture to regrow the following year (Fernández-Giménez et al., 2011).

Despite the fact that Ecological Construction Programs have been widely introduced in the pastoral areas of China for more than ten years, grassland degradation is still severe (Waldron et al., 2010; Li and Huntsinger, 2011; Ministry of Agriculture of China, 2012; Li et al., 2014). Although the average vegetation coverage of China's grasslands increased by $0.4 \%$ between 2014 and 2015, and there has been an increase of $3 \%$ since 2011, more than one third of the grasslands are still suffering moderate and serious degradation (Ministry of Agriculture of China, 2014; 2016). Some academic studies have therefore criticized the effectiveness of the Ecological Construction Programs on grassland conservation, and attributed the causes of this ineffectiveness to inappropriate policy measures and failed implementation (Li and Zhang, 2009). For example, some authors argue that the determination of a maximum stocking rate and various grazing bans are inappropriate management measures for the conservation of grasslands in arid and semi-arid areas (Higgins et al., 2007). In particular, deterministic stocking rates are questioned because they largely ignore the grasslands' spatial heterogeneity and climate variability (Li and Huntsinger, 2011). Moreover, it is claimed that appropriate grazing is beneficial to plant succession processes (Zhang et al., 2015). Deterministic stocking rates have also led to resistance from local herders that are unwilling to limit their own livestock numbers based on a topdown government measure (Li and Zhang, 2009). High supervision costs of the implementation of the policy make that deterministic stocking rates and grazing bans are difficult to sustain effectively for a long period, especially in extensive grassland areas with a scattered population distribution (Li and Zhang, 2009; Waldron et al., 2010). Considering these criticisms and the fact that the grassland 
condition is still deteriorating, despite the current policy measures, this paper will examine the effectiveness of Ecological Construction Programs on grassland protection and discuss the potential factors that impact the policy effectiveness.

Some academic studies and governmental reports discuss the impacts of Ecological Construction Programs. A number of them focus on limited regions based on household-level or experimental field data (e.g. Gu and Li, 2013; Zhang et al., 2015). Others conduct spatial and temporal comparisons but without controlling for the possible impacts of other socio-economic and climate factors on the grassland condition. Some studies also have systematically discussed the impacts of particular aspects of eco-environmental policy interventions, including grassland laws (Nelson, 2006), grazing bans (Yeh, 2005), and herder resettlement policies (Dickinson and Webber, 2007), but they have mainly used qualitative analysis. In short, the existing literature lacks estimations on the effectiveness of Ecological Construction Programs for grassland conservation that are based on large-scale and long-term samples and control for the impacts of other potential factors through a quantitative analysis. This paper employs an econometric model based on data from 54 counties in the extensive pastoral areas of Inner Mongolia from 2001 to 2014 to disentangle the impact of one specific Ecological Construction Programs, namely the SISGC, on the grassland condition. In the following, the research region, data collection and methods are described. Next, the empirical results about the relationship between SISGC and grassland condition are presented and interpreted. Ultimately, we conclude with an assessment of the effectiveness of SISGC for grassland conservation based on the comparison between the estimated results from our model and the actual condition of the grassland.

\subsection{Material and methods}

\subsubsection{Research region}

We conduct our empirical study based on Inner Mongolia, which is located in northern China and in which animal husbandry is the traditional and dominant agricultural industry. Most of the population are indigenous Mongolians and are reliant on grazing animals on the natural grasslands in order to maintain a livelihood. Inner Mongolia belongs to the arid and semi-arid areas of China and contains $21.7 \%$ of the area of China's natural grasslands. Approximately $67 \%$ of the total land in Inner Mongolia is classified as grassland, the majority of which can be sub-classified as temperate grassland (Angerer et al., 2008). The current administrative divisions of Inner Mongolia include 102 counties, consisting of 33 pastoral counties and 21 semi-pastoral counties. The remaining 48 counties are dominated by crop farming or urban districts. The agricultural industry of pastoral counties is characterized by its extensive grazing; natural grassland is the dominant land type. In semi-pastoral counties, both natural grassland and cropland are the dominant land types, in which there is more intensive animal husbandry along with cropping (Waldron et al., 2010). The pastoral and semi-pastoral counties include almost all of the natural 
grasslands of Inner Mongolia. Figure 5.1 illustrates the location of Inner Mongolia in China and the distribution of its pastoral and semi-pastoral counties.
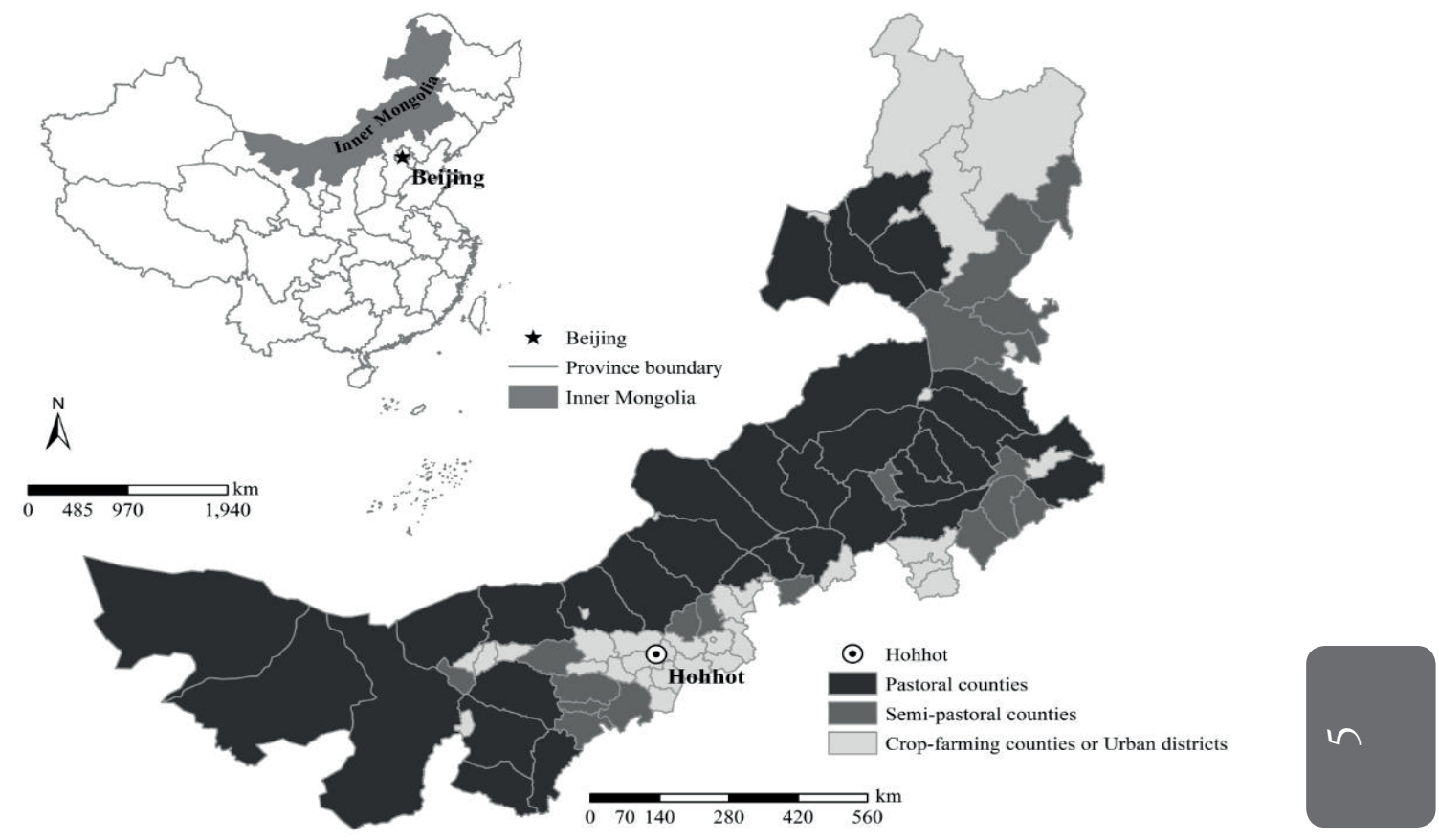

Figure 5.1 Inner Mongolia and its pastoral and semi-pastoral counties

According to government reports, by the year $2000,90 \%$ of the natural grasslands of Inner Mongolia had been degraded to some extent, reflected by the degraded composition of plant species, declining biodiversity, accelerated soil erosion etc. (Waldron et al., 2010; Briske et al., 2015). Moreover, the results of large-scale field ecological surveys highlighted that the average grassland biomass productivity in Inner Mongolia has reduced from $1871 \mathrm{~kg} / \mathrm{ha}$ in 1961 to $900 \mathrm{~kg} / \mathrm{ha}$ in 2010 (Wang et al., 2013). The extensive grasslands of Inner Mongolia play an important role as ecological barriers for northern China. For instance, the colossal dust storms which rumbled through hundreds of cities and villages of northern China and blanketed the sky of Beijing between 1998 and 2001 were said to have originated from dryland areas and degraded grasslands mainly in Inner Mongolia (Wu et al., 2015). Subsequently, the pastoral areas of Inner Mongolia have become the typical regions for implementing various Ecological Construction Programs for grassland conservation in China since the early 2000s.

Since 2011, the SISGC has been initiated in Inner Mongolia. Considering that the SISGC is currently the most important large-scale Ecological Construction Program for grassland conservation and inherits the main management measures from earlier programs, namely the deterministic stocking rate and permanent grazing ban, we take it as a typical example to explore the effectiveness of Ecological 
Construction Programs in the extensive pastoral areas of China. It is reported by the local government that 67.3 million hectares of available natural grasslands are covered by SISGC, which includes almost all of the available natural grassland areas of Inner Mongolia. 30 million hectares of them belong to the area with the permanent grazing ban and the remaining 37.3 million hectares belong to the foragelivestock balance area. In practice, every county in the pastoral areas contains different areas of grasslands which are subject to the permanent grazing ban, deterministic stocking rate or both of them. Almost all rural households in the pastoral areas have been covered by SISGC, and they have been given subsidies (or incentives) as well as the obligation to comply with the permanent grazing ban (or the deterministic stocking rate).

\subsubsection{Data collection}

The empirical model is conducted using county-level data to estimate the impact of the SISGC on the condition of grasslands in the pastoral areas of Inner Mongolia. The dataset includes 54 counties consisting of the 33 pastoral counties and 21 semi-pastoral counties, and spans 14 years from 2001 to 2014 including the period before and after the introduction of the SISGC. The data collected include indicators of the grassland condition, the status of SISGC, and climate and socio-economic factors. In the existing literature, the grassland condition has been indicated by vegetation coverage, height, density, biomass production and density of perennial vegetation ( $\mathrm{Gu}$ and Li, 2013; Yu and Farrell, 2013). These indicators are commonly measured using two methods: direct sampling tests undertaken during smallscale fieldwork; and estimation over large areas with remote sensing technology (Gu and Li, 2013). The former focuses on measuring the micro-indices of grass, while the latter estimates the macro grassland condition on the basis of satellite images. For this study, the remote sensing technology appeared more feasible and appropriate considering that we aim to quantify the grassland condition of the 54 counties in Inner Mongolia over 14 years. The Normalised Difference Vegetation Index (NDVI) is a widelyused indicator to quantify the grassland condition on the basis of the remote sensing technology (e.g. Yang et al., 1998; Liu et al., 2013; Gong et al., 2015). Theoretically, the measurement of NDVI is based on the differential absorption, transmittance and reflectance of energy by the vegetation in the red and near-infrared portions of the electromagnetic spectrum (Senay and Elliott, 2000). NDVI is calculated on a per-pixel basis as the ratio of the difference of the near infrared and red bands over their sum from a remotely-sensed image. It provides a clear description of land surface features and is regarded as a proxy for terrestrial vegetation condition because it is strongly associated with percentage of vegetation coverage, leaf area index, potential photosynthesis, aboveground net primary productivity and biomass availability (Tan and Li, 2015). Based on the data set of MOD13A1 from NASA's Earth Science Data Systems Program, which is the Moderate Resolution Imaging Spectroradiometer (MODIS) imagery with $500 \mathrm{~m}$ spatial resolution and 16 days temporal resolution, we employed the Maximum Value 
Composite (MVC) method to get the NDVI of each year during 2001-2014 (Holben, 1986). Ultimately, the image layer of administrative divisions of Inner Mongolia is used to determine the NDVI for each county.

Information about SISGC was provided by the Agriculture and Animal Husbandry Bureau of Inner Mongolia. Moreover, interviews were conducted with local herders and public officers who are key informants on the implementation of Ecological Construction Programs in Inner Mongolia to improve our understanding of these programs and their possible impacts. The data on socio-economic indicators was collected based on existing statistical data gathered by national and local Statistical bureaus. For instance, the producer price of live sheep was collected based on the Annual Compilation of Costbenefit Data of Chinese Agricultural Products and deflated with the Producer Price Index of Agricultural Products of Inner Mongolia. The data on climate indicators were gathered from the Statistical Yearbooks of Inner Mongolia. It should be noted that we used the city-level climate data to represent the temperature and precipitation of each county that affiliates to its corresponding city.

\subsubsection{Statistical analysis on grassland condition}

Based on the data of NDVI over the 54 counties of Inner Mongolia from 2001 to 2014, table 5.1 outlines the changes in grassland condition at different time intervals.

Table 5.1 Grassland condition (NDVI) at different time intervals of SISGC

\begin{tabular}{|c|c|c|c|c|c|c|c|c|}
\hline \multicolumn{2}{|c|}{ Periods } & Status of SISGC & Obs. & Mean & $\begin{array}{l}\text { Std. } \\
\text { Dev. }\end{array}$ & Min & Max & $\begin{array}{l}\text { Welch's t- } \\
\text { test }\end{array}$ \\
\hline \multirow{2}{*}{\multicolumn{2}{|c|}{$\begin{array}{l}\text { Period } 1 \\
(2001-2010) \\
\text { Period } 2 \\
(2011-2014)\end{array}$}} & Before SISGC & 540 & 0.467 & 0.199 & 0.074 & 0.853 & na \\
\hline & & After SISGC & 216 & 0.502 & 0.201 & 0.083 & 0.851 & $-0.035 * *$ \\
\hline \multirow{4}{*}{$\frac{0}{2}$} & 2011 & $\begin{array}{l}\text { The first year of } \\
\text { SISGC }\end{array}$ & 54 & 0.482 & 0.208 & 0.084 & 0.851 & -0.015 \\
\hline & 2012 & $\begin{array}{l}\text { The second year of } \\
\text { SISGC }\end{array}$ & 54 & 0.528 & 0.186 & 0.085 & 0.850 & $-0.061 * *$ \\
\hline & 2013 & $\begin{array}{l}\text { The third year of } \\
\text { SISGC }\end{array}$ & 54 & 0.520 & 0.203 & 0.084 & 0.840 & $-0.053 *$ \\
\hline & 2014 & $\begin{array}{l}\text { The fourth year of } \\
\text { SISGC }\end{array}$ & 54 & 0.480 & 0.208 & 0.083 & 0.850 & -0.013 \\
\hline
\end{tabular}

Sources: Statistics are derived from the data set of NASA's Earth Science Data Systems Program Note: *significant at $10 \%$; **significant at $5 \%$; ***significant at $1 \%$.

According to the Welch's t-test on NDVI between periods 1 and 2 (Lee, 1992), the overall mean of NDVI is significantly larger in the period after SISGC than before, which implies an improvement in overall grassland condition. Moreover, all of the mean NDVI values are larger in the years with SISGC than the overall mean of NDVI in the period before SISGC. However, the Welch's t-test on NDVI 
between period 1 and each year after SISGC indicates that the difference is only significant in the years 2012 and 2013.

\subsubsection{Fixed effects model}

A fixed effects model has been widely used in economic research, primarily to study the causes of changes within entities over time (e.g. Fergusson et al., 2002; Huang et al., 2006). The model employs within transformation to remove all time-invariant (fixed) explanatory variables, i.e. the model is performed in deviations from individual means (Verbeek, 2012). As such, the fixed effects model provides a method that takes observable explanatory variables as well as unobservable time-invariant variables into account, but the estimation does not depend on the value of time-invariant (fixed) variables (Verbeek, 2012). Such an approach is appropriate for this study because the causes of grassland condition changes within each county over time can be studied by controlling for the measured as well as unmeasured time-invariant heterogeneity between counties. In addition, our research samples include all of the counties in the pastoral areas of Inner Mongolia, rather than random draws, which preliminarily indicates that the fixed effects model is more appropriate than the random effects model (Verbeek, 2012). Nevertheless, the appropriateness of the fixed effects model will be further examined through statistical testing. Based on the theoretical framework of the fixed effects model, we formulate the impacts of SISGC and other potential factors on grassland condition in the following equation:

$$
\begin{gathered}
G_{i t}=h_{i}+\sum_{y=2011}^{2014} a_{y} P_{i y}+\sum_{y=2011}^{2014} b_{y}\left(P_{i y} * D_{i}\right)+c_{1} S_{i t-2}+\sum_{m=4}^{9} d_{m} T_{i t m}+d_{1} T V_{i t}+\sum_{m=4}^{9} e_{m} R_{i t m} \\
+e_{1} R V_{i t}+f_{1} Y_{t}+g_{1}\left(Y_{t} * D_{i}\right)+\varepsilon_{i t}
\end{gathered}
$$

where $i$ and $t$ indicate the $i^{\text {th }}$ county and year t, from 2001 to 2014. Grassland condition $\left(G_{i t}\right)$, presented by NDVI, is employed as the dependent variable of equation (1). $P_{i y}$ is a dummy variable to manifest whether county i implemented SISGC in the specific year y which involves the first year with SISGC $(y=2011)$, the second year $(y=2012)$, the third year $(y=2013)$ and the fourth year $(y=2014)$. The interaction term of SISGC $\left(P_{i y}\right)$ and the pastoral or semi-pastoral attribute of county $\mathrm{i}\left(D_{i}\right)$ is considered.

Besides the policy variables, other potential factors are controlled. For example, the livestock production and climate factor are prevalently discussed as the drivers that impact the grassland condition in the arid and semi-arid areas (e.g. Li et al., 2012; He et al., 2014). In this study, the real producer price of live sheep $\left(S_{i t}\right)$ is used as the proxy variable of livestock production in the pastoral areas because of the limitations of the data. More specifically, the livestock population in the pastoral areas was underreported by herders due to the stocking rate regulation (Brown et al., 2008). Furthermore, in the 
statistical data on the meat output of the pastoral areas of Inner Mongolia, no distinction is made between outputs from extensive grazing, and outputs from industrial raising and intensive animal husbandry. Since sheep is the animal which is most often raised by local herders (Zhang et al., 2012), the real producer price of live sheep with a two-year lag $\left(S_{i t-2}\right)$ is used to indicate the situation of livestock production in the empirical model. In this regard, the price is exogenously decided by the global market of China, and the two-year lag is considered as the timespan during which local herders adjust their sheep population to respond to the changes in sheep price. According to information from our household survey in Inner Mongolia, the timespan is around two years because it covers the breeding period of breeders; herders then reserve more new lambs in order to expand their sheep population during the next production stage. The climate factor is elaborated by the monthly average temperature $\left(T_{i t m}\right)$ and precipitation $\left(R_{i t m}\right)$ during the growing season of grass, including the six months from April to September with $\mathrm{m}=4$ to 9 (Zhao and Guo, 2009), and the variance of annual average temperature ( $\left.T V_{i t}\right)$ and precipitation $\left(R V_{i t}\right)$. The annual variance is presented by the standard deviations of monthly average temperature and precipitation in all twelve months of each year. In addition, time trend $\left(Y_{t}\right)$ is included considering the impact of factors that change with time, such as the development of intensive animal husbandry and the increasing area of artificial grass for grassland restoration. The interaction term of time trend and the pastoral or semi-pastoral attribute of county i $\left(Y_{t} * D_{i}\right)$ is also considered in order to explore whether there are differences in the grassland condition with time change between pastoral and semi-pastoral counties. Finally, the factors, such as elevation, slope, soil type, distance to the provincial capital etc., that reflect the heterogeneity of grasslands and do not change over time are treated as timeinvariant (fixed) factors in the model, and are denoted by $h_{i}$ in equation (1). $a_{y}, b_{y}, c_{1}, d_{m}, d_{1}, e_{m}, e_{1}$, $f_{1}$ and $g_{1}$ are the coefficients of the independent variables and $\varepsilon_{i t}$ is the random error term. The specific definition of these variables is stated in table 5.2. 
Table 5.2 Variable definitions and their expected signs in the model

\begin{tabular}{|c|c|c|c|}
\hline Variables & Variable definition & Unit & Expected signs \\
\hline$G_{i t}$ & NDVI of county $i$ in year $t$ & na & $\begin{array}{l}\text { Dependent } \\
\text { variable }\end{array}$ \\
\hline$P_{i y}$ & $\begin{array}{l}=1 \text { if county i implemented SISGC in year y } \\
(y=2011,2012,2013 \text { and } 2014),=0 \text { otherwise }\end{array}$ & na & + \\
\hline$D_{i}$ & $\begin{array}{l}=1 \text { if county } i \text { is a pastoral county, }=0 \\
\text { otherwise }\end{array}$ & na & na† \\
\hline$S_{i t}$ & $\begin{array}{l}\text { The ratio of real producer price of live sheep } \\
\text { in county } i \text { between year } t \text { and year } 2001\end{array}$ & na & - \\
\hline$T_{i t m}$ & $\begin{array}{l}\text { The average temperature of county } \mathrm{i} \text { in month } \\
\mathrm{m} \text { of year } \mathrm{t}(\mathrm{m}=4,5,6,7,8 \text { and } 9)\end{array}$ & Degrees Celsius & $+/-$ \\
\hline$T V_{i t}$ & The temperature variation of county $i$ in year $t$ & Degrees Celsius & $+/-$ \\
\hline$R_{i t m}$ & $\begin{array}{l}\text { The total precipitation of county } i \text { in month } \mathrm{m} \\
\text { of year } \mathrm{t}(\mathrm{m}=4,5,6,7,8 \text { and } 9)\end{array}$ & Millimeters & + \\
\hline$R V_{i t}$ & $\begin{array}{l}\text { The precipitation variation of county } i \text { in year } \\
t\end{array}$ & Millimeters & $+/-$ \\
\hline$Y_{t}$ & Year $\mathrm{t}$ & na & + \\
\hline
\end{tabular}

Note: $\uparrow$ indicates that $D_{i}$ is included in the interaction terms of $\left(P_{i y} * D_{i}\right)$ and $\left(Y_{t} * D_{i}\right)$. The text presents the expected signs of $\left(P_{i y} * D_{i}\right)$ and $\left(Y_{t} * D_{i}\right)$

According to the existing literature, we propose the expected signs of the explanatory variables on grassland condition in table 5.2. Given that the government reports and most of academic findings present that SISGC has improved the grassland condition of Inner Mongolia (Li et al., 2014; Ministry of Agriculture of China, 2016), we expect positive coefficients for $P_{i y}$ in each year when SISGC was implemented. The expected signs of the interaction terms $\left(D_{i} * P_{i y}\right)$ in our estimations are ambiguous because it is uncertain whether the effectiveness of SISGC is better in the pastoral counties than in the semi-pastoral counties or vice versa. Additionally, the real producer price of live sheep $\left(S_{i t}\right)$ is expected to have negative effects on the grassland condition because higher prices stimulate more livestock production that may result in excessive grazing pressure and further lead to grassland degradation (Zhang et al., 2014). The expected signs of monthly average temperature $\left(T_{i t m}\right)$ in the growing season are ambiguous because the high temperature facilitates plant growth as well as the evaporation of the ground surfaces and the evapotranspiration from the vegetation (Deng et al., 2013), and fast evaporation and evapotranspiration have negative effects on plant growth in the arid and semi-arid areas. Given that precipitation is considered as the crucial factor in improving grassland condition in the arid and semiarid areas (Li and Zhang, 2009), we expect positive coefficients for $R_{i t m}$ in the model. The expected signs of the annual variation in temperature $\left(T V_{i t}\right)$ and precipitation $\left(R V_{i t}\right)$ are ambiguous as the uneven distribution of climate has uncertain effects on grass growth. Time variable $\left(Y_{t}\right)$ is expected to have positive effects on grassland condition. For instance, the development of intensive animal husbandry is supposed to replace extensive grazing and further reduce the use and damage of natural grasslands. 
Furthermore, the interaction term of time variable and the attribute of county i $\left(Y_{t} * D_{i}\right)$ is expected to have a negative coefficient because the pastoral counties experienced less intensive animal husbandry than the semi-pastoral counties (Waldron et al., 2010).

In addition, we expect that these explanatory variables may have different effects in different types of counties, especially for counties that have a different initial grassland condition. It is suggested that the effectiveness of large-scale ecological conservation programs has been heterogeneous in different regions even under the same policy context with incentive measures ( $\mathrm{Lv}$ et al., 2015). The 54 counties in the sample are therefore divided over two groups based on the NDVI of each county in 2001. This results in 27 counties in the low NDVI group and 27 counties in the high NDVI group. NDVI of the low NDVI group in 2001 ranges from 0.074 to 0.427 , and the mean is 0.254 . The range of NDVI in the high NDVI group in 2001 is between 0.453 and 0.836 , and the mean is 0.614 . The fixed effects model (equation (1)) will be conducted separately for three groups of counties: all counties; low NDVI counties; high NDVI counties.

\subsubsection{Descriptive statistics for the variables}

Table 5.3 shows the characteristics of the variables included in the fixed effects model. The overall mean of NDVI $\left(G_{i t}\right)$ is 0.477 for all 54 counties from 2001 to 2014, 0.314 for the 27 low NDVI counties, and 0.641 for the 27 high NDVI counties. Because all counties implemented SISGC in 2011, therefore the mean value of $P_{i 2011}$ over 14 years is 0.071 . The mean value of $D_{i} * P_{i 2011}(0.044)$ indicates that the percentage of samples from the pastoral counties in 2011 (33) is $4.4 \%$ of the total observations (756). 


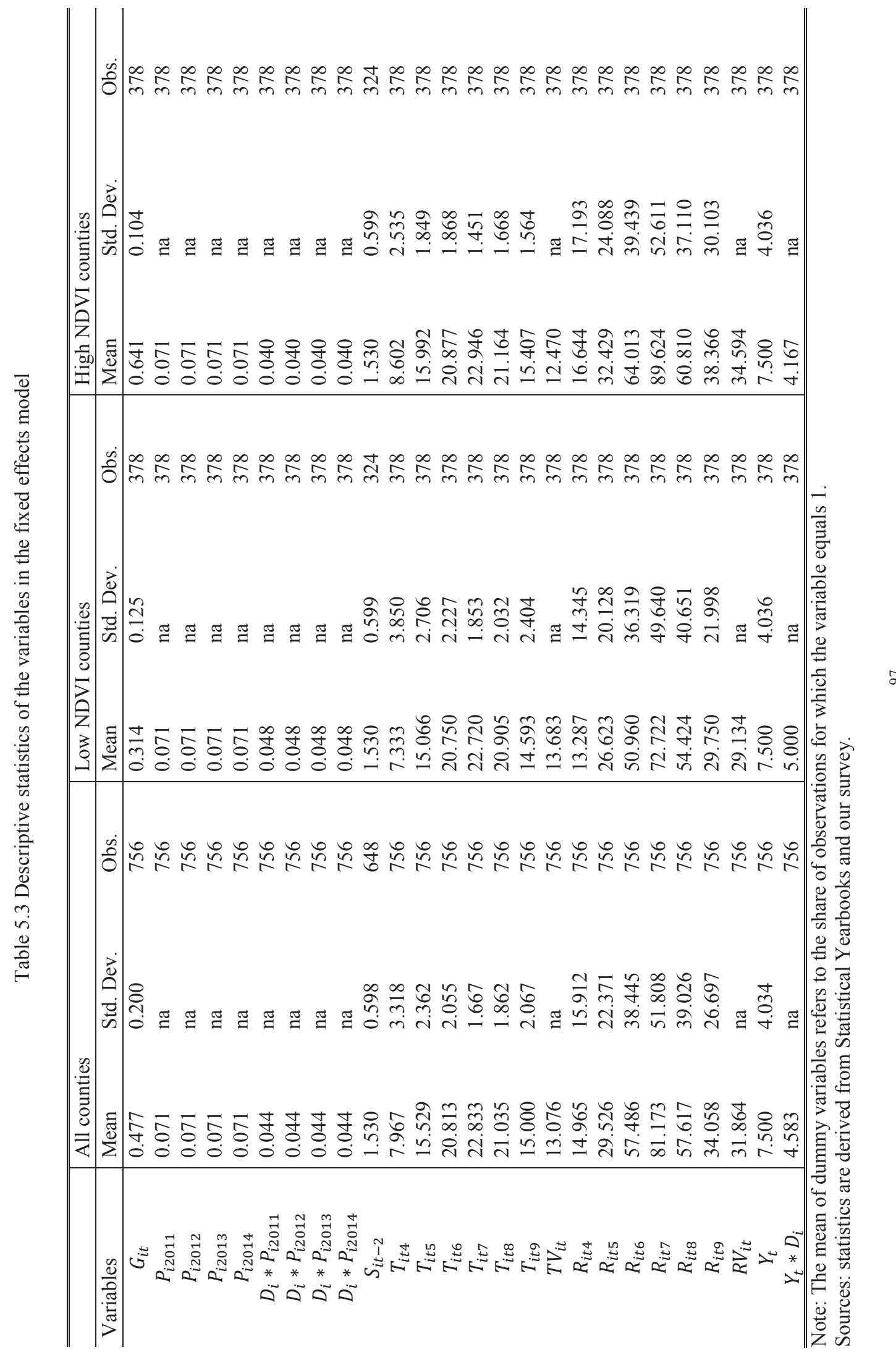




\subsection{Results}

\subsubsection{Model results}

The Hausman test is employed to determine whether the fixed effects model is more appropriate than the random effects model. The Hausman test rejected the null hypothesis at $p<0.05$, indicating that the fixed effects model is more appropriate for our estimation.

Table 5.4 Estimated results of the fixed effects model

\begin{tabular}{|c|c|c|c|c|c|c|}
\hline & \multicolumn{2}{|l|}{ All counties } & \multicolumn{2}{|c|}{ Low NDVI counties } & \multicolumn{2}{|c|}{ High NDVI counties } \\
\hline Variable & Coefficient & $\mathrm{t}$ & Coefficient & $\mathrm{t}$ & Coefficient & $\mathrm{t}$ \\
\hline$P_{i 2011}$ & $0.042 * * *$ & 2.83 & 0.025 & 0.81 & $0.056^{* *}$ & 2.60 \\
\hline$P_{i 2012}$ & $0.130 * * *$ & 7.36 & $0.153 * * *$ & 5.46 & $0.110 * * *$ & 3.74 \\
\hline$P_{i 2013}$ & $0.189 * * *$ & 7.33 & $0.210 * * *$ & 3.96 & $0.185 * * *$ & 4.07 \\
\hline$P_{i 2014}$ & $0.150 * * *$ & 4.91 & $0.163 * * *$ & 3.14 & $0.141 * * *$ & 3.24 \\
\hline$D_{i} * P_{i 2011}$ & 0.016 & 1.20 & 0.035 & 1.23 & 0.008 & 0.64 \\
\hline$D_{i} * P_{i 2012}$ & 0.018 & 1.24 & 0.016 & 0.81 & 0.022 & 0.88 \\
\hline$D_{i} * P_{i 2013}$ & 0.012 & 0.78 & 0.014 & 0.43 & 0.016 & 0.61 \\
\hline$D_{i} * P_{i 2014}$ & 0.010 & 0.62 & 0.026 & 1.29 & 0.014 & 0.64 \\
\hline$S_{i t-2}$ & $-0.110 * * *$ & -5.11 & $-0.161 * * *$ & -3.94 & $-0.065^{*}$ & -2.04 \\
\hline$T_{i t 4}$ & -0.001 & -1.02 & 0.001 & 0.34 & -0.001 & -0.71 \\
\hline$T_{i t 5}$ & $-0.008 * * *$ & -3.17 & -0.001 & -0.46 & $-0.015 * * *$ & -4.91 \\
\hline$T_{i t 6}$ & $-0.007 * * *$ & -3.66 & -0.003 & -0.72 & $-0.010 * * *$ & -3.78 \\
\hline$T_{i t 7}$ & -0.005 & -1.52 & $-0.011 * *$ & -2.64 & 0.003 & 0.57 \\
\hline$T_{i t 8}$ & $-0.006^{* * *}$ & -2.83 & $-0.008 * * *$ & -3.14 & -0.001 & -0.17 \\
\hline$T_{i t 9}$ & 0.0003 & 0.09 & -0.001 & -0.27 & -0.0003 & -0.05 \\
\hline$T V_{i t}$ & -0.001 & -0.59 & $-0.004 * *$ & -2.69 & $0.009 * * *$ & 2.85 \\
\hline$R_{i t 4}$ & -0.0002 & -1.21 & -0.0001 & -0.68 & -0.0001 & -0.88 \\
\hline$R_{i t 5}$ & $0.0003 * * *$ & 3.07 & $0.001 * * *$ & 3.04 & 0.0001 & 0.96 \\
\hline$R_{i t 6}$ & -0.00001 & -0.09 & 0.0001 & 0.73 & -0.0001 & -0.84 \\
\hline$R_{i t 7}$ & -0.0001 & -0.94 & -0.000005 & -0.03 & -0.0001 & -0.60 \\
\hline$R_{i t 8}$ & 0.00005 & 0.57 & $0.0002 * *$ & 2.11 & 0.0001 & 0.72 \\
\hline$R_{i t 9}$ & 0.0001 & 1.23 & $0.0004 * * *$ & 2.79 & -0.00003 & -0.26 \\
\hline$R V_{i t}$ & -0.0001 & -0.30 & $-0.001^{*}$ & -1.74 & 0.0002 & 0.34 \\
\hline$Y_{t}$ & $0.005 * * *$ & 2.61 & $0.012 * * *$ & 3.96 & -0.003 & -1.24 \\
\hline$Y_{t} * D_{i}$ & $-0.003 *$ & -1.69 & -0.004 & -1.10 & -0.003 & -0.90 \\
\hline Constant & 1.085 & 10.02 & $0.985 * * *$ & 6.36 & $1.039 * * *$ & 5.51 \\
\hline$R^{2}$ & 0.3913 & & 0.4483 & & 0.5156 & \\
\hline Observations & 648 & & 324 & & 324 & \\
\hline
\end{tabular}

Note: *significant at $10 \% ; * *$ significant at $5 \% ; * * *$ significant at $1 \%$.

Table 5.4 presents the estimated results of the fixed effects model for the three groups of counties. In the group of all counties, the coefficients of the variables about SISGC in each year are significant and positive. Specifically, the significant coefficient of $\mathrm{P}_{\mathrm{i} 2011}$ indicates that 
NDVI increases by 0.042 in the first year of SISGC when the effects of other potential factors on NDVI are controlled. Similarly, NDVI increases by 0.13 until the second year of SISGC, 0.189 until the third year, and 0.15 until the fourth year. The effectiveness of SISGC is accumulated year by year. Therefore, the effectiveness of SISGC on NDVI in the first year is increased by $0.042,0.088$ for the second year and 0.059 for the third year. It is remarkable that the effectiveness of SISGC in the fourth year is -0.039 , although the accumulated effectiveness of SISGC on NDVI is a 0.15 increase by then. The interaction terms of SISGC in each year and pastoral attribute of the county are not significant, which indicates that there are no significant differences in the impacts of SISGC on NDVI between pastoral counties and semi-pastoral counties. With respect to the effects of other potential factors, the variable of the real producer price of live sheep presents significant and negative impacts on NDVI. It indicates that a $1 \%$ increase in the real producer price in year $t-2$ relative to the price in 2001 causes a decrease of 0.11 in NDVI when the factors of SISGC, climate, time trend and time-invariant heterogeneity between counties remain constant. Moreover, the temperature in May, June and August has significant and negative effects on NDVI. This is explained through the increasing temperature causing faster evaporation from the ground surfaces and evapotranspiration from the vegetation, and allowing more pests and mice to breed in the arid and semi-arid areas, which are significantly detrimental to grassland condition in the growing season (Li, 2009; Li et al., 2013). Precipitation in May, on the other hand, has significant and positive effects. Abundant precipitation is beneficial to the restoration of grassland condition ( $\mathrm{Li}$ and Zhang, 2009). The grassland condition is improved slowly with the factors that change with time trend, and the effects of time variance on grassland condition are stronger in the semi-pastoral counties than in the pastoral counties.

Comparing the model results between the groups of low NDVI counties and high NDVI counties, the coefficient of the variable of SISGC in the first year is not significant in the group of low NDVI counties. This may be explained by the lagged implementation of SISGC in the low NDVI counties considering that these counties are not first regions for initiating ecological construction programs and are usually located in the relatively remote areas. However, the coefficients of the variables of SISGC in the second, third and fourth years are larger in the group of low NDVI counties than in the group of high NDVI counties. This indicates that SISGC has stronger impacts on the grassland conservation in the low NDVI counties than in the high NDVI counties. This result is consistent with the implementation planning of SISGC, namely, grazing bans that provide higher subsidies and implement more strict constraints for 
grazing are conducted in the areas with more severe degradation or inferior grassland condition. Interestingly, the significant and negative coefficient of the real producer price indicates that a $1 \%$ increase causes a 0.161 decrease in NDVI in the low NDVI counties, but only a 0.065 decrease in NDVI in the high NDVI counties. Market forces seem to have a stronger impact in the counties with worse initial grassland condition. Similarly, climate changes seem to have more impact in the counties with worse initial grassland condition.

\subsubsection{Comparison between the estimated results and actual grassland condition}

Figure 5.2 depicts the estimated NDVI based on the significant coefficients of the variables of SISGC in the model including all counties. The mean value of actual NDVI in the period 20012010 is used as the initial value. The actual NDVI is drawn from the mean value of NDVI of the 54 counties in the periods 2001-2010, 2011, 2012, 2013 and 2014.

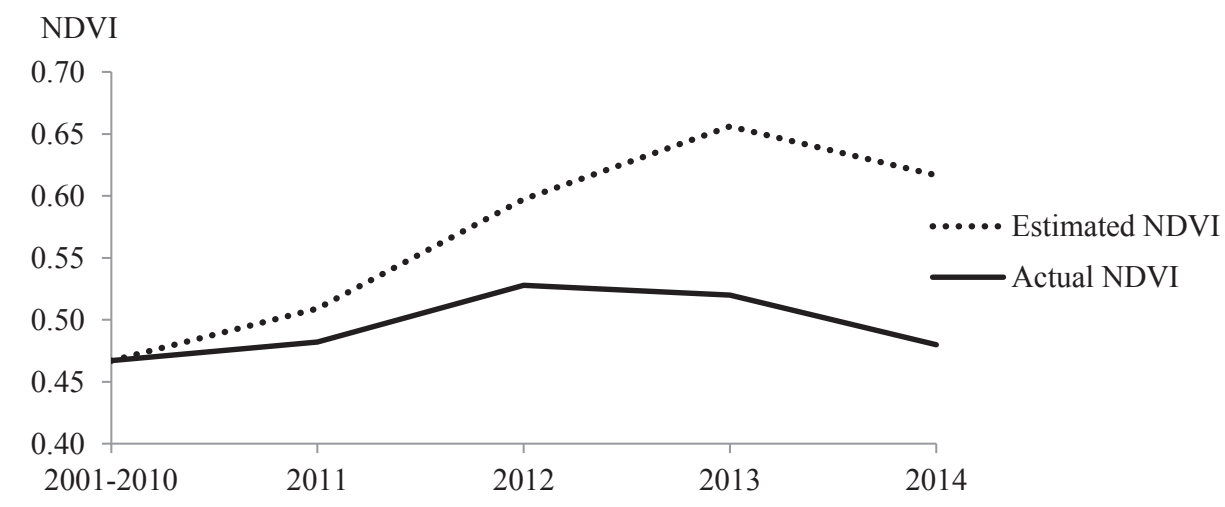

Figure 5.2 Comparison between the estimated NDVI and actual NDVI

Sources: The data of actual NDVI is derived from the data set of NASA's Earth Science Data Systems Program

The estimated NDVI and actual NDVI in each year of SISGC are larger than the initial value. Comparing the estimated NDVI and actual NDVI in figure 5.2, it shows that the actual NDVI is clearly lower than the estimated NDVI during the years of SISGC. The differences between the actual and estimated grassland condition are attributed to the other potential factors that offset the effectiveness of SISGC, including the producer price and climate factors which showed significant coefficients in the model results. For instance, data showed that the producer price continuously increased in the period 2011 to 2014 from 1.48 times to 2.54 times the producer price in 2001. Although the large increase in the producer price cannot impact upon 
grassland condition directly, strong market forces may stimulate herders to raise much more livestock. Increased grazing pressure following the large increase in the producer price induces significantly negative impacts on the grassland condition that reduces or neutralises the positive impacts stemming from SISGC, with the result that the actual grassland condition under the SISGC is not as good as expected.

\subsection{Discussion}

The effectiveness of SISGC with first an increasing and then a decreasing trend is in line with the results of existing research that questioned the failed implementation and ineffective management measures of Ecological Construction Programs (Bao and Chen, 1997; Waldron et al., 2010). For example, it is suggested that top-down management entails high supervision costs, making the implementation of the Ecological Construction Programs difficult to sustain for a long period effectively (Li and Zhang, 2009; Waldron et al., 2010). In our case, the local governments, who follow the instructions of the national government as planned at the beginning of SISGC, encountered increasing supervision costs when the producer price of live sheep soared especially in the third and fourth years of SISGC which prompted local herders to gain more economic benefits by increasing illegal grazing. It thus may incur the implementation of SISGC failure during the later years of SISGC. With respect to the ineffective management measures, it has been proved that grassland is in a better condition, including plant species diversity and herbage mass, during the early years of the permanent grazing ban, while there is a subsequent decline or level-off during its later years (Yang et al., 2005; Zhang et al., 2015). The ecological explanation for this is that annual and biennial vegetation could invade during the early years of permanent grazing ban, which would increase species richness. However, the subsequent recovery of dominant species increases their prevalence and further leads to a decrease in biodiversity in the next years (Bao and Chen, 1997). Considering that the permanent grazing ban is widely employed in SISGC, the fact that the grassland condition showed a gradual increase at first and then decreased under the impact of SISGC may correspond to this process of ecological succession.

In addition, we would like to point out several limitations of our research. Firstly, the four years of SISGC which we studied may not be long enough to estimate the changing trend of its effectiveness on grassland condition. Secondly, we used dummy variables to present the status of SISGC in our model due to data limitations. Indicators that involve specific differences of SISGC among counties, such as grassland areas under SISGC, amount of subsidies and 
enforcement strength of each county, would be more meaningful for estimating the effectiveness of policy intervention than the dummy variables. In our case, because all of the counties in the sample have participated in SISGC since 2011, the dummy variables of SISGC do not distinguish the specific differences of implementation of SISGC between counties and between years, and only the differences between before and after SISGC are presented. Moreover, we considered SISGC as a single policy, rather than investigating the results of its two specific regulations, deterministic stocking rates and permanent grazing bans, separately. Our research thus only presented the general result of SISGC. Although we showed that SISGC has a stronger impact in low NDVI counties, the impacts of specific measures need to be explored more thoroughly. Finally, our empirical model does not allow disentangling the impacts of other Ecological Construction Programs that were mainly implemented before SISGC started, such as the Conversion of Cropland to Forest and Grassland Program, Returning Grazing to Grassland Program, or the Program to Combat Desertification around Beijing and Tianjin.

\subsection{Conclusions}

This paper began by sketching a review about the policy interventions for grassland protection in China, involving the national Grassland Law and a series of Ecological Construction Programs. And then we took the latest Ecological Construction Program (SISGC) as an example to examine its effectiveness for grassland conservation in the extensive pastoral areas over the long term. The grassland condition was presented by the NDVI, rendered by remote sensing technology. The situation of SISGC was defined by dummy variables, which presented the situation of each year with SISGC. The fixed effects model was used to control for the factors that obscure the relationships between grassland condition and SISGC, including livestock production, climate factor, time trend and time-invariant heterogeneity between counties. Based on the data of 54 sample counties in the pastoral areas of Inner Mongolia from 2001 to 2014, the empirical model results provided quantitative evidence that grassland condition has been generally improved under the auspices of SISGC. The comparison between the actual NDVI and the estimated results show that the actual grassland condition is worse than the estimated results when other factors are assumed constant. One explanation for this is that the effectiveness of SISGC on grassland condition is offset by the impact of other potential factors, such as producer price and climate changes. Moreover, the impact of SISGC on the grassland condition is stronger in the low NDVI counties, while the offset from producer price and climate factors is more pronounced in these counties as well. In conclusion, our research findings are 
that the Ecological Construction Programs such as SISGC are effective for grassland conservation, but that the effectiveness on grassland protection is reduced or neutralised by other socio-economic and climate factors. For future policy design, an improvement in the Ecological Construction Programs should take into account the potential offsetting forces from other factors related to market and climate conditions. 


\section{ACKNOWLEDGEMENT:}

Funding for this research was supported by grant from the National Natural Sciences Foundation of China (71333013) and INTASAVE-CARIBSAVE Group (ACCC-027). The authors would like to thank Jiliang $\mathrm{Hu}$, Meng Yao and Guanghua Qiao for their help during the data collection. We are also grateful to the enthusiastic herders for their any help in our survey. 


\section{Chapter 6}

\section{Discussion and conclusions}




\section{DISCUSSION AND CONCLUSIONS}

\subsection{Introduction}

China is faced with grassland degradation, rapid increases in demand for livestock products and high levels of poverty among rural households. This dissertation outlines China's grassland policies and studies the outcomes of the policy interventions for grassland systems in Inner Mongolia. More specifically, this thesis focuses on evaluating the effects of the land tenure reform and Ecological Construction Programs. These policy evaluations essentially show the outcomes of the government-driven transformation of traditional pastoralism and differ from other existing research that has been concerned with the internal process of pastoralism transformation (e.g. Mwangi, 2007).

To date, the transformation of pastoralism has widely been employed by governments around the world by developing sedentarisation instead of nomadism, privatisation of grasslands instead of common use, intensification instead of extensive grazing, commercialisation of livestock systems instead of subsistence, determinative stocking rate instead of opportunistic strategies with stochastic stocking rates, to name a few (Homewood, 1995; Li and Zhang, 2009). Although plenty of studies have discussed the pros and cons of these pastoralism transformation programs from the perspective of ecology, sociology, and other fields (e.g. Suttie et al., 2005; Mwangi, 2007; Li and Zhang, 2009; Hua and Squires, 2015), there is a lack of literature based on large-scale areas and long-term observation to provide empirical evidence for scientific debate. This study employs panel data involving extensive pastoral areas and spanning several decades to quantify the ecological and economic outcomes of the pastoralism transformation in Inner Mongolia, China. Specifically, the impact of land tenure reform represents the outcomes of grassland privatisation instead of communal tenure. The effectiveness of Ecological Construction Programs presents the outcomes of current management systems on the grasslands, such as the grazing ban and deterministic stocking rate instead of stochastic stocking rates. Moreover, the preference for grasslands by stakeholders reflects the perception of grassland resource users on the pastoralism transformation. The conceptual framework for our research is based on Ostrom's Social-Ecological Systems (SESs) framework (Ostrom, 2007; 2009). Chapters 2 through 5 address four specific research questions.

Chapter 2 starts with studying the perceptions of users on grassland use under the current policy interventions. The specific research question is, what are the individual and social optima of 
rural land allocation by stakeholders: among cultivated land, grassland, forest and other rural land? It is answered by quantifying the preference of different stakeholders over rural land allocation, and thereby reflects the different interests of different stakeholders over grassland use. Chapters 3, 4 and 5 focus on estimating the outcomes of policy interventions targeting the grasslands. Chapter 3 addresses the question, what is the impact of land tenure reform on the grassland condition? It first outlines the process of land tenure reform in the pastoral areas of China and then investigates the changes in grassland quantity and quality that are caused by the reform. Chapter 4 answers the question, what is the impact of the land tenure reform on livestock production? It presents the economic outcome of the land tenure reform by exploring the effects of the reform on the livestock population and meat output. Chapter 5 focuses on the question, what is the impact of Ecological Construction Programs on grassland conservation? It estimates the ecological outcome of one typical Ecological Construction Program (the Subsidy and Incentive System for Grassland Conservation).

This final chapter recaps the main findings of each chapter, presents the contribution to the existing scientific debates and draws lessons for policy improvement. It concludes with the research limitation and recommendations for future research.

\subsection{Synthesis of research findings}

\subsubsection{Different preference on grassland use by different stakeholders}

The individual optima of rural land allocation reveal the different preferences of different stakeholders for grassland use. The social optima illustrate a possible trade-off among stakeholders over grassland use. The comparisons between individual optima, social optima and actual allocation reflect the conflicts over grassland use among different stakeholders. In our case study, the optima of ecological and economic authorities for desirable grassland areas are within the range of the social optimum, whereas herders prefer more and farmers prefer less grassland than the social optimum. In addition, the actual area of grassland already exceeds the upper range of social optima, implying the further need to reduce the grassland area for the sake of social welfare. This finding appears to contradict the prevailing policy direction of grassland conservation that attempts to expand the grassland area. 


\subsubsection{Grassland privatisation is a significant reason to cause grassland degradation in a}

\section{long term}

Land tenure reform in the pastoral areas of China engages in privatising use rights of grasslands (Banks et al., 2003). The impact of land tenure reform on the grassland ecosystem reflects the ecological effectiveness of grassland privatisation. The results of this research prove that grassland privatisation has a significant and negative impact on the condition of the grasslands. More specifically, private use causes the reduction of the total grassland area and leads to the degradation of dense and moderate grasslands into sparse grassland in the long run. As such, we observe "a tragedy of privatisation" (Guelke, 2003; Li and Huntsinger, 2011), as opposed to the well-known "tragedy of the commons".

\subsubsection{Grassland privatisation puts a ceiling on the livestock production of pastoral areas, but it promotes the development of livestock productivity}

The implementation of land tenure reform is shown to have significant and negative effects on the increase in livestock production. That is, land tenure reform that refers to the privatisation of grassland use rights puts a ceiling on livestock production. This may be a possible reason for why the reform has not been implemented as successfully in the grasslands as in cropland of China. However, land reform in itself is unable to offset the impact of other factors that stimulate the increase in livestock production in practice. Moreover, the constraining effect of land tenure reform on livestock production steadily decreases following the initial implementation of the reform and ultimately disappears. Furthermore, the constraining effect of land tenure reform is stronger on the increase of livestock population than on that of meat output, indicating that land tenure reform improves livestock productivity.

\subsubsection{Ecological Construction Programs have significant impacts on preventing grassland degradation}

A series of Ecological Construction Programs have been initiated for grassland conservation in the 2000s. This research provides quantitative evidence that the condition of grasslands has improved significantly under the auspices of Ecological Construction Programs, specifically under the program of Subsidy and Incentive System for Grassland Conservation (SISGC). However, the ecological effectiveness of the Ecological Construction Programs is offset to some extent by other socio-economic and climate factors, such as market conditions and climate change. This may explain why the actual condition of the grasslands is not as good as had been 
expected. In addition, the case of SISGC shows that the impact of Ecological Construction Programs on grassland conservation is stronger in the counties with worse initial grassland condition, while the effects of market conditions and climate factors were also more pronounced in these counties. Finally, the effectiveness of SISGC is shown to experience an initial increasing but subsequently decreasing trend in the years since SISGC is first implemented.

In summary, the findings of the research presented in chapters 2 to 5 suggest that the transformation of traditional pastoralism through policy intervention impacts the grassland system significantly and complexly. For instance, the outcomes of grassland privatisation (i.e. land tenure reform) have two different sides. On the one side, it causes further grassland degradation, but on the other, it is beneficial to the development of animal husbandry in pastoral areas by controlling excessive growth of the livestock population while prompting livestock productivity. Moreover, Ecological Construction Programs that mainly rely on the control of livestock grazing for grassland conservation has led to an improvement in the grassland conditions, but this effect is offset to some extent by other socio-economic and climate factors.

\subsection{Contribution to scientific debates}

\subsubsection{The tragedy of the commons versus the tragedy of privatisation}

The concept of the tragedy of the commons has long been part of the conventional wisdom in ecology, economics and political science (McEvoy 1987). It contends that resource degradation is inevitable unless the commons are either privatised or maintained as common land with clear rights of entry and use (Hardin 1968). Similarly, the theorem of property rights proposes a clear assignment of property rights as a precondition for economically efficient resource allocation and environmental sustainability (Coase 1960). Moreover, privatisation is expected to increase agricultural productivity and the wise use and conservation of resources, because the transferability of rights under private property arrangements is supposed to ensure that resources end up with the most productive users (Mwangi, 2007). As such, some scholars and policy makers have repeatedly identified traditional pastoralism as an irrational, ecologically destructive and economically inefficient system (Homewood, 1995; Kamara et al., 2005; Ho and Azadi, 2010).

However, Hardin's theory of the tragedy of the commons and Coase's theorem of property rights have been rejected by pastoral specialists, who found that these theoretical findings provided a poor guide toward the sustainable use and management of grasslands (Feeny et al. 
1990; Behnke 1994; Sneath 1998). Some new arguments have arisen in support of traditional pastoralism, emphasising mobility, flexibility and reciprocity of grassland use, which conforms to the attribute of grassland resources with strong temporal variability and spatial heterogeneity (Fernandez-Gimenez and Le Febre, 2006). It is argued that traditional pastoralism could maintain ecosystem stability and biological diversity in terms of the sustainable use of grasslands (Fernandez-Gimenez and Le Febre, 2006; Fan et al., 2015). In particular, the communal tenure of traditional pastoralism buffers change and uncertainty in grasslands, allowing pastoralists to maintain a relatively reliable flow of resources from a relatively unreliable environment (Roe et al. 1998). Indeed, traditional pastoralism has developed flexible institutions that enable the persistence of production on such patchy and unpredictable lowproductivity environments for centuries (Fernandez-Gimenez and Le Febre, 2006; Li and Huntsinger, 2011).

Recently, the literature has increasing interests in the common property regime of grasslands, especially considering the benefits of mobility, flexibility and reciprocity of grassland use, such as mutual aid, pooled labour as well as access to water resources, medicinal herbs and natural shelters, which potentially maintain the ecological and economic resilience of the grassland systems (Cao et al., 2013). In contrast, the exclusionary land tenure and pasture enclosure are suggested to be counterproductive to improve grassland systems because they threaten the integrity of ecological systems of arid and semi-arid areas, particularly impeding mobility and resource access in times of disaster (Mwangi, 2007; Galvin 2009). In this regard, the tragedy of privatisation is put forward (Guelke 2003; Li and Huntsinger 2011), in contrast to the wellknown tragedy of the commons. In addition, grassland privatisation reduces the amount of land available for livestock grazing, further leading to a reduction in the number of livestock that an individual can potentially own, ultimately resulting in poverty Mwangi (2007). Some scholars suggested that the highly spatial heterogeneity of grassland resources leads to dramatically inequitable assignments, especially the forage quality and water access, which may cause severe conflicts over grassland use (Yan et al., 2005). The other negative social consequences of the implementation of grassland privatisation include increased labour burdens for each household and the loss of labour economies of scale (Yan et al., 2005; Cao et al., 2013).

Given these arguments over traditional pastoralism, especially regarding property rights and use rights, Chapters 3 and 4 of this research provide the empirical analysis on the ecological and economic impacts of the transformation of grassland use rights in China. Chapter 3 shows 
that grassland privatisation causes grassland degradation in pastoral areas. Chapter 4 finds that grassland privatisation places a ceiling on the livestock production of pastoral areas, while it stimulates the development of livestock productivity. Hence, this research supports the idea of a tragedy of privatisation, drawing from the negative ecological outcomes of privatisation. Nevertheless, grassland privatisation is beneficial to the development of local animal husbandry considering the effects of controlling excessive growth of the livestock population and prompting livestock productivity, showing that grassland privatisation can stimulate herders to increase efforts to improve the output per animal, instead of increasing the number of animals.

\subsubsection{Deterministic stocking rates versus stochastic stocking rates}

The control of the livestock population has been the most widespread approach to halting grassland degradation in China, Africa and other parts of the world since overgrazing became a concern in the 2000s (Vetter, 2005). However, a debate around the validity of the control of the livestock population for preventing grassland degradation in the arid and semi-arid areas has emerged, often referred to as a debate between the equilibrium model and the nonequilibrium model (e.g. Clements, 1916; Ho, 2001; Vetter, 2005). The equilibrium model, or Clementsian succession theory (Clements, 1916), advocates the stability and predictability of grasslands, which stresses the importance of biotic feedbacks such as density-dependent regulation of livestock population and the feedback of livestock density on vegetation composition, cover and productivity (Ho, 2001; Vetter, 2005). In other words, the equilibrium model suggests that the stocking rate is predictable and deterministic, and grassland degradation occurs if the carrying capacity ${ }^{25}$ is exceeded due to overstocking. The use and management of grasslands based on the equilibrium model therefore focus on deterministic and low stocking rates, i.e. controlling the livestock population for grassland conservation.

In contrast, the non-equilibrium model advocates that the grassland condition in the arid and semi-arid areas are primarily driven by stochastic abiotic factors which result in highly variable and unpredictable primary production, particularly due to the factor of precipitation (Ho, 2001). The argument carried further implies that grassland degradation is part of a natural process of vegetation decline and growth in response to precipitation (Ho, 2001). The grassland use and management based on the non-equilibrium model claims that the livestock population has negligible feedback on the vegetation as the number of animals is kept below equilibrium densities by frequent droughts, and that grassland degradation as a result of overgrazing is thus

\footnotetext{
${ }^{25}$ Carrying capacity indicates that grazing pressure is counterbalanced by the natural regeneration of plants.
} 
unlikely (Sullivan and Rohde, 2002). As such, the non-equilibrium model embraces opportunistic strategies with high and stochastic stocking rates in which the number of livestock is maximised according to the availability of forage, and grassland degradation is not caused by overgrazing.

The debates over grassland management between the equilibrium model and the nonequilibrium model eventually are reflected in the question of whether the livestock population can be allowed to increase without the threaten of grassland degradation (Vetter, 2005). The Chinese policy interventions provide an outstanding example of managing grasslands based on the equilibrium model. It is believed that overgrazing is the main cause of grassland degradation, therefore the control of the livestock population has been employed for grassland conservation. Chapter 5 of this research investigates the ecological outcomes of the policy intervention of deterministic stocking rates and grazing bans in Inner Mongolia, China. It suggests that control of the livestock population improves the grassland condition significantly in the arid and semiarid areas of China in the short term. However, there are some doubts over the long term, as the effectiveness of grassland conservation measures appears to decrease in later years. As such, this research agrees that grassland management based on the equilibrium model might be effective for grassland conservation in the arid and semi-arid pastoral areas temporarily, but that the non-equilibrium model may be more valid for long-term strategies.

\subsubsection{Top-down intervention versus bottom-up intervention}

The debate over concrete uses and management strategies for natural resources is still ongoing: in particular, whether a top-down or a bottom-up approach can best achieve conservation goals (Oestreicher et al., 2009; Mauerhofer, 2011). The top-down approach assumes that legislation and policies set explicit aims and objectives, providing a blueprint that is then directly translated into action on the ground (Urwin and Jordan, 2008). Top-down intervention generally follows a decision by government authorities and policy makers. Although such official acts in the public interest are considered capable of designing optimal rules to govern resource use for an entire region, this prescription is not supported by empirical research (Ostrom, 1999). The topdown approach has been criticised as leading to poor compliance with statutory law and limited local community participation in monitoring and enforcing natural resource conservation regulations (Hartter and Ryan, 2010). Hence, top-down resource management strategies have been linked to marginalising poor populations and exacerbating natural resource depletion (Oestreicher et al., 2009). 
A bottom-up approach that aims to guide self-organisation towards desirable states (Ball and Helbing, 2012), recognises the decisions and strategies of local resource users in managing resources (Castella et al., 2007). It has been suggested that sustainable natural resource management directives must be initiated from the grassroots level, where the problems and solutions are perceived as local (Hartter and Ryan, 2010). Research in multiple disciplines has found that some top-down policy interventions accelerate resource destruction, whereas selforganisation by some resource users has been successful in resource conservation (Ostrom, 2009). Field studies also have found that local resource users, with or without the assistance of external authorities, have created a wide diversity of institutional arrangements for coping with common-pool resources ${ }^{26}$ (Ostrom, 1999). Moreover, a series of relatively autonomous, selforganised resource governance systems might do a better job of regulating small common-pool resources than a single central authority. A decentralised, polycentric, bottom-up approach, involving multiple institutions instead of a single global one, may provide better conditions both for cooperation to thrive and for ensuring the maintenance of such institutions (Vasconcelos et al., 2013). Local resource users, who share moral and ethical standards for how to behave in the groups they form, face lower transaction costs in reaching agreements and lower costs of monitoring (Ostrom, 2009). In terms of grassland management, Sneath (1998) showed that the grasslands under central government management in China and Russia are associated with more degradation than those under traditional, self-organised group-property regimes in Mongolia.

Scholars have increasingly embraced the bottom-up, self-organised approach to policy intervention. The research cases by Schoon (2008) found that the bottom-up approach increases cooperation and coordination at the operational level, but that top-down approach can generate successful cooperation at higher levels of governance. Policy interventions in grassland conservation in China have generally been conducted via a top-down approach, starting with explicit aims and quotas that are distributed from the central government to the provinces, followed by subsequent distribution down through counties, townships, and finally to participating villages (Bennett, 2008). This is criticised because of the lack of sufficient consultation with local communities and rural households to identify their needs and learn the local constraints (Bennett, 2008). Chapter 5 focuses on investigating the ecological outcome of top-down interventions into grassland conservation in China. The research results reveal that

\footnotetext{
${ }^{26}$ A common-pool resource, such as an irrigation system, a fishing ground, a forest, or open access grasslands, is a natural or man-made resource, from which it is difficult to exclude or limit users once the resource is provided, where one person's consumption of resource units makes those units unavailable to others (Ostrom et al., 1994).
} 
the policy intervention impacts grassland condition significantly and positively, but the effectiveness on grassland conservation is not as good as expected because of the counterbalancing effect of other factors. In this regard, the policy improvement of grassland conservation in China could consider more bottom-up self-organisation interventions that involve learning about local market forces, climate conditions, and so on.

\subsubsection{The one-size-fits-all versus tailor-made policies for resource governance}

Scholars have tended to develop simple theoretical models to analyse aspects of resource problems and to prescribe universal solutions for resource use (Ostrom, 2009). Governmental agencies often impose one-size-fits-all policy for resource governance. However, the universal policy solution frequently fails (Pritchett and Woolcock, 2004; Ostrom, 2009). In particular, national government agencies are often unsuccessful in their efforts to design effective and uniform sets of rules to regulate important common-pool resources across a broad domain (Ostrom, 1999).

In the case of China, land tenure reform started with the Household Production Responsibility System in cropland areas in the late 1970s and spread to the pastoral areas by the early 1980s. The reform intended to reallocate communal land to peasant households. In the cropland areas, the household-based use rights system was established rapidly, and $94.2 \%$ of rural households had adopted the system by the end of 1983 (Lin, 1987; Banks et al., 2003). Chinese scholars showed that this reform of cropland use rights created millions of smallholders with relative autonomy over land use decisions and crop selection (Tilt, 2008). Moreover, the householdbased farming system improved the incentive structure for agricultural production when monitoring was difficult within the commune system (Lin, 1987). This assignment of cropland resulted in the growth of agricultural output and income in the reform period.

However, in the pastoral areas, the implementation of the land tenure reform is not as successful as was the case in the cropland areas. The assignment of grassland use rights was implemented slowly and was still in progress after 30 years of efforts, and a second round of reform to accelerate the implementation in the 1990s. The adoption of actual private use by individual households evidently lagged behind the assignment of formal use rights by governments. The research results in Chapter 3 showed that the land tenure reform was detrimental to the grassland ecosystem, although it is beneficial to the development of the animal husbandry system of pastoral areas according to the research results in Chapter 4. The conclusion can be 
made that the land tenure reform that seemed suitable for managing cropland resources may not fit the management of grassland resources. This result is in line with the research finding that individual property may not be suitable for most pastoral settings in which resource productivity is variable due to environmental variability (Mwangi, 2007).

With respect to resource conservation, the Chinese government initiated a series of ecological programs for ecological restoration and resource development in its forest sector in the late 1990s, including the Natural Forest Protection Program, the Sloping Land Conversion Program, the Desertification Combating Program around Beijing and Tianjin, the Shelterbelt Development Program, and the Wildlife Conservation and Nature Reserve Development Program (Liu et al., 2010). Plenty of scholars have shown that these ecological programs for forest conservation have significant and positive impacts on improving resource conditions as well as increasing rural households' income (e.g. Liu et al., 2010; Mullan et al., 2010). Following these ecological programs for forest conservation, a series of programs have been initiated to protect the grasslands of China, especially during the 2000s. In general, sowing grass and reducing grazing (such as with a grazing ban) are imposed as key components for grassland conservation, which coincide with the main measures of planting trees and restricting logging (such as with a logging ban) for forest conservation (Mullan et al., 2010). Chapter 5 of this research shows that the effectiveness of the large-scale ecological programs differs across different regions with the same policy context. In addition, Chapter 2 of this research shows that different stakeholders have divergent preferences in different types of rural land. Given these research results, it is evident that there is no one-size-fits-all policy for the governance of cropland, grassland and forest land, as well as for the interests of different stakeholders. In this case, tailor-made policies that take into account the specific circumstances, such as the resource types and stakeholders, are needed for resource governance.

\subsection{Policy implications}

With severe grassland degradation, high population pressure and increased production requirements, the sustainable use and management of grasslands, which enables the maintenance of productive capacity without compromising the ecological interests of human communities and the ecosystem itself, are essential. An increasing number of scholars support the model of traditional pastoralism as one approach for sustainable grassland use, due to its advantages of mobility, flexibility and reciprocity that fit grassland use for heterogeneously distributed resources. In this respect, some have suggested abolishing the existing grassland 
privatisation, tearing down wire fences between the patches, repealing the deterministic stocking rates and further resuming nomadism ( $\mathrm{Wu}$ and $\mathrm{Du}, 2008)$. However, there has also been criticism of traditional pastoralism as being incapable of coping with the rapidly increasing population pressure and economic demands relying on finite grassland resources, because traditional pastoralism is primarily subsistence-oriented. In other words, traditional pastoralism may only operate well during the phases of low economic demand and minimal environmental degradation. As such, it is important to transform the traditional pastoralism into a model that can adapt to contemporary socio-economic conditions.

The case of Inner Mongolia presents lessons for the improvement of the government-driven transformation of traditional pastoralism in arid and semi-arid pastoral areas. In particular, it shows that the assignment of grassland use rights to individual households has negative impacts on improving the grassland condition. On the other hand, the privatised use rights have put a ceiling on the livestock production of pastoral areas, while it promotes the development of livestock productivity. Some scholars have mentioned that the household is not an efficient unit for meeting the demands of large-scale animal husbandry, and household-based privatisation has provided a rapid increase in livestock production costs in the pastoral areas of China (Li et al., 2014). Admittedly, the cooperative use of grasslands on a large scale offers the opportunity to benefit from the maximum heterogeneity in the landscape. Given the status quo of privatisation implemented in pastoral societies, a possible solution is to stimulate the local community toward cooperative use and management of grassland resources based on the existing privatised property rights or use rights of grasslands. In this regard, the privatisation of grassland property rights or use rights could be viewed as a precondition for guaranteeing stable cooperation. The cooperative households who reach an agreement are encouraged to remove their fences and pool their grassland resource in order to provide a better match for forage and water availability. Besides the grassland resource, other agricultural inputs like labour and capital could be pooled for efficient distribution as well. Economies of scale in production and the exclusion of outsiders are also important (Mwangi, 2007). The proposal of cooperative use is in line with the research findings of Mwangi (2007) that showed how parcel re-aggregation can offer promise for ecosystem sustainability as well as for the economic sustainability of African grasslands.

In addition, a wide diversity of institutional arrangements for grassland use are needed, considering the heterogeneity in grassland resources per se and the different socio-economic 
and cultural backgrounds of pastoral societies, instead of extending the same policy measures designed for crop-farming areas to pastoral areas. This study has found that the same land tenure reform had different policy effectiveness on grassland and cropland. Especially some unintended effects were observed on grassland systems, which suggest the need to clarify the different attributes between grassland systems and cropland systems before transforming the property rights or use rights of grasslands. Clearly, the top-down decision by central governments for resource management makes it difficult to consider all of the specific attributes of each resource at local levels, but it is advocated that resource users who understand the local Social-Ecological Systems (SESs) well are able to use the resource more efficiently through self-organisation and self-crafted institutions (e.g. Ostrom, 1999; Baerlein et al., 2015). Users that have full autonomy at the collective-choice level to craft and enforce some of their own rules, also confront lower transaction costs (Ostrom, 2009). As such, it is recommended to create specific institutional agreements for grassland use by local communities. This bottomup self-organisation management would have the advantage of relatively complete information for developing efficient use of grasslands, which specifically takes into account the highly variable topography of grasslands, strongly spatial and temporal heterogeneity of grassland resources, traditional knowledge about grassland use and production, and other important factors (Yan et al., 2005; Wu and Du, 2008; Fernandez-Gimenez et al., 2012).

Theoretically, cooperative use of grasslands among neighbouring households could conform to the theory of "common pool resources" which involves self-organisation by the local community in efforts to achieve a sustainable Social-Ecological System (Ostrom, 2009). Nevertheless, cooperative use of grasslands and bottom-up self-organisation management should undergo further research concerning internal organisation, transaction costs, etc. Moreover, although the self-organisation by local herders is predominantly suggested as a localised management model, the assistance of external authorities plays an important role in balancing the various needs of the whole society. The long-term sustainability of rules devised at a SES level depends on monitoring and enforcement, without being overruled by government policies (Ostrom, 2009). As such, a combination of top-down and bottom-up approaches is perhaps the most effective approach to be considered. The study by Fernandez-Gimenez et al. (2012) also demonstrated that the strengthening of adaptive capacity and resilience of grassland systems requires joint efforts and improved communication between the government and local communities. 


\subsection{Limitations and recommendations for future research}

To conclude, I would like to point out a number of limitations of this study and challenges for future research. First, I follow Ostrom (2007)'s recommendation that the problems linked to SESs require serious study of complex, multivariable, nonlinear, cross-scale and changing systems, and that more knowledge about specific variables of SESs, the interactions between variables and dynamics of SESs need to be explored more deeply. More specifically, in Chapter 2, we assume four categories of rural land, four stakeholder types and three scenarios to simplify the reality of land allocation in the SES. For further research, the more components and the more complicated interactions between the components of rural land allocation linked SESs need to be considered. Moreover, chapters 3, 4 and 5 present general outcomes of the policy interventions in grassland systems, whereas the interaction between grassland condition and livestock production is a significant aspect to be studied more concretely.

With regard to the complex SESs of grasslands, our research provides preliminary outcomes of governance system to grassland system at county-level. An interesting avenue for future research is to understand the specific impacts of policy interventions at the household-level, such as the costs and benefits that herders faced during the policy interventions. Further research would be to explore this in more detail, for example: what changes herders adopted in order to adapt to the government-driven transformation of traditional pastoralism; how herders adjusted their grassland use and livestock production patterns coping with the increasing population, the growing demand for livestock products and the grassland degradation; what is the resilience of pastoral societies in the changing natural and social environment. Moreover, our research focuses on the pastoral areas of Inner Mongolia, which is a typical region for studying the SESs of grasslands of China. However, the crop-farming areas that also include some permanent grassland have more complicated SESs and more serious grassland degradation than the pastoral areas, and thus even more problems to be addressed. The same research questions that are addressed in this study for the pastoral areas would be also interesting for those crop farming areas, such as the dynamics of their grassland ecosystem, livestock production and household livelihoods under the changing social, economic and political settings. Moreover, the accuracy of Chinese livestock statistics is questionable (Waldron et al., 2007). The standardisation of data collection on livestock population and meat output must be improved, especially regarding the production of rural households. Given more reliable data on livestock production, the scepticism over the existence and extent of 
overgrazing would be dissected, which would significantly contribute to the debates between the equilibrium model and non-equilibrium model for arid and semi-arid areas.

Last but not least, cooperative use of grasslands on a large scale and bottom-up self-organisation management are considered possible solutions for policy improvement in this research, but more empirical analysis is required to testify to their validity and investigate the possibility of implementation. There are no simple solutions to complex governance problems (Ostrom, 2007). As such, we call for more research to learn about the SESs of grasslands based on the same framework introduced by Ostrom, in order to develop broader and more integrated insights into SESs. A large number of government-driven transformations of traditional pastoralism are under way in Africa, Asia and other regions. The quest to better understand the approaches and paths of these transformations is an important part of ensuring the sustainability of grassland SESs around the world. 


\section{References}

Angelsen, A. (2001). Playing games in the forest: State-local conflicts of land appropriation. Land Economics 77(2): 285-299.

Angerer, J., Han, G., Fujisaki, I., and Havstad, K. (2008). Climate change and ecosystems of Asia with emphasis on Inner Mongolia and Mongolia. Rangelands 30: 46-51.

Baerlein, T., Kasymov, U., and Zikos, D. (2015). Self-governance and sustainable common pool resource management in Kyrgyzstan. Sustainability (Switzerland) 7(1): 496-521. doi: 10.3390/su7010496

Ball, P., and Helbing, D. (Eds.) (2012). Why society is a complex matter: Meeting twentyfirst century challenges with a new kind of science. Springer: Berlin Heidelberg

Bao, Y., Chen, M. (1997). The studies of changes in plant diversity on degenerated steppe in enclosed process. Journal of Inner Mongolia Universit (Acta Scientiarum Naturalium Universitatis NeiMongol) 28: 87-91.

Banks, T. (2003). Property rights reform in rangeland China: Dilemmas on the road to the household ranch. World Development 31(12): 2129-2142.

Banks, T., Richard, C., Li, P., and Yan, Z. (2003). Community-based grassland management in Western China: rationale, pilot project experience and policy implications. Mountain Research and Development 23: 132-140.

Barker, A. J., and Selman, P. H. (1990). Managing the rural environment: An emerging role for planning authorities. Journal of Environmental Management 31(2): 185-196.

Behnke, R. (1994). Natural resource management in pastoral Africa. Development Policy Review 12: 5-27.

Bennett, M. T. (2008). China's sloping land conversion program: Institutional innovation or business as usual? Ecological Economics 65(4): 699-711. doi: 10.1016/j.ecolecon.2007.09.017

Boone, R. B., and Hobbs, N. T. (2004). Lines around fragments: Effects of fencing on large herbivores. African Journal of Range and Forage Science 21(3): 147-158.

Boone, R. B., BurnSilver, S. B., Thornton, P. K., Worden, J. S., and Calvin, K. A. (2005). Quantifying declines in livestock due to land subdivision. Rangeland Ecology and Management 58(5): 523-532. doi: 10.2111/1551-5028(2005)58[523:qdildt]2.0.co;2

Boone, R. B., and Hobbs, N. T. (2004). Lines Around Fragments: Effects of Fencing on Large Herbivores. African Journal of Range and Forage Science 21: 147-158.

Briske, D.D., Zhao, M., Han, G., Xiu, C., Kemp, D.R., Willms, W., Havstad, K., Kang, L., Wang, Z., Wu, J., Han, X., and Bai, Y. (2015). Strategies to alleviate poverty and grassland degradation in Inner Mongolia: Intensification vs production efficiency of livestock systems. Journal of Environmental Management 152: 177-182. doi: 10.1016/j.jenvman.2014.07.036

Brown, C. G., Waldron, S. A., and Longworth, J. W. (Eds.) (2008). Sustainable development in Western China: Managing people, livestock and grasslands in pastoral areas. Edward Elgar Pub: Cheltenham, United Kingdom

Bureau of Animal husbandry of Inner Mongolia. (2000). History of Animal husbandry of Inner Mongolia. People's publishing house of Inner Mongolia: Hohhot. [in Chinese] 
Bureau of Animal husbandry of Inner Mongolia. (2015). Report of the progress on privatising grassland use rights of Inner Mongolia. Bureau of Animal husbandry of Inner Mongolia: Hohhot. [in Chinese]

Cao, J., Yeh, E.T., Holden, N.M., Yang, Y., and Du, G. (2013a). The effects of enclosures and land-use contracts on rangeland degradation on the Qinghai-Tibetan plateau. Journal of Arid Environments 97: 3-8. DOI: 10.1016/j.jaridenv.2013.05.002

Cao, J., Yeh, E. T., Holden, N. M., Qin, Y., and Ren, Z. (2013b). The roles of overgrazing, climate change and policy as drivers of degradation of china's grasslands. Nomadic Peoples 17(2): 82-101. doi: 10.3167/np.2013.170207

Castella, J. C., Pheng Kam, S., Dinh Quang, D., Verburg, P. H., and Thai Hoanh, C. (2007). Combining top-down and bottom-up modelling approaches of land use/cover change to support public policies: Application to sustainable management of natural resources in northern Vietnam. Land Use Policy 24(3): 531-545. doi: 10.1016/j.landusepol.2005.09.009

China Animal Industry Yearbook. (2014). Editorial Office of China Animal Industry Yearbook. Agricultural publishing house of China: Beijing (in Chinese).

Clements, F. E. (Eds.) (1916). Plant Succession: An Analysis of the Development of Vegetation. Carnegie Institute Publications: Washington, DC

Coase, R. H. (1960). The problem of social cost. Journal of Law and Economics. 56(4): 837877.

Conte, T. J. (2015). The effects of China's grassland contract policy on Mongolian herders' attitudes towards grassland management in northeastern Inner Mongolia. Journal of Political Ecology 22(1): 79-97.

Daun-Barnett, N. (2011). Community college baccalaureate: A fixed effects, multi-year study of the influence of state policy on nursing degree production. Higher Education Policy 24(3): 377-398. doi: 10.1057/hep.2011.10

De Haan, C., Steinfeld, H., and Blackburn, H. (Eds.), (1996). Livestock and the Environment: Finding a Balance. Commission of the European Communities, World Bank. http://agrienvarchive.ca/bioenergy/download/livestock_env_fao.pdf.

DeFries, R., Hansen, A., Turner, B. L., Reid, R., and Liu, J. G. (2007). Land use change around protected areas: Management to balance human needs and ecological function. Ecological Applications 17(4): 1031-1038. doi: 10.1890/05-1111

Demsetz, H. (1967). Toward a theory of property rights. American Economic Review 62, 347-359.

Deng, S.F., Yang, T.B., Zeng, B., Zhu, X.F., and Xu, H.J. (2013). Vegetation cover variation in the Qilian Mountains and its response to climate change in 2000-2011. Journal of Mountain Science 10: 1050-1062. doi: 10.1007/s11629-013-2558-Z

Deng, X., Huang, J., Huang, Q., Rozelle, S., and Gibson, J. (2011). Do roads lead to grassland degradation or restoration? A case study in Inner Mongolia, China. Environment and Development Economics 16(6): 751-773. doi: 10.1017/s1355770x11000180

Dickinson, D., and Webber, M. (2007). Environmental resettlement and development, on the Steppes of inner Mongolia, PRC. Journal of Development Studies 43: 537-561. doi: $10.1080 / 00220380701204513$ 
Fan, J., Zhong, H., Harris, W., Yu, G., Wang, S., Hu, Z., and Yue, Y. (2008). Carbon storage in the grasslands of China based on field measurements of above- and below-ground biomass. Climatic Change 86(3-4): 375-396. doi: 10.1007/s10584-007-9316-6

Fan, M., Li, Y., and Li, W. (2015). Solving One Problem by Creating a Bigger one: The Consequences of Ecological Resettlement for Grassland Restoration and Poverty Alleviation in Northwestern China. Land Use Policy 42: 124-130. doi: 10.1016/j.landusepol.2014.07.011

FAO. (2008). Are grasslands under threat? Brief analysis of FAO statistical data on pasture and fodder crops (27-1-2016). http://www.fao.org/ag/agp/agpc/doc/grass_stats/grassstats.htm

FAO. (2015). Livestock and the environment. From http://www.fao.org/livestockenvironment/en/

FAO. (2016). Livestock environment and development. From http://www.fao.org/agriculture/lead/lead/networks/china1/en/

Feeny, D., Berkes, F., McCay, B. J., and Acheson, J. M. (1990). The Tragedy of the Commons: Twenty-Two Years Later. Human Ecology 18: 1-19.

Feng, Y., Lu, Q., Tokola, T., Liu, H., and Wang, X. (2009). Assessment of Grassland Degradation in Guinan County Qinghai Province China In the Past 30 Years. Land Degradation and Development 20: 55-68. doi: 10.1002/ldr.877

Fergusson, D. M., Swain-Campbell, N. R., and Horwood, L. J. (2002). Deviant peer affiliations, crime and substance use: A fixed effects regression analysis. Journal of Abnormal Child Psychology 30(4): 419-430. doi: 10.1023/a:1015774125952

Fernandez-Gimenez, M. E. (2000). The role of Mongolian nomadic pastoralists' ecological knowledge in rangeland management. Ecological Applications 10(5): 1318-1326. doi: $10.2307 / 2641287$

Fernandez-Gimenez, M. E. (2002). Spatial and social boundaries and the paradox of pastoral land tenure: A case study from postsocialist Mongolia. Human Ecology 30(1): 49-78. doi: 10.1023/a:1014562913014

Fernandez-Gimenez, M. E., and Le Febre, S. (2006). Mobility in pastoral systems: Dynamic flux or downward trend? International Journal of Sustainable Development and World Ecology 13(5): 341-362.

Fernandez-Gimenez, M. E., Wang, X., Batkhishig, B., Klein, JA., and Reid, RS. (Eds.) (2012). Restoring community connections to the land: Building resilience through community-based rangeland management in China and Mongolia. CABI Publishing: Wallingford, UK

Finan, F., Sadoulet, E., and De Janvry, A. (2005). Measuring the poverty reduction potential of land in rural Mexico. Journal of Development Economics 77(1): 27-51. doi: 10.1016/j.jdeveco.2004.02.004

Galvin, K. A. (2009). Transitions: Pastoralists Living with Change. Annual Review of Anthropology 38: 185-198.

Gao, Q.Z., Wan, Y.F., Xu, H.M., Li, Y., Jiangcun, W.Z., and Borjigidai, A. (2010). Alpine Grassland Degradation Index and Its Response toRecent Climate Variability in Northern Tibet, China. Quaternary International 226: 143-150. DOI: 10.1016/j.quaint.2009.10.035 
Gerlagha, R., and Keyzer, M. A. (2003). Efficiency of conservationist measures: An optimist viewpoint. Journal of Environmental Economics and Management 46(2): 310-333. doi: 10.1016/s0095-0696(02)00037-2

Gerlagh, R., and Keyzer, M. A. (2004). Path-dependence in a Ramsey model with resource amenities and limited regeneration. Journal of Economic Dynamics and Control 28(6):1159-1184. doi: 10.1016/s0165-1889(03)00078-2

Gollier, C. (2010). Ecological discounting. Journal of Economic Theory 145(2): 812-829.

Gong, Z., Kawamura, K., Ishikawa, N., Goto, M., Wulan, T., Alateng, D., Yin, T., and Ito, Y. (2015). MODIS normalized difference vegetation index (NDVI) and vegetation phenology dynamics in the Inner Mongolia grassland. Solid Earth 6: 1185-1194. doi: $10.5194 / \mathrm{se}-6-1185-2015$

Gu, Y., and Li, W. (2013). Research on the "Grazing Ban" Policy's Effect to Grassland Quality: Analysis on the Scale of Herdsman Households. Acta Scientiarum Naturalium Universitatis Pekinensis 49: 288-296 (in Chinese).

Guelke, L. (2003). The Tragedy of Privatisation: Some Environmental Consequences of the Dutch Invasion of Khoikhoi South Africa. South African Geographical Journal 85: 90 98.

Griffin, K. (Eds.) (1995). Poverty and the Transition to a Market Economy in Mongolia. Macmillan: St. Martin's Press.

Han, J.G., Zhang, Y.J., Wang, C.J., Bai, W.M., Wang, Y.R., Han, G.D., and Li, L.H. (2008). Rangeland Degradation and Restoration Management in China. Rangeland Journal 30: 233-239. DOI: $10.1071 /$ rj08009

Hardin, G. (1968). The Tragedy of Commons. Science 162: 1243-1248.

Harris, R. B. (2010). Rangeland degradation on the Qinghai-Tibetan plateau: A review of the evidence of its magnitude and causes. Journal of Arid Environments 74(1): 1-12. doi: 10.1016/j.jaridenv.2009.06.014

Hartter, J., and Ryan, S. J. (2010). Top-down or bottom-up?. Decentralization, natural resource management, and usufruct rights in the forests and wetlands of western Uganda. Land Use Policy 27(3): 815-826. doi: 10.1016/j.landusepol.2009.11.001

He, C., Tian, J., Gao, B., and Zhao, Y. (2014). Differentiating Climate- and Human-induced Drivers of Grassland Degradation in the Liao River Basin, China. Environmental Monitoring and Assessment 187. DOI: 10.1007/s10661-014-4199-2

He, S., and Richards, K. (2015). Impact of Meadow Degradation on Soil Water Status and Pasture Management-A Case Study in Tibet. Land Degradation and Development 26(5): 468-479. doi: 10.1002/ldr.2358

Heijman, W. J., and Mouche, P. (2013). A procedure for determining an optimal landscape and its monetary value. In CMVD Heide and WJM Heijman (Ed.), The Economic Value of Landscapes: 123-129. Routledge: Oxon

Henry, B., Charmley, E., Eckard, R., Gaughan, J. B., and Hegarty, R. (2012). Livestock production in a changing climate: Adaptation and mitigation research in Australia. Crop and Pasture Science 63(3): 191-202. doi: 10.1071/cp11169

Hinton, W. (Eds.) (1990). The Privatisation of China, the Great Reversal. Earthscan Publications: London 
Higgins, S.I., Kantelhardt, J., Scheiter, S., and Boerner, J. 2007. Sustainable management of extensively managed savanna rangelands. Ecological Economics 62: 102-114. doi: 10.1016/j.ecolecon.2006.05.019

Hobbs, N. T., Galvin, K. A., Stokes, C. J., Lackett, J. M., Ash, A. J., Boone, R. B., Reid, R.S., and Thornton, P. K. (2008). Fragmentation of rangelands: Implications for humans, animals, and landscapes. Global Environmental Change 18(4): 776-785. doi: 10.1016/j.gloenvcha.2008.07.011

Holben, B.N. (1986). Characteristics of maximum-value composite images from temporal AVHRR data. International Journal of Remote Sensing 7: 1417-1434. doi: $10.1080 / 01431168608948945$

Homewood, K. (1995). Development, demarcation and ecological outcomes in Maasailand. Africa 65(3): 331-350. doi: 10.2307/1161050

Ho, P. (1996). Ownership and control in Chinese grassland management since Mao: The case of free-riding in Ningxia. Pastoral Development Network Series 39. Overseas Development Institute: London

Ho, P. (2000). The Clash Over State and Collective Property: The Making of The Rangeland law. China Quarterly 161: 240-263.

Ho, P. (2001). Rangeland degradation in North China revisited? A preliminary statistical analysis to validate non-equilibrium range ecology. Journal of Development Studies 37(3): 99-133. doi: 10.1080/00220380412331321991

Ho, P., and Azadi, H. (2010). Rangeland degradation in North China: Perceptions of pastoralists. Environmental Research 110(3): 302-307.

Hobbs, N.T., Galvin, K.A., Stokes, C.J., Lackett, J.M., Ash, A.J., Boone, R.B., Reid, R.S., and Thornton, P.K. (2008). Fragmentation of Rangelands: Implications for Humans, Animals and Landscapes. Global Environmental Change 18: 776-785. DOI: 10.1016/j.gloenvcha.2008.07.011

$\mathrm{Hu}, \mathrm{W}$. (1997). Household land tenure reform in China: Its impact on farming land use and agro-environment. Land Use Policy 14(3): 175-186.

Hua, L., and Squires, V. R. (2015). Managing China's Pastoral Lands: Current Problems and Future Prospects. Land Use Policy 43: 129-137. doi: 10.1016/j.landusepol.2014.11.004

Huang, L., Xiao, T., Zhao, Z., Sun, C., Liu, J., Shao, Q., Fan, J., and Wang, J. (2013). Effects of grassland restoration programs on ecosystems in arid and semiarid China. Journal of Environmental Management 117: 268-275. doi: 10.1016/j.jenvman.2012.12.040

Huang, Q., Rozelle, S., Lohmar, B., Huang, J., and Wang, J. (2006). Irrigation, Agricultural Performance and Poverty Reduction in China. Food Policy 31: 30-52. DOI:10.1016/j.foodpol.2005.06.004

Hua, L., and Squires, V.R. (2015). Managing China's pastoral lands: Current problems and future prospects. Land Use Policy 43: 129-137. doi: 10.1016/j.landusepol.2014.11.004

IFAD. (2009). Livestock and Pastoralists. Livestock Thematic Papers Tools for Project Design http://www.ifad.org/lrkm/factsheet/Pastoralists.pdf.

Kamara, A., Kirk, M., and Swallow, B. (2005). Property rights and land use change: Implications for sustainable resource management in Borana, southern Ethiopia. Journal of Sustainable Agriculture 25(2): 45-61. doi: 10.1300/J064v25n02_05 
Kang, L., Han, X., Zhang, Z., and Sun, O. J. (2007). Grassland ecosystems in China: Review of current knowledge and research advancement. Philosophical Transactions of the Royal Society B: Biological Sciences 362(1482): 997-1008. doi: 10.1098/rstb.2007.2029

Komarek, A. M., Waldron, S. A., and Brown, C. G. (2012). An exploration of livestockdevelopment policies in western china. Food Policy 37(1): 12-20. doi: 10.1016/j.foodpol.2011.10.001

Koo, J. L., Koo, B. L., and Shin, Y. H. (2013). An optimal investment, consumption, leisure, and voluntary retirement problem with Cobb-Douglas utility: Dynamic programming approaches. Applied Mathematics Letters 26 (4): 481-486. doi: 10.1016/j.aml.2012.11.012

Kou, M., Jiao, J., Yin, Q., Wang, N., Wang, Z., Li, Y., Yu, W., Wei, Y., Yan, F., and Cao, B. (2016). Successional Trajectory Over 10 Years of Vegetation Restoration of Abandoned Slope Croplands in the Hill-Gully Region of the Loess Plateau. Land Degradation and Development 27: 919-932. doi: 10.1002/ldr.2356

Krusekopf, C. C. (2002). Diversity in land-tenure arrangements under the household responsibility system in China. China Economic Review 13(2-3): 297-312.

Lee, A.F.S. (1992). Optimal sample sizes determined by two-sample welch's t test. Communications in Statistics - Simulation and Computation 21: 689-696. doi: 10.1080/03610919208813043

Lesorogol, C.K. (2003). Transforming Institutions among Pastoralists: Inequality and Land Privatization. American Anthropologist 105: 531-542.

Lesorogol, C.K. (2008). Land Privatization and Pastoralist Well-being in Kenya. Development and Change 39: 309-331.

Levin, S., Xepapadeas, T., Crepin, A.-S., Norberg, J., De Zeeuw, A., Folke, C., Hughes, T., Arrow, K., Barrett, S., Daily, G., Ehrlich, P., Kautsky, N., Maler, K.-G., Polasky, S., Troell, M., Vincent, J. R., and Walker, B. (2013). Social-ecological systems as complex adaptive systems: modeling and policy implications. Environment and Development Economics 18: 111-132. doi:10.1017/s1355770x12000460

$\mathrm{Li}, \mathrm{J}$. (2012). Land tenure change and sustainable management of alpine grasslands on the tibetan plateau: A case from hongyuan county, Sichuan province, China. Nomadic Peoples 16(1): 36-49.

Li, M., Wu, J., and Deng, X. (2016). Land use change and soil carbon sequestration in China: Where does it pay to conserve? Regional Environmental Change 1-13. doi: 10.1007/s10113-016-0948-9

Li, P. J. (2009). Exponential growth, animal welfare, environmental and food safety impact: The case of China's livestock production. Journal of Agricultural and Environmental Ethics 22(3): 217-240. doi: 10.1007/s10806-008-9140-7

Li, Q.L. (2009). The grey correlative degree analysis between forage yield with temperature and precipitation in natural grasslands. Qinghai Prataculture 18: 12-14. [in Chinese]

Li, S., Verburg, P.H., Lv, S., Wu, J., and Li, X. (2012). Spatial snalysis of the driving factors of grassland degradation under conditions of climate change and intensive use in Inner Mongolia, China. Regional Environmental Change 12: 461-474. 
Li, W., Ali, S.H., and Zhang, Q. (2007). Property rights and grassland degradation: a study of the Xilingol pasture, Inner Mongolia, China. Journal of Environmental Management 85: 461-470. DOI: 10.1016/j.jenvman.2006.10.010

Li, W., and Huntsinger, L. (2011). China's grassland contract policy and its impacts on herder ability to benefit in Inner Mongolia: Tragic feedbacks. Ecology and Society 16(2).

Li, W., Ali, S. H., and Zhang, Q. (2007). Property rights and grassland degradation: A study of the Xilingol Pasture, Inner Mongolia, China. Journal of Environmental Management 85(2): 461-470. doi: 10.1016/j.jenvman.2006.10.010

Li, W., and Zhang, Q. (Eds.) (2009). Interpretation the predicament on pastural area of China: fosucing on the use and management issues for arid and semi-arid grassland. Beijing: Economic Science Press. [in Chinese]

Li, X., Yuan, Q., Wan, L., and He, F. (2008). Perspectives on livestock production systems in China. Rangeland Journal 30(2): 211-220. doi: 10.1071/rj08011

Li, X.B., Li, R.H., Li, G.Q., Wang, H., Li, Z.F., Li, X., and Hou, X.Y. (2016). Humaninduced vegetation degradation and response of soil nitrogen storage in typical steppes in Inner Mongolia, China. Journal of Arid Environments 124: 80-90. DOI: 10.1016/j.jaridenv.2015.07.013

Li, X. L., Gao, J., Brierley, G., Qiao, Y. M., Zhang, J., and Yang, Y. W. (2013). Rangeland degradation on the Qinghai-Tibet plateau: implications for rehabilitation. Land Degradation and Development 24(1): 72-80. doi: 10.1002/ldr.1108

Li, Y., Gong, B., and Li, W. (2014). A review of China's rangeland management policies IIED Country Report. London: IIED.

Liao, Z. (2009). The changes in price of production factors, technology development and grassland tenure. Issues in Agricultural Economy 4: 64-69. doi: 10.13246/j.cnki.iae.2009.04.012. [in Chinese]

Lin, J. Y. (1987). The Household Responsibility System Reform in China: A peasant's institutional choice. American Journal of Agricultural Economics 69(2): 410-415. doi: $10.2307 / 1242295$

Lin, L., Li, Y.K., Xu, X.L., Zhang, F.W., Du, Y.G., Liu, S.L., Guo, X.W., and Cao, G.M. (2015). Predicting parameters of degradation succession processes of Tibetan Kobresia grasslands. Solid Earth 6: 1237-1246. doi: 10.5194/se-6-1237-2015

Little, P. (Eds.) (1992). The elusive granary: herder, farmer and state in Northern Kenya. Cambridge University Press: Cambridge, UK.

Liu, C., Lu, J., and Yin, R. 2010. An estimation of the effects of china's priority forestry programs on farmers' income. Environmental Management 45: 526-540.

Liu, J., Zhang, Z., Xu, X., Kuang, W., Zhou, W., Zhang, S., Li, R., Yan, C., Yu, D., Wu, S., and Jiang, N. (2010). Spatial patterns and driving forces of land use change in China during the early 21 st century. Journal of Geographical Sciences 20 (4): 483-494. doi: $10.1007 / \mathrm{s} 11442-010-0483-4$

Liu, J., and Diamond, J. (2005). China's environment in a globalizing world. Nature 435(7046): 1179-1186.

Liu, M., Dries, L., Heijman, W., Huang, J., Zhu, X., and Deng, X. (2015). Tragedy of the commons or tragedy of privatisation? The impact of land tenure reform on grassland condition in Inner Mongolia, China. (unpublished) 
Liu, M., Dries, L., Heijman, W., Huang, J., Zhu, X., Hu, Y., and Chen, H. (2016). The impact of eco-environmental policies on the condition of grasslands in China's pastoral area. (unpublished)

Liu, S., Yan, D.H., Shi, X.L., Wang, G., Yuan, Z., and Yin, J. (2013). Grassland NDVI response to climate factors in different vegetation regionalizations in China. Communications in Computer and Information Science 399: 370-380.

Lopez, R. A., Shah, F. A., and Altobello, M. A. (1994). Amenity benefits and the optimal allocation of land. Land Economics 70(1): 53-62.

Lu, X., Yan, Y., Sun, J., Zhang, X., Chen, Y., Wang, X., and Cheng, G. (2015). Short-term grazing exclusion has no impact on soil properties and nutrients of degraded alpine grassland in Tibet, China. Solid Earth 6: 1195-1205. doi: 10.5194/se-6-1195-2015

Lv, Y., Zhang, L., Feng, X., Zeng, Y., Fu, B., Yao, X., Li, J., and Wu, B. (2015). Recent ecological transitions in China: Greening, browning, and influential factors. Scientific Reports 5. doi: 10.1038/srep08732

Manne, A., and Rutherford, T. F. (1994). International trade, capital flows and sectoral analysis: formulation and solution of intertemporal equilibrium models. New Directions in Computational Economics. Kluwer Academic Publishers: Dordrecht

Mauerhofer, V. (2011). A bottom-up 'Convention-Check' to improve top-down global protected area governance. Land Use Policy 28(4): 877-886. doi: 10.1016/j.landusepol.2011.03.004

McEvoy, A. F. (1987). Toward an interactive theory of nature and culture: ecology, production, and cognition in the California fishing industry. Environmental Review 11(4): 289-305.

Mei, H., Zhang, G., Gan, X., Ranlong, L., and Han, G. (2013). Carbon and nitrogen storage and loss as affected by grassland degradation in Inner Mongolia, China. Journal of Food, Agriculture and Environment 11(3-4): 2071-2076.

Meng, L., and Gao, H. (2002). The status of grassland degradation of China and the strategies for grassland conservation. Paper presented at the 6th Chinese International Rangeland Congress: Beijing.

Meyer, N. (2006). Desertification and restoration of grasslands in Inner Mongolia. Journal of Forestry 104: 328-331.

Miao, L., Moore, J. C., Zeng, F., Lei, J., Ding, J., He, B., and Cui, X. (2015). Footprint of research in desertification management in China. Land Degradation and Development 26: 450-457. doi: 10.1002/ldr.2399

Millennium Ecosystem Assessment. (2003). Ecosystems and human well-being: a framework for assessment. Island Press: Washington, DC

Ministry of Agriculture of China. (2012). China national grassland monitoring report of 2011. Beijing: Retrieved from http://www.agri.gov.cn/V20/SC/jjps/201204/t20120409_2598547.htm. access: 19 May 2016

Ministry of Agriculture of China. (2014). China national grassland monitoring report of 2013. Beijing: Retrieved from http://www.sdcy.gov.cn/art/2014/7/31/art_5561_82075.html. access: 19 May 2016 
Ministry of Agriculture of China. (2015). China national grassland monitoring report of 2014. Beijing: Retrieved from http://www.moa.gov.cn/zwllm/jcyj/zh/201504/t20150414_4526567.htm. access: 19 May 2016

Ministry of Agriculture of China. (2016). China national grassland monitoring report of 2015. Beijing: Retrieved from http://www.dxddcx.com/news/a/201602/10027.html. access: 19 May 2016

Mullan, K., Kontoleon, A., Swanson, T. M., and Zhang, S. (2010). Evaluation of the impact of the natural forest protection program on rural household livelihoods. Environmental Management 45(3): 513-525. doi: 10.1007/s00267-009-9288-6

Mwangi, E. (Eds.) (2007). Socioeconomic change and land use in Africa : the transformation of property rights in Maasailand. Palgrave Macmillan: New York, US

National Bureau of Statistics of China. (2009). China Statistical Yearbook 2008. Statistics Press: Beijing, China

National People's Congress of the People's Republic of China. (2002). The Grassland Law of The People's Republic of China. Beijing (in Chinese).

National Research Council. (1992). Grasslands and grassland sciences in northern China. National Academy Press: Washington, D.C.

Negishi, T. (Eds.) (1972). General equilibrium theory and international trade. North-Holland Publishing Company: Amsterdam

Niamir-Fuller, M., and Turner, M. D. (1999). A review of recent literature on pastoralism and transhumance in Africa. In M. Niamir-Fuller (Ed.), Managing Mobility in African Rangelands, the Legitimization of Transhumance. Intermediate Technology Publications: London

Nelson, R. (2006). Regulating grassland degradation in China: shallow-rooted laws? AsianPacific Law and Policy Journal 7: 385-416.

Oestreicher, J. S., Benessaiah, K., Ruiz-Jaen, M. C., Sloan, S., Turner, K., Pelletier, J., Guay, B., Clark, K. E., Roche, D. G., Meiners, M., and Potvin, C. (2009). Avoiding deforestation in Panamanian protected areas: An analysis of protection effectiveness and implications for reducing emissions from deforestation and forest degradation. Global Environmental Change 19(2): 279-291. doi: 10.1016/j.gloenvcha.2009.01.003

Ostrom, E. (Eds.) (1990). Governing the commons: the evolution of institutions for collective action. Cambridge University Press: Cambridge.

Ostrom, E., Gardner, R., and Walker, J. (Eds.) (1994). Rules, games, and common-pool resources. The University of Michigan Press: Ann Arbor

Ostrom, E. (1999). Coping with tragedies of the commons. Annual Review of Political Science 2: 493-535.

Ostrom, E. (2007). A diagnostic approach for going beyond panaceas. PNAS 104(39): 1518115187. doi: 10.1073/pnas.0702288104

Ostrom, E. (2009). A general framework for analysing sustainability of social-ecological systems. Science 325 (5939): 419-422. doi: 10.1126/science.1172133

Ostrom, E., and Cox, M. (2010). Moving beyond panaceas: A multi-tiered diagnostic approach for social-ecological analysis. Environmental Conservation 37(4): 451-463. doi: $10.1017 / \mathrm{s} 0376892910000834$ 
Ouyang, Z.Y. (2013). Ecosystem service assessment and applications for conservation policies in China. Paper presented at the Sustainable Natural Resource Management in Rural China -Governing markets? Nanjing, P.R. China.

Pacione, M. (2013). Private profit, public interest and land use planning-A conflict interpretation of residential development pressure in Glasgow's rural-urban fringe. Land Use Policy 32: 61-77.

Parras-Alcántara, L., Díaz-Jaimes, L., and Lozano-García, B. (2015). Management effects on soil organic carbon stock in mediterranean open rangelands-treeless grasslands. Land Degradation and Development 26: 22-34. doi: 10.1002/ldr.2269

Perman, R., Ma, Y., Common, M. S., Maddison, D., and McGilvray, J. (Eds.) (2011). Natural resource and environmental economics (4 ed.). Pearson Education Limited: England

Petit, S. (2009). The dimensions of land use change in rural landscapes: Lessons learnt from the GB Countryside Surveys. Journal of Environmental Management 90(9): 28512856. doi: 10.1016/j.jenvman.2008.05.023

Piao, S., Mohammat, A., Fang, J., Cai, Q., and Feng, J. (2006). NDVI-based increase in growth of temperate grasslands and its responses to climate changes in China. Global Environmental Change 16(4): 340-348. doi: 10.1016/j.gloenvcha.2006.02.002

Pollak, R. A. (1979). Bergson-samuelson social welfare functions and the theory of social choice. Quarterly Journal of Economics 93(1): 73-90.

Pritchett, L., and Woolcock, M. (2004). Solutions when the solution is the problem: Arraying the disarray in development. World Development 32(2): 191-212. doi: 10.1016/j.worlddev.2003.08.009

Qasim, M., Hubacek, K., and Termansen, M. (2013). Underlying and proximate driving causes of land use change in district Swat, Pakistan. Land Use Policy 34: 146-157.

Qu, F., Kuyvenhoven, A., Shi, X., and Heerink, N. (2011). Sustainable natural resource use in rural China: recent trends and policies. China Economic Review 22(4): 444-460. doi: 10.1016/j.chieco.2010.08.005

Rambonilaza, M., and Dachary-Bernard, J. (2007). Land-use planning and public preferences: What can we learn from choice experiment method?" Landscape and Urban Planning 83(4): 318-326. doi: 10.1016/j.landurbplan.2007.05.013

Ren, H., Shen, W. J., Lu, H. F., Wen, X. Y., and Jian, S. G. (2007). Degraded ecosystems in China: Status, causes, and restoration efforts. Landscape and Ecological Engineering 3(1): 1-13. doi: 10.1007/s11355-006-0018-4

Richard, C., Yan, Z., and Du, G. (2006). The Paradox of the individual household responsibility system in the grasslands of the Tibetan plateau, China. Paper presented at the Rangelands of Central Asia: Proceedings of the Conference on Transformations, Issues, and Future Challenges: Salt Lake City, UT.

Saaty, T. (Eds.) (1980). The analytic hierarchy process. McGraw-Hill: New York

Saaty, T. (1990). How to make a decision: The analytic hierarchy process. European Journal of Operational Research 48(1): 9-26.

Senay, G.B., and Elliott, R.L. (2000). Combining AVHRR-NDVI and landuse data to describe temporal and spatial dynamics of vegetation. Forest Ecology and Management 128: 83-91. doi: 10.1016/s0378-1127(99)00275-3 
Schoon, M. L. (2008). Building robustness to disturbance: Governance in southern African peace parks. (Ph.D Dissertation), Indiana University (3344618)

Sheehy, D. P., Miller, D., and Johnson, D. A. (2006). Transformation of traditional pastoral livestock systems on the Tibetan steppe. Science et changements planétaires/Sécheresse 17(1): 142-151.

Sneath, D. (1998). State Policy and Pasture Degradation in Inner Asia. Science 281(5380): 1147-1148.

Squires, V. R., Lu, X.S., Lu, Q., Wang, T., and Yang, Y.L. (Eds.) (2009). Rangeland degradation and recovery in China's pastoral lands. CABI: Wallingford, UK

State Council of the People's Republic of China. (2010). The decision of establishing the subsidy and incentive system for grassland conservation by the State Council of the People's Republic of China. The Central People's Government of the People's Republic of China: Beijing. Retrieved from http://www.gov.cn/ldhd/201010/12/content_1720555.htm. access: 19 May 2016

Stanton, E. A. 2011. Negishi welfare weights in integrated assessment models: The mathematics of global inequality. Climatic Change 107(3): 417-432.

$\mathrm{Su}, \mathrm{Y}$. (2010). Research on the competitiveness of grassland animal husbandry in Inner Mongolia. Inner Mongolia University Press: Hohhot [in Chinese]

Sullivan, S., and Rohde, R. (2002). On non-equilibrium in arid and semi-arid grazing systems. Journal of Biogeography 29(12): 1595-1618. doi: 10.1046/j.1365-2699.2002.00799.x

Suttie, J. M., Reynolds, S. G., and Batello, C. (Eds.) (2005). Grasslands of the World. Food and Agricultural Organization of the United Nations: Rome

Tan M, and Li X. (2015). Does the green great wall effectively decrease dust storm intensity in China? A study based on NOAA NDVI and weather station data. Land Use Policy 43: 42-47. doi: 10.1016/j.landusepol.2014.10.017

Taylor, J. L. (2006). Negotiating the grassland: The policy of pasture enclosures and contested resource use in Inner Mongolia. Human Organization 65(4): 374-386.

Tessema, W. K., Ingenbleek, P. T. M., and Van Trijp, H. C. M. (2014). Pastoralism, sustainability, and marketing. A review. Agronomy for Sustainable Development 34(1): 75-92. doi: 10.1007/s13593-013-0167-4

Tilt, B. (2008). Smallholders and the 'household responsibility system': Adapting to institutional change in Chinese agriculture. Human Ecology 36(2): 189-199. doi: 10.1007/s10745-007-9127-4

Train, K., and McFadden, D. (1978). The goods/leisure trade-off and disaggregate work trip mode choice models. Transportation Research 12(5): 349 -353.

Turner Ii, B. L., Moss, R. H., and Skole, D. L. (1993). Relating land use and global landcover change. A proposal for an IGBP-HDP core project.

Turner Ii, B. L., Meyer, W. B., and Skole, D. L. (1994). Global land-use/land-cover change: towards an integrated study. AMBIO 23(1): 91-95.

Turner, M. D. (1999). The role of social networks, indefinite boundaries and political bargaining in maintaining the ecological and economic resilience of the transhumance systems of sudano-sahelian west africa. In M. Niamir-Fuller (Ed.), Managing mobility in african rangelands: the legitimization of transhumance. Intermediate Technology Publications Ltd, London. 
Unkovich, M., and Nan, Z. (2008). Problems and prospects of grassland agroecosystems in western China. Agriculture, Ecosystems and Environment 124(1-2): 1-2. doi: 10.1016/j.agee.2007.08.012

Urwin, K., and Jordan, A. (2008). Does public policy support or undermine climate change adaptation? Exploring policy interplay across different scales of governance. Global Environmental Change 18(1): 180-191. doi: 10.1016/j.gloenvcha.2007.08.002

Vaidya, O. S., and Kumar, S. (2006). Analytic hierarchy process: An overview of applications. European Journal of Operational Research 169(1): 1-29.

Vargas, L. G. (1990). An overview of the analytic hierarchy process and its applications. European Journal of Operational Research 48(1): 2-8. doi: 10.1016/03772217(90)90056-h

Vasconcelos, V. V., Santos, F. C., and Pacheco, J. M. (2013). A bottom-up institutional approach to cooperative governance of risky commons. Nature Climate Change 3(9): 797-801. doi: 10.1038/nclimate1927

Verbeek, M. (Eds.) (2012). Models Based on Panel Data: A guide to modern econometrics (4 ed.). John Wiley and Sons Ltd: United Kingdom.

Verburg, P. H., Eickhout, B., and Van Meijl, H. (2008). A multi-scale, multi-model approach for analyzing the future dynamics of European land use. Annals of Regional Science 42(1): 57-77. doi: 10.1007/s00168-007-0136-4

Vetter, S. (2005). Rangelands at Equilibrium and Non-equilibrium: Recent developments in the debate. Journal of Arid Environments 62: 321-341. DOI: 10.1016/j.jaridenv.2004.11.015

Waldron, S., Brown, C., Longworth, J., and Cungen, Z. (Eds.) (2007). China's livestock revolution: Agribusiness and policy developments in the sheep meat industry. Athenaeum Press: Gateshead, UK

Waldron, S., Brown, C., and Longworth, J. (2010). Grassland degradation and livelihoods in China's western pastoral region: A framework for understanding and refining China's recent policy responses. China Agricultural Economic Review 2(3): 298-320. doi: 10.1108/17561371011078435

Wang, J., Brown, D. G., and Agrawal, A. (2013). Climate adaptation, local institutions, and rural livelihoods: A comparative study of herder communities in Mongolia and Inner Mongolia, China. Global Environmental Change 23(6): 1673-1683. doi: 10.1016/j.gloenvcha.2013.08.014

Wang, X. (2009). From 'rangeland leasing' to 'recentralization in rangeland conservation'— policies of rangeland conservation in North China. China Rural Survey 27(1): 3646.

Williams, K. J. H., and Schirmer, J. (2012). Understanding the relationship between social change and its impacts: The experience of rural land use change in south-eastern Australia. Journal of Rural Studies 28(4): 538-548. doi: 10.1016/j.jrurstud.2012.05.002

Wu, D., Gao, P., and Dong, J. (2012). Impact of subsidy on low-rent housing lessees' welfare in China. International Journal of Information Technology and Decision Making 11(3): 643-660. 
Wu, J., Zhang, Q., Li, A., and Liang, C. (2015). Historical landscape dynamics of Inner Mongolia: patterns, drivers, and impacts. Landscape Ecology 30(9): 1579-1598. doi: 10.1007/s10980-015-0209-1

Wu, Z., and Du, W. (2008). Pastoral nomad rights in Inner Mongolia. Nomadic Peoples 12(2): 13-33. doi: 10.3167/np.2008.120202

Wu, Z.Y. (Eds.) (1980). China's vegetation. Science press: Beijing, China

Yan, J., Wu, Y., and Zhang, Y. (2011). Adaptation strategies to pasture degradation: Gap between government and local nomads in the eastern Tibetan Plateau. Journal of Geographical Sciences 21(6): 1112-1122. doi: 10.1007/s11442-011-0904-Z

Yan, Z., Wu, N., Dorji, Y., and Ru, J. (2005). A review of rangeland privatisation and its implications in the Tibetan Plateau, China. Nomadic Peoples 9(1-2): 31-51.

Yang, D., Zhang, Y., Wu, Y., Wang, D., Bao, C., (2004). The problems and sustainable development of pratacultural industry in Hulunbeier. Grassland and Turf (Quarterly) $1,14-16$.

Yang, Y. F., Niu, P., and Zhu, L. Q. (2012). Study on the evaluation of rural land-use conflict intensity. Journal of Food, Agriculture and Environment 10(3-4): 1479-1482.

Yang, L. (2007). Grassland management: how to improve the implementation of Household Production Responsibility System in the pastoral areas of China. Chinese Rural Economy: 62-67. [in Chinese]

Yang, L., Wylie, B.K., Tieszen, L.L., and Reed, B.C. (1998). An analysis of relationships among climate forcing and time-integrated NDVI of grasslands over the U.S. northern and central Great Plains. Remote Sensing of Environment 65: 25-37. doi: 10.1016/s0034-4257(98)00012-1

Yang, X.H., Zhang, K.B., and Hou, R.P. (2005). Impacts of exclusion on vegetative features and aboveground biomass in semi-arid degraded rangeland. Ecology and Environment 14: 730-734.

Yang, Z., and Nordhaus, W. D. (2006). Magnitude and direction of technological transfers for mitigating GHG emissions. Energy Economics 28(5-6): 730-741. doi: 10.1016/j.eneco.2006.05.015

Ybarra, M. (2009). Violent visions of an ownership society: The land administration project in Petén, Guatemala. Land Use Policy 26(1): 44-54.

Yeh, ET. (2005). Green governmentality and pastoralism in Western China: 'Converting pastures to grasslands'. Nomadic Peoples 9: 9-29.

Yuan, J., Ouyang, Z., Zheng, H., and Xu, W. (2011). The research on the ecosystem management in the eco-fragile regions of China. China Population, Resources and Environment 21(3): 97-99.

Yu, L., and Farrell, K. N. (2013). Individualized pastureland use: responses of herders to institutional arrangements in pastoral China. Human Ecology 41(5): 759-771. doi: 10.1007/s10745-013-9580-1

Zhan, J. Y., Deng, X. Z., Jiang, Q., and Shi, N. (2007). The application of system dynamics and CLUE-S model in land use change dynamic simulation: a case study in Taips County, inner Mongolia of China. Proceedings Paper. Conference on Systems Science, Management Science and System Dynamics. 
Zhang, H., Buongiorno, J., and Zhu, S. (2012a). Domestic and foreign consequences of China's land tenure reform on collective forests. International Forestry Review 14(3): 349-362. doi: 10.1505/146554812802646648

Zhang, K., Yu, Z., Li, X., Zhou ,W., and Zhang, D. (2007). Land use change and land degradation in China from 1991 to 2001. Land Degradation and Development 18: 209-219. DOI: $10.1002 / 1 \mathrm{dr} .757$

Zhang, L., Pan, J., and Chen, J. (2012). The optimal scale of livestock production in differnt types of rangelands. Issues in Agricultural Economy 4: 90-97. [in Chinese]

Zhang, J., Zhang, L., Liu, W., Qi, Y., and Wo, X. (2014). Livestock-carrying capacity and overgrazing status of alpine grassland in the Three-River Headwaters region, China. Journal of Geographical Sciences 24: 303-312. doi: 10.1007/s11442-014-1089-Z

Zhang, W.N., Ganjurjav, H., Liang, Y., Gao, Q.Z., Wan, Y.F., Li, Y., Baima, Y.Z., and Xirao, Z.M. (2015). Effect of a grazing ban on restoring the degraded alpine meadows of Northern Tibet, China. Rangeland Journal 37: 89-95. doi: 10.1071/rj14092

Zhao, J., and Guo, J. (2009). Study on statistic models of drought prediction for grassland in Inner Mongolia. Pratacultural Science 26: 14-19.

Zheng, Y. R., Xie, Z. X., Robert, C., Jiang, L. H., and Shimizu, H. (2006). Did climate drive ecosystem change and induce desertification in Otindag sandy land, China over the past 40 years?" Journal of Arid Environments 64(3): 523-541.

Zhou, G., Wang, Y., and Wang, S. (2002). Responses of grassland ecosystems to precipitation and land use along the Northeast China Transect. Journal of Vegetation Science 13: 361-368.

Zhu, X. (2004). Environmental-economic modelling of novel protein foods: A general equilibrium approach. Ph.D Thesis. Social Sciences, Wageningen University, Wageningen.

Zhu, X., and van Ierland, E. (2006). The enlargement of the European Union: Effects on trade and emissions of greenhouse gases. Ecological Economics 57(1): 1-14. doi:

10.1016/j.ecolecon.2005.03.030 


\section{Appendixes}

Appendix 2-A: Derivation of the individually optimal allocation of land

For the individual optimal allocation of land, each stakeholder type $i$ ( $i=1,23$ and 4 representing four stakeholder types, including the herders, the farmers, the ecological public authorities and economic public authorities) maximizes its utility function by choosing the amounts of land for different purposes. That is:

$$
M A X U_{i}=l_{\text {cul(i) }}^{a_{i}} l_{\text {ran(i) }}^{b_{i}} l_{\text {for }(i)}^{c_{i}} l_{\text {oth(i) }}^{d_{i}}
$$

Subject to:

$$
l_{\text {cul }(i)}+l_{\text {ran }(i)}+l_{\text {for }(i)}+l_{o t h(i)}=L,
$$

where $\quad l_{\text {cul }(i)}, l_{\text {ran }(i)}, l_{\text {for }(i)}, l_{\text {oth }(i)} \geq 0 ; 0 \leq a_{i}, b_{i}, c_{i}, d_{i} \leq 1 ; a_{i}+b_{i}+c_{i}+d_{i}=1$

The logarithmic transformation of the utility function gives:

$$
u_{i}=\ln U_{i}=a_{i} \ln l_{c u l(i)}+b_{i} \ln l_{\text {ran }(i)}+c_{i} \ln l_{f o r(i)}+d_{i} \ln l_{\text {oth }(i)} .
$$

The Lagrange function is then:

$$
\begin{aligned}
L u_{i}= & a_{i} \ln l_{\operatorname{cul}(i)}+b_{i} \ln l_{\text {ran }(i)}+c_{i} \ln l_{\text {for }(i)}+d_{i} \ln l_{\text {oth }(i)} \\
& +\lambda\left(L-l_{\operatorname{cro}(i)}-l_{\text {ran }(i)}-l_{f o r(i)}-l_{\text {oth }(i)}\right)
\end{aligned}
$$

Taking the partial derivations of $\mathrm{Lu}_{\mathrm{i}}$ with respect to each variable, and setting the first order condition gives:

$$
\begin{gathered}
\frac{\partial L u_{i}}{\partial l_{\text {cul }(i)}}=\frac{a_{i}}{l_{\text {far }(i)}}-\lambda=0, \\
\frac{\partial L u_{i}}{\partial l_{\text {ran }(i)}}=\frac{b_{i}}{l_{\text {ran }(i)}}-\lambda=0, \\
\frac{\partial L u_{i}}{\partial l_{\text {for }(i)}}=\frac{c_{i}}{l_{\text {for }(i)}}-\lambda=0, \\
\frac{\partial L u_{i}}{\partial l_{\text {oth }(i)}}=\frac{d_{i}}{l_{\text {oth }(i)}}-\lambda=0 .
\end{gathered}
$$


Combining (2A.5) to (2A.8) gives:

$$
\frac{a_{i}}{l_{\text {cul }(i)}}=\frac{b_{i}}{l_{\text {ran }(i)}}=\frac{c_{i}}{l_{\text {for }(i)}}=\frac{d_{i}}{l_{\text {oth }(i)}},
$$

Or :

$$
a_{i} l_{\text {ran }(i)}=b_{i} l_{\text {cul }(i)}, a_{i} l_{\text {for }(i)}=c_{i} l_{\text {cul }(i)}, a_{i} l_{\text {oth }(i)}=d_{i} l_{\text {cul }(i)} .
$$

Combining (A2) with (A9), we have:

$$
\frac{a_{i}}{l_{\operatorname{cul}(i)}}=\frac{a_{i}}{L-l_{\text {ran }(i)}-l_{\text {for }(i)}-l_{\text {oth }(i)}}
$$

Rearrange (A10) and (A11) combined with $a_{i}+b_{i}+c_{i}+d_{i}=1$, we obtain:

$$
\begin{aligned}
& l_{\text {cul }(i)}^{0}=a_{i} \times L, \\
& l_{\text {ran }(i)}^{0}=b_{i} \times L, \\
& l_{\text {for }(i)}^{0}=c_{i} \times L, \\
& l_{o t h(i)}^{0}=d_{i} \times L,
\end{aligned}
$$

This completes the proof of equation (3) to (6) in the main text of Chapter 2. 
Appendix 2-B: Derivation of the socially optimal allocation of land

For the social optimal allocation of land, maximizing the social welfare is:

$$
M A X W=\prod_{i=1}^{4} U_{i}^{\beta_{i}}
$$

Subject to:

$$
l_{\text {cul }(s)}+l_{\text {ran }(s)}+l_{\text {for }(s)}+l_{\text {oth }(s)}=L,
$$

where $\sum_{i=1}^{4} \beta_{i}=1, . \beta_{i} \geq 0,0 \leq a_{i}, b_{i}, c_{i}, d_{i} \leq 1 ; l_{\text {culs }}, l_{\text {rans }}, l_{\text {fors }}, l_{\text {oths }} \geq 0 ; \sum_{i=1}^{4} \beta_{i}$

$$
=1 \text { and } \beta_{i} \geq 0
$$

Plugging equation (2A.1) into (2B.1), we obtain:

$$
\begin{gathered}
W=\left(l_{\text {cul }(s)}^{a_{1}} l_{\text {ran }(s)}^{b_{1}} l_{\text {for }(s)}^{c_{1}} l_{\text {oth }(s)}^{d_{1}}\right)^{\beta_{1}} *\left(l_{\text {cul }(s)}^{a_{2}} l_{\text {ran }(s)}^{b_{2}} l_{\text {for }(s)}^{c_{2}} l_{\text {oth }(s)}^{d_{2}}\right)^{\beta_{2}} \\
*\left(l_{\text {cul }(s)}^{a_{3}} l_{\text {ran }(s)}^{b_{3}} l_{\text {for }(s)}^{c_{3}} l_{\text {oth }(s)}^{d_{3}}\right)^{\beta_{3}} \\
*\left(l_{\text {cul }(s)}^{a_{4}} l_{\text {ran }(s)}^{b_{4}} l_{\text {for }(s)}^{c_{4}} l_{\text {oth }(s)}^{d_{4}}\right)^{\beta_{4}}
\end{gathered}
$$

The logarithmic transformation of the social welfare function is:

$$
\begin{aligned}
w=\ln W=\beta_{1} & \left.\ln \left(l_{\text {cul }(s)}^{a_{1}} l_{\text {ran }(s)}^{b_{1}} l_{\text {for }(s)}^{c_{1}} l_{\text {oth }(s)}^{d_{1}}\right)+\beta_{2} \ln \left(l_{\text {cul }(s)}^{a_{2}} l_{\text {ran }(s)}^{b_{2}} l_{\text {for }(s)}^{c_{2}}\right)\right) \\
& +\beta_{3} \ln \left(l_{\text {cul }(s)}^{a_{3}} l_{\text {ran }(s)}^{b_{3}} l_{\text {for }(s)}^{c_{3}} l_{\text {oth }(s)}^{d_{3}}\right) \\
& +\beta_{4} \ln \left(l_{\text {cul }(s)}^{a_{4}} l_{\text {ran }(s)}^{b_{4}} l_{\text {for }(s)}^{c_{4}} l_{\text {oth }(s)}^{d_{4}}\right)
\end{aligned}
$$

The Lagrange function is then:

$$
\begin{aligned}
L w=\beta_{1} \ln \left(l_{\text {cul }(s)}^{a_{1}} l_{\text {gra }}^{b_{1}} l_{\text {for }(s)} l_{\text {oth }(s)}^{d_{1}}\right)+\beta_{2} \ln \left(l_{\text {cul }(s)}^{a_{2}} l_{\text {ran }(s)}^{b_{2}} l_{\text {for }(s)}^{c_{2}} l_{\text {oth }(s)}^{d_{2}}\right) & \\
& +\beta_{3} \ln \left(l_{\text {cul }(s)}^{a_{3}} l_{\text {ran }(s)}^{b_{3}} l_{\text {for }(s)}^{c_{3}} l_{\text {oth }(s)}^{d_{3}}\right)+\beta_{4} \ln \left(l_{\text {cul }(s)}^{a_{4}} l_{\text {ran }(s)}^{b_{4}} l_{\text {for }(s)}^{c_{4}} l_{\text {oth }(s)}^{d_{4}}\right) \\
& +\lambda\left(L-l_{\text {cul }(s)}-l_{\text {ran }(s)}-l_{\text {for }(s)}-l_{\text {oth }(s)}\right)
\end{aligned}
$$

Taking the partial derivations of $L w$ with respect to each variable, and setting the first order condition gives: 


$$
\begin{gathered}
\frac{\partial L w}{\partial l_{\text {cul }(s)}}=\frac{\sum_{i=1}^{4} \beta_{i} a_{i}}{l_{\text {cul }(s)}}-\lambda=0, \\
\frac{\partial L w}{\partial l_{\text {ran }(s)}}=\frac{\sum_{i=1}^{4} \beta_{i} b_{i}}{l_{\text {ran }(s)}}-\lambda=0, \\
\frac{\partial L w}{\partial l_{\text {for }(s)}}=\frac{\sum_{i=1}^{4} \beta_{i} c_{i}}{l_{\text {for }(s)}}-\lambda=0, \\
\frac{\partial L w}{\partial l_{\text {oth }(s)}}=\frac{\sum_{i=1}^{4} \beta_{i} d_{i}}{l_{\text {oth }(s)}}-\lambda=0,
\end{gathered}
$$

Combining (B6) to (B9) gives:

$$
\frac{\sum_{i=1}^{4} \beta_{i} a_{i}}{l_{\text {cul }(s)}}=\frac{\sum_{i=1}^{4} \beta_{i} b_{i}}{l_{\text {ran }(s)}}=\frac{\sum_{i=1}^{4} \beta_{i} c_{i}}{l_{\text {for }(s)}}=\frac{\sum_{i=1}^{4} \beta_{i} d_{i}}{l_{\text {oth }(s)}},
$$

Or:

$$
\begin{aligned}
& \sum_{i=1}^{4} \beta_{i} a_{i} l_{\text {ran }(s)}=\sum_{i=1}^{4} \beta_{i} b_{i} l_{\text {far }(s)} \\
& \sum_{i=1}^{4} \beta_{i} a_{i} l_{\text {for }(s)}=\sum_{i=1}^{4} \beta_{i} c_{i} l_{\text {far }(s)}, \\
& \sum_{i=1}^{4} \beta_{i} a_{i} l_{\text {oth }(s)}=\sum_{i=1}^{4} \beta_{i} d_{i} l_{\text {far }(s)} .
\end{aligned}
$$

Combining (B2) with (B10), we have:

$$
\frac{\sum_{i=1}^{4} \beta_{i} a_{i}}{l_{\operatorname{cul}(s)}}=\frac{\sum_{i=1}^{4} \beta_{i} a_{i}}{L-l_{\operatorname{ran}(s)}-l_{\text {for }(s)}-l_{\text {oth }(s)}},
$$

Plug (B11)(B12) and (B13)into (B14), we obtain:

$$
l_{c u l(s)}^{*}=\frac{\sum_{i=1}^{4} \beta_{i} a_{i}}{\sum_{i=1}^{4} \beta_{i} a_{i}+\sum_{i=1}^{4} \beta_{i} b_{i}+\sum_{i=1}^{4} \beta_{i} c_{i}+\sum_{i=1}^{4} \beta_{i} d_{i}} L,
$$




$$
\begin{aligned}
& l_{\text {ran }(s)}^{*}=\frac{\sum_{i=1}^{4} \beta_{i} b_{i}}{\sum_{i=1}^{4} \beta_{i} a_{i}+\sum_{i=1}^{4} \beta_{i} b_{i}+\sum_{i=1}^{4} \beta_{i} c_{i}+\sum_{i=1}^{4} \beta_{i} d_{i}} L, \\
& l_{\text {for }(s)}^{*}=\frac{\sum_{i=1}^{4} \beta_{i} c_{i}}{\sum_{i=1}^{4} \beta_{i} a_{i}+\sum_{i=1}^{4} \beta_{i} b_{i}+\sum_{i=1}^{4} \beta_{i} c_{i}+\sum_{i=1}^{4} \beta_{i} d_{i}} L, \\
& l_{\text {oth }(s)}^{*}=\frac{\sum_{i=1}^{4} \beta_{i} d_{i}}{\sum_{i=1}^{4} \beta_{i} a_{i}+\sum_{i=1}^{4} \beta_{i} b_{i}+\sum_{i=1}^{4} \beta_{i} c_{i}+\sum_{i=1}^{4} \beta_{i} d_{i}} L,
\end{aligned}
$$

Since $\sum_{i=1}^{4} \beta_{i} a_{i}+\sum_{i=1}^{4} \beta_{i} b_{i}+\sum_{i=1}^{4} \beta_{i} c_{i}+\sum_{i=1}^{4} \beta_{i} d_{i}=1$

We have:

$$
\begin{aligned}
& l_{\text {cul }(s)}^{*}=L \times \sum_{i=1}^{4} \beta_{i} a_{i} \\
& l_{\text {ran }(s)}^{*}=L \times \sum_{i=1}^{4} \beta_{i} b_{i} \\
& l_{\text {for }(s)}^{*}=L \times \sum_{i=1}^{4} \beta_{i} c_{i} \\
& l_{\text {oth }(s)}^{*}=L \times \sum_{i=1}^{4} \beta_{i} d_{i}
\end{aligned}
$$

This completes the proof of equation (9) to (12) in the main text of Chapter 2. 
Appendix 2-C: Questionnaires and results of Analytic Hierarchy Process

Appendix 2-C1: Questionnaires of Analytic Hierarchy Process

1. Which is your stakeholder type in rural land allocation?
a. Herder
b. Farmer
c. Economic authorities
d. Ecological authorities

2. Comparing the economic benefit and ecological benefit of rural land, which one concerning the efficient allocation of rural land is more important for you, and how much important?

Economic benefit

Ecological benefit

\begin{tabular}{|l|l|l|l|l|l|l|l|l|l|l|l|l|l|l|l|l|}
\hline 9 & 8 & 7 & 6 & 5 & 4 & 3 & 2 & 1 & 2 & 3 & 4 & 5 & 6 & 7 & 8 & 9 \\
\hline
\end{tabular}

3. Comparing the cultivated land and grassland, which one concerning the economic benefit is more beneficial to you, and how many benefits?

Cultivated land

Grassland

\begin{tabular}{|l|l|l|l|l|l|l|l|l|l|l|l|l|l|l|l|l|}
\hline 9 & 8 & 7 & 6 & 5 & 4 & 3 & 2 & 1 & 2 & 3 & 4 & 5 & 6 & 7 & 8 & 9 \\
\hline
\end{tabular}

4. Comparing the cultivated land and forest land, which one concerning the economic benefit is more beneficial to you, and how many benefits?

Cultivated land

Forest land

\begin{tabular}{|l|l|l|l|l|l|l|l|l|l|l|l|l|l|l|l|l|}
\hline 9 & 8 & 7 & 6 & 5 & 4 & 3 & 2 & 1 & 2 & 3 & 4 & 5 & 6 & 7 & 8 & 9 \\
\hline
\end{tabular}

5. Comparing the cultivated land and other rural land, which one concerning the economic benefit is more beneficial to you, and how many benefits?

Cultivated land

Other rural land

\begin{tabular}{|l|l|l|l|l|l|l|l|l|l|l|l|l|l|l|l|l|}
\hline 9 & 8 & 7 & 6 & 5 & 4 & 3 & 2 & 1 & 2 & 3 & 4 & 5 & 6 & 7 & 8 & 9 \\
\hline
\end{tabular}

6. Comparing the grassland and forest land, which one concerning the economic benefit is more beneficial to you, and how many benefits?

Grassland

Forest land

\begin{tabular}{|l|l|l|l|l|l|l|l|l|l|l|l|l|l|l|l|l|}
\hline 9 & 8 & 7 & 6 & 5 & 4 & 3 & 2 & 1 & 2 & 3 & 4 & 5 & 6 & 7 & 8 & 9 \\
\hline
\end{tabular}

7. Comparing the grassland and other rural land, which one concerning the economic benefit is more beneficial to you, and how many benefits?

Grassland

Other rural land

\begin{tabular}{|l|l|l|l|l|l|l|l|l|l|l|l|l|l|l|l|l|}
\hline 9 & 8 & 7 & 6 & 5 & 4 & 3 & 2 & 1 & 2 & 3 & 4 & 5 & 6 & 7 & 8 & 9 \\
\hline
\end{tabular}


8. Comparing the forest land and other rural land, which one concerning the economic benefit is more beneficial to you, and how many benefits?

Forest land

Other rural land

\begin{tabular}{|l|l|l|l|l|l|l|l|l|l|l|l|l|l|l|l|l|}
\hline 9 & 8 & 7 & 6 & 5 & 4 & 3 & 2 & 1 & 2 & 3 & 4 & 5 & 6 & 7 & 8 & 9 \\
\hline
\end{tabular}

9. Comparing the cultivated land and grassland, which one concerning the ecological benefit is more beneficial to you, and how many benefits?

Cultivated land

\begin{tabular}{|l|l|l|l|l|l|l|l|l|l|l|l|l|l|l|l|l|}
\hline 9 & 8 & 7 & 6 & 5 & 4 & 3 & 2 & 1 & 2 & 3 & 4 & 5 & 6 & 7 & 8 & 9 \\
\hline
\end{tabular}

10. Comparing the cultivated land and forest land, which one concerning the ecological benefit is more beneficial to you, and how many benefits?

Cultivated land

Forest land

\begin{tabular}{|l|l|l|l|l|l|l|l|l|l|l|l|l|l|l|l|l|}
\hline 9 & 8 & 7 & 6 & 5 & 4 & 3 & 2 & 1 & 2 & 3 & 4 & 5 & 6 & 7 & 8 & 9 \\
\hline
\end{tabular}

11. Comparing the cultivated land and other rural land, which one concerning the ecological benefit is more beneficial to you, and how many benefits?

Cultivated land

Other rural land

\begin{tabular}{|l|l|l|l|l|l|l|l|l|l|l|l|l|l|l|l|l|}
\hline 9 & 8 & 7 & 6 & 5 & 4 & 3 & 2 & 1 & 2 & 3 & 4 & 5 & 6 & 7 & 8 & 9 \\
\hline
\end{tabular}

12. Comparing the grassland and forest land, which one concerning the ecological benefit is more beneficial to you, and how many benefits?

Grassland

Forest land

\begin{tabular}{|l|l|l|l|l|l|l|l|l|l|l|l|l|l|l|l|l|}
\hline 9 & 8 & 7 & 6 & 5 & 4 & 3 & 2 & 1 & 2 & 3 & 4 & 5 & 6 & 7 & 8 & 9 \\
\hline
\end{tabular}

13. Comparing the grassland and other rural land, which one concerning the ecological benefit is more beneficial to you, and how many benefits?

Grassland

Other rural land

\begin{tabular}{|l|l|l|l|l|l|l|l|l|l|l|l|l|l|l|l|l|}
\hline 9 & 8 & 7 & 6 & 5 & 4 & 3 & 2 & 1 & 2 & 3 & 4 & 5 & 6 & 7 & 8 & 9 \\
\hline
\end{tabular}

14. Comparing the forest land and other rural land, which one concerning the ecological benefit is more beneficial to you, and how many benefits?

Forest land

Other rural land

\begin{tabular}{|l|l|l|l|l|l|l|l|l|l|l|l|l|l|l|l|l|}
\hline 9 & 8 & 7 & 6 & 5 & 4 & 3 & 2 & 1 & 2 & 3 & 4 & 5 & 6 & 7 & 8 & 9 \\
\hline
\end{tabular}

Note: other rural land indicates land used for raising animals, agricultural facilities, agricultural roads, pit-ponds, fishponds, irrigation, drying grains and forming ridges among croplands.

For above scoring in paired comparisons, the following Fundamental Scale is used to make judgments:1= Equal; 2=Between Equal and Moderate; 3=Moderate; $4=$ Between Moderate and Strong; $5=$ Strong; 6=Between Strong and Very Strong; 7=Very Strong; 8=Between Very Strong and Extreme; 9=Extreme 
Appendix 2-C2: Results of Analytic Hierarchy Process

Based on the data from above questionnaires, we employ Super Decisions software to calculate every stakeholder's preference on four types of rural land. And then we take the average value of all representatives of each stakeholder type to represent each stakeholder type's decision in allocation of rural land.

Table 2-C1 Values of $a_{1}, b_{1}, c_{1}$ and $d_{1}$ (herders)

\begin{tabular}{lllll}
\hline \hline \multicolumn{5}{l}{ Weights for interviewees in the herder type } \\
\hline Alternatives Cultivated land & $\begin{array}{l}\text { Grassland } \\
\left(a_{1}\right)\end{array}$ & $\begin{array}{l}\text { Forest land } \\
\left(c_{1}\right)\end{array}$ & $\begin{array}{l}\text { Other rural land } \\
\left(d_{1}\right)\end{array}$ \\
\hline 1 & 0.1377 & 0.6311 & 0.1032 & 0.1279 \\
2 & 0.1207 & 0.6529 & 0.1120 & 0.1145 \\
3 & 0.1232 & 0.5577 & 0.1877 & 0.1314 \\
4 & 0.2252 & 0.5715 & 0.1381 & 0.0651 \\
5 & 0.1730 & 0.5388 & 0.1653 & 0.1230 \\
6 & 0.2014 & 0.5049 & 0.2174 & 0.0763 \\
7 & 0.2781 & 0.4993 & 0.1336 & 0.0890 \\
8 & 0.1836 & 0.3494 & 0.2909 & 0.1760 \\
9 & 0.2409 & 0.5294 & 0.1372 & 0.0925 \\
10 & 0.2464 & 0.4913 & 0.1615 & 0.1007 \\
11 & 0.1907 & 0.5105 & 0.1716 & 0.1271 \\
12 & 0.2679 & 0.5079 & 0.1565 & 0.0676 \\
13 & 0.1254 & 0.6754 & 0.1069 & 0.0923 \\
14 & 0.3548 & 0.4256 & 0.1487 & 0.0708 \\
15 & 0.2573 & 0.4838 & 0.1779 & 0.0811 \\
\hline Average & 0.2084 & 0.5286 & 0.1606 & 0.1024 \\
Variance & 0.0046 & 0.0070 & 0.0023 & 0.0009 \\
\hline \hline
\end{tabular}


Table 2-C2 Values of $a_{2}, b_{2}, c_{2}$ and $d_{2}$ (farmers)

\begin{tabular}{lllll}
\hline \hline \multicolumn{5}{l}{ Weights for interviewees in the farmer type } \\
\hline Alternatives & $\begin{array}{l}\text { Cultivated land } \\
\left(a_{2}\right)\end{array}$ & $\begin{array}{l}\text { Grassland } \\
\left(b_{2}\right)\end{array}$ & $\begin{array}{l}\text { Forest land } \\
\left(c_{2}\right)\end{array}$ & $\begin{array}{l}\text { Other rural land } \\
\left(d_{2}\right)\end{array}$ \\
\hline 1 & 0.4873 & 0.2432 & 0.2003 & 0.0692 \\
2 & 0.3031 & 0.4334 & 0.1906 & 0.0729 \\
3 & 0.4909 & 0.1336 & 0.2824 & 0.0932 \\
4 & 0.4564 & 0.2182 & 0.2531 & 0.0723 \\
5 & 0.5433 & 0.1180 & 0.2527 & 0.0859 \\
6 & 0.4681 & 0.2129 & 0.2324 & 0.0866 \\
7 & 0.3800 & 0.2071 & 0.2929 & 0.1200 \\
8 & 0.4695 & 0.2701 & 0.1813 & 0.0790 \\
9 & 0.4768 & 0.3130 & 0.1466 & 0.0636 \\
10 & 0.5239 & 0.1900 & 0.1831 & 0.1030 \\
11 & 0.3352 & 0.4396 & 0.1739 & 0.0513 \\
12 & 0.4853 & 0.1285 & 0.2944 & 0.0918 \\
13 & 0.3750 & 0.3639 & 0.1942 & 0.0669 \\
14 & 0.3661 & 0.3595 & 0.2215 & 0.0529 \\
15 & 0.3146 & 0.4114 & 0.2041 & 0.0699 \\
\hline Average & 0.4317 & 0.2695 & 0.2202 & 0.0786 \\
Variance & 0.0061 & 0.0123 & 0.0021 & 0.0003 \\
\hline \hline
\end{tabular}

Table 2-C3 Values of $a_{3}, b_{3}, c_{3}$ and $d_{3}$ (ecological authorities)

\begin{tabular}{lllll}
\hline \hline \multicolumn{5}{l}{ Weights for interviewees in the ecological authorities type } \\
\hline \multirow{2}{*}{ Alternatives } & $\begin{array}{l}\text { Cultivated land } \\
\left(a_{3}\right)\end{array}$ & $\begin{array}{l}\text { Grassland } \\
\left(b_{3}\right)\end{array}$ & $\begin{array}{l}\text { Forest land } \\
\left(c_{3}\right)\end{array}$ & $\begin{array}{l}\text { Other rural land } \\
\left(d_{3}\right)\end{array}$ \\
\hline 1 & 0.1867 & 0.3099 & 0.3808 & 0.1227 \\
2 & 0.1963 & 0.3318 & 0.3740 & 0.0979 \\
3 & 0.1685 & 0.3894 & 0.3647 & 0.0774 \\
4 & 0.2507 & 0.2620 & 0.4008 & 0.0865 \\
5 & 0.1985 & 0.3178 & 0.3836 & 0.1000 \\
6 & 0.2718 & 0.2930 & 0.3438 & 0.0915 \\
\hline Average & 0.2121 & 0.3173 & 0.3746 & 0.0960 \\
Variance & 0.0016 & 0.0018 & 0.0004 & 0.0002 \\
\hline \hline
\end{tabular}


Table 2-C4 Values of $a_{4}, b_{4}, c_{4}$ and $d_{4}$ (economic authorities)

\begin{tabular}{lllll}
\hline \hline \multicolumn{4}{l}{ Weights for interviewees in the ecological authorities type } \\
\hline \multirow{2}{*}{ Alternatives } & $\begin{array}{l}\text { Cultivated land } \\
\left(a_{4}\right)\end{array}$ & $\begin{array}{l}\text { Grassland } \\
\left(b_{4}\right)\end{array}$ & $\begin{array}{l}\text { Forest land } \\
\left(c_{4}\right)\end{array}$ & $\begin{array}{l}\text { Other rural land } \\
\left(d_{4}\right)\end{array}$ \\
\hline 1 & 0.5768 & 0.1787 & 0.1082 & 0.1364 \\
2 & 0.4479 & 0.3403 & 0.0848 & 0.1271 \\
3 & 0.4815 & 0.2614 & 0.1194 & 0.1377 \\
4 & 0.3849 & 0.2982 & 0.1183 & 0.1986 \\
5 & 0.3246 & 0.4247 & 0.1374 & 0.1133 \\
6 & 0.3669 & 0.3768 & 0.1242 & 0.1321 \\
\hline Average & 0.4304 & 0.3133 & 0.1154 & 0.1409 \\
Variance & 0.0083 & 0.0076 & 0.0003 & 0.0009 \\
\hline \hline
\end{tabular}


Appendix 2-D: Estimation of parameter $\boldsymbol{\beta}_{\boldsymbol{i}}$

Table 2-D1 Data for welfare weights $\beta_{i}$

\begin{tabular}{lll}
\hline \hline Item & Unit & Value \\
\hline Population of farmers & Person & 168514 \\
Farmer's net income in 2012 & RMB per capita & 6730 \\
Farmers' total income & Million RMB & 1134.10 \\
\hline Population of herders & Person & 2986 \\
Herder's net income in 2012 & RMB per capita & 7898 \\
Herders' total income & Million RMB & 23.58 \\
\hline Ecological expenditure in 2012 & Million RMB & 118.96 \\
Rural ecological expenditure share & $\%$ & 70 \\
Ecological expenditure on rural area & Million RMB & 83.3 \\
\hline Economic expenditure in 2012 & Million RMB & 1109.42 \\
Rural population share & \% & 81.2 \\
Economic expenditure on rural area & Million RMB & 900.8 \\
\hline \hline
\end{tabular}

Source: Statistical Bureau, Tai Pusi County in 2012.

Table 2-D2 Value of $\beta_{i}$ based on income distribution and labour force of stakeholder types

\begin{tabular}{llllll}
\hline \hline & $\begin{array}{l}\text { Herders } \\
\left(\beta_{1}\right)\end{array}$ & $\begin{array}{l}\text { Farmers } \\
\left(\beta_{2}\right)\end{array}$ & $\begin{array}{l}\text { Ecological } \\
\text { public } \\
\text { authorities }\left(\beta_{3}\right)\end{array}$ & $\begin{array}{l}\text { Economic } \\
\text { public } \\
\text { authorities }\left(\beta_{4}\right)\end{array}$ & Total \\
\hline $\begin{array}{l}\text { Income in 2012 } \\
\text { (million RMB) }\end{array}$ & 23.58 & 1134.099 & 83.3 & 900.8 & 2158.669 \\
$\begin{array}{l}\text { Income } \\
\text { distribution }\left(\beta_{\mathrm{i}}\right)\end{array}$ & 0.0110 & 0.5295 & 0.0389 & 0.4206 & 1 \\
$\begin{array}{l}\text { Labour force in } \\
\text { each stakeholder } \\
\text { type in 2012 }\end{array}$ & 1962 & 55665 & 200 & 6601 & 64428 \\
$\begin{array}{l}\text { Labour force } \\
\text { distribution }\left(\beta_{\mathrm{i}}\right)\end{array}$ & 0.0304 & 0.8640 & 0.0031 & 0.1025 & 1 \\
\hline \hline
\end{tabular}

Source: Statistical Bureau, Tai Pusi County in 2012. 
Appendix 4-A: Descriptive statistics of the model variables

Table 4-A1 Descriptive statistics of the model variables

\begin{tabular}{clllll}
\hline Variables & Mean & Std. Dev. & Min & Max & Observations \\
\hline $\log \left(S_{i t}\right)$ & 0.36 & 0.54 & $-1.59^{27}$ & 3.14 & 1080 \\
$\log \left(C_{i t}\right)$ & -0.05 & 0.49 & -2.08 & 2.93 & 1080 \\
$\log \left(U_{i t}\right)$ & 1.02 & 0.81 & -0.50 & 4.23 & 1080 \\
$\log \left(F_{i t}\right)$ & 1.05 & 0.79 & -2.00 & 4.17 & 1080 \\
$\log \left(R_{i t-1}\right)$ & -1.13 & 3.30 & -4.61 & 3.26 & 1080 \\
$1 /\left(R_{i t-1}\right)$ & 46.69 & 49.80 & 0.04 & $100^{28}$ & 1080 \\
$\log \left(M_{i t-1}\right)$ & 0.05 & 0.41 & -0.53 & 0.66 & 1035 \\
$\log \left(B_{i t-1}\right)$ & 0.12 & 0.50 & -0.45 & 1.13 & 1035 \\
$\log \left(T_{i t-1}\right)$ & -0.03 & 0.06 & -0.23 & 0.10 & 1035 \\
$\log \left(G_{i t-1}\right)$ & -0.28 & 0.42 & -2.40 & 0.01 & 1035 \\
$Y_{t}$ & 12.50 & 6.93 & $1^{29}$ & 24 & 1080 \\
$P_{i} * Y_{t}$ & 7.50 & 8.14 & 0 & 24 & 1080 \\
\hline \hline
\end{tabular}

${ }^{27}$ The logarithm of any positive number less than 1 is negative.

${ }^{28} 1 /\left(R_{i t-1}\right)$ has the max value of 100 because we assigned a small original value $(0.01)$ to $R_{i t-1}$. In this case, it indicates $R_{i t-1}$ equals to 0 .

${ }^{29}$ Year 1985 equals 1, 1986 equals 2, etc. 
Appendix 4-B: The model specification with quadratic term

With respect to the specification of our models, we use the quadratic term instead of the reciprocal of land tenure reform variable. That is, $1 /\left(R_{i t-1}\right)$ is replaced by $\left[\log \left(R_{i t-1}\right)\right]^{2}$, as every equation in below. Comparing table 4.3 with table 4-B1, and figure 4.9 with figure $4-B 1$, model results for these two types of specification are almost the same, which indicates the model specification is reliable and the model results are robust.

$$
\begin{aligned}
\log \left(S_{i t}\right)=s_{i} & +a_{1} \log \left(R_{i t-1}\right)+a_{2}\left[\log \left(R_{i t-1}\right)\right]^{2}+a_{3} \log \left(M_{i t-1}\right)+a_{4} \log \left(T_{i t-1}\right) \\
& +a_{5} \log \left(G_{i t-1}\right)+a_{6} Y_{t}+a_{7} P_{i} * Y_{t}+\varepsilon_{i t}
\end{aligned}
$$




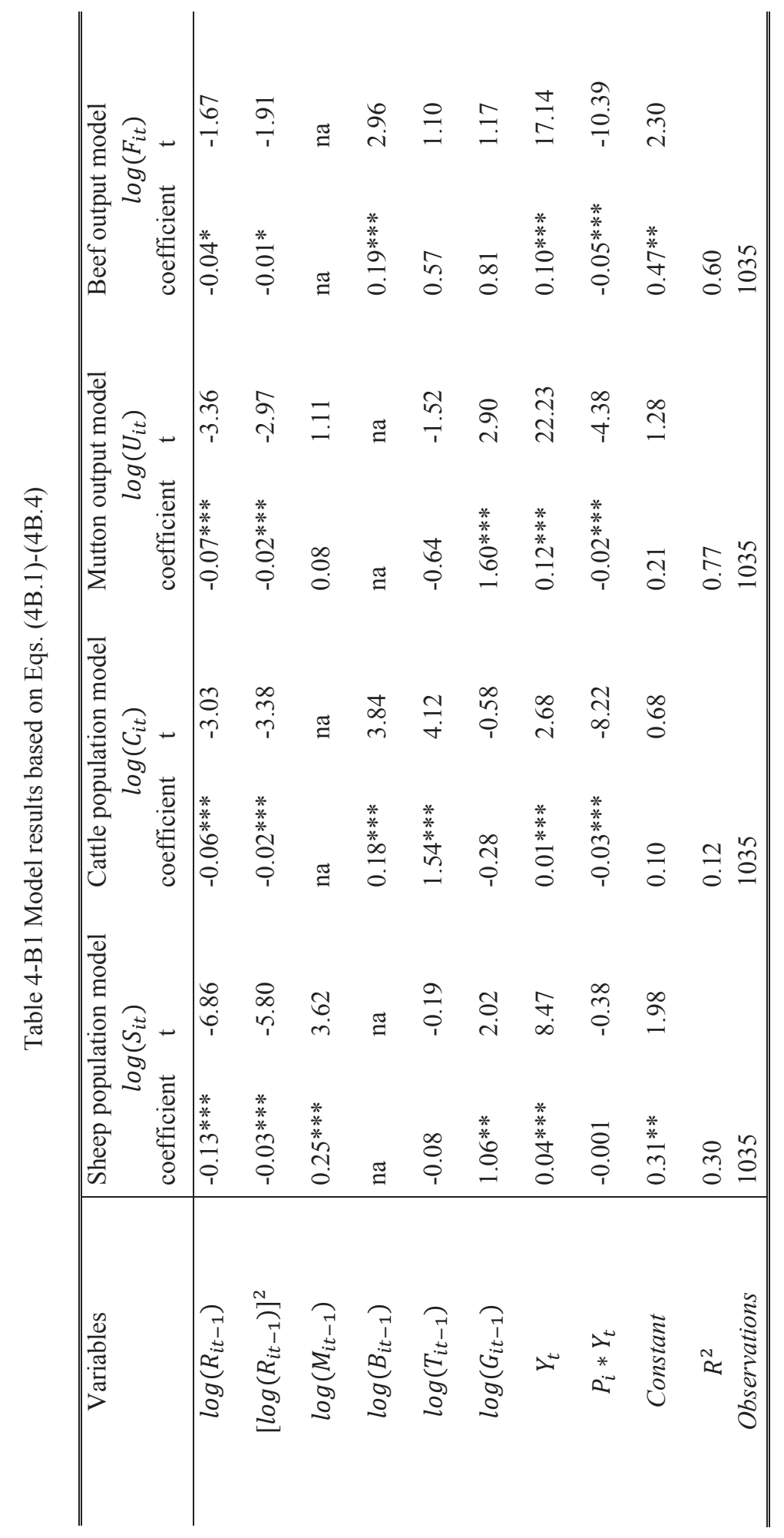




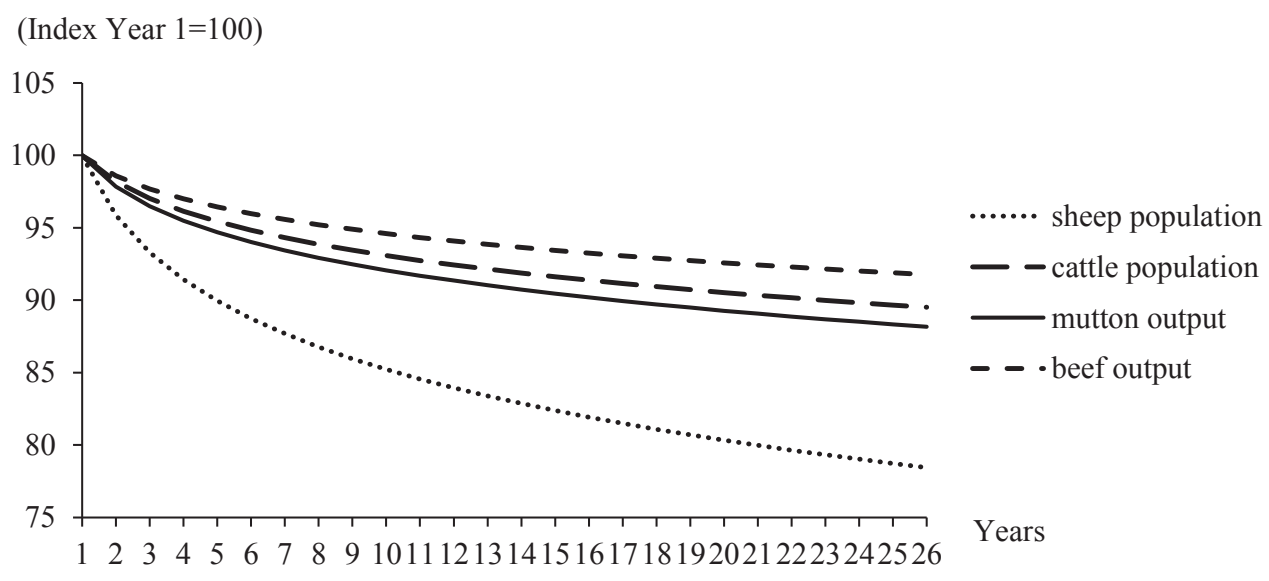

Figure 4-B1 Relationship between land tenure reform and livestock production based on the model results in table 4-B1 


\section{Summary}

Grasslands play a significant role in the global ecosystem, livestock production and millions of household livelihoods. However, grassland degradation has become a worldwide problem, and rural poverty has become exacerbated in some pastoral areas. The sustainable management and use of grasslands that maintain the productive and adaptive capacity of ecosystems while providing for the well-being of human communities are crucial concerns. In practice, various policy interventions have been initiated by governments all over the world to devote to grassland conservation, livestock production and improving local household livelihoods. This research aims to evaluate the effectiveness of the policy interventions for grassland ecosystems and livestock production in the pastoral areas of China. The conceptual framework for this research is based on Ostrom's Social-Ecological Systems (SESs) framework. Four specific research questions are addressed. It is hoped that the research findings of this thesis can make a contribution to providing some references for policy development in light of the sustainable management and use of grasslands.

China has around 392 million hectares of grasslands, accounting for $12 \%$ of the world's grasslands and $41.7 \%$ of the national land area. The study about China's grassland system and its grassland policies could provide significant views to understand the grasslands of this world. Inner Mongolia, that includes the typical pastoral areas of China, is employed as the specific research region. The impacts of China's grassland policies on the grassland systems are dissected based on the methodology of econometrics, welfare economics and institutional economics and data from remote sensing technology and socioeconomic survey. More specifically, the major policy interventions for the governance of grasslands in China include the land tenure reform during the 1980s-1990s and a series of Ecological Construction Programs occurring mainly after the year 2000. The former aims at privatizing use rights of grasslands to individual households and displacing traditional common use. The latter mainly concerns grassland conservation through employing grazing bans and deterministic stocking rates. The effectiveness of these policy interventions is investigated through estimating their impact on grassland condition and livestock production. The empirical analysis about policy impacts is conducted in chapter 3, 4 and 5, based on panel data that spans several decades. In addition, a case study based on a county in the ecofragile area is conducted in chapter 2 to study the preference for different types of rural land by different stakeholders, which mirrors the perception of resource users on grassland use under the social, economic and political settings.

More in detail, chapter 2 analyses the divergence in preferences among different stakeholders over the allocation of four types of rural land: cultivated land, grassland, forest and other land. Considering the heterogeneity of stakeholders that are concerned with land-use decisions, four types of stakeholders are 
distinguished, namely, ecological authorities, economic authorities, herders and farmers. The diverging preferences of these four stakeholder types over the different types of land use were quantified using the Analytic Hierarchy Process. Weights for each stakeholder type were derived for three scenarios: equal weights, weights based on income distribution and weights based on labour force distribution. Welfare analysis was employed then to determine the individual optimal allocation by maximising the utility function of each stakeholder type. Social optimal allocation was derived by maximising the social welfare function, which is the weighted sum of individual utilities. Tai Pusi County, located in an ecofragile area of northern China, was taken as a case to present the empirical analysis. Individual optima revealed the degree of divergences among stakeholders, and the social optima revealed the optimal allocation based on social welfare. The research results provide insights on how to achieve an efficient allocation of rural land, balancing the ecological and economic benefits of different stakeholders from different types of land. As such, the desirable area of grasslands for different users as well as for the whole society is revealed, which further reflects the conflicts of different stakeholders on grassland use.

Prior to the policy intervention of assigning the grasslands to individual households, grazing was mobile and flexible in China, which allowed herders and their animals to roam over forage and water resources. Since the start of the land tenure reform in the pastoral areas of China in the 1980s, grassland use rights have increasingly been assigned to individual households and subsequently more grasslands have been in private use. On the other hand, most of the grasslands in China have experienced severe degradation after the reform. Chapter 3 aims at examining whether land tenure reform plays a significant role in grassland degradation, i.e. the impact of grassland privatisation on grassland condition. It first outlines the process of land tenure reform in the pastoral areas of China over time and then investigates the changes in grassland condition that are caused by the reform. Grassland condition is presented by grassland quantity and quality using spatial information based on remote sensing. The timing of the assignment of grassland use rights and the timing of the actual adoption of private use by households differ among counties, which allows to disentangle the impact of the land tenure reform at county-level. A fixed effects model that controls for the factors of climate, agricultural activity and environmental heterogeneity is used to conduct the empirical analysis, based on a dataset involving 60 counties of Inner Mongolia between 1985 and 2008. The model results show that the private use of grasslands following the land tenure reform causes the reduction of the total grassland area and leads to the degradation of dense and moderate grasslands into sparse grasslands in the long run. These results point to the existence of "a tragedy of privatisation", as opposed to the well-known "tragedy of the commons".

Chapter 4 aims at understanding whether land tenure reform has played a role in the changes in livestock production of pastoral areas, i.e. the impact of grassland privatisation on local animal husbandry. This objective is investigated based on county-level data for Inner Mongolia between 1985 and 2008. The 
changes in livestock production over time are examined by analysing data on changes in livestock population and meat output. The descriptive analysis shows that livestock production increased at a higher speed in the crop farming areas, but the development of livestock productivity was faster in the pastoral areas. In the empirical analysis, we employed a fixed effects model to disentangle the effects of land tenure reform on livestock production from factors related to market forces, grassland condition, technology development and environmental heterogeneity. The model results reveal that the implementation of land tenure reform had significant and negative effects on the increase in livestock production, although the total livestock production actually increased over the research period. This shows that land reform in itself is unable to offset the impact of other factors that accelerate the increase in livestock production. Moreover, the constraining effect of land tenure reform on the increase in livestock production decreases with the years of implementing land tenure reform and ultimately disappears. Remarkably, the constraining effect of land tenure reform is stronger on the increase of livestock population than that of meat output. This indicates that land tenure reform has led to an improvement in livestock productivity. In conclusion, land tenure reform puts a ceiling on livestock production, which could be a possible reason why it has been difficult to implement the reform on grasslands. However, the reform has improved the livestock productivity of pastoral areas.

A series of Ecological Construction Programs have been initiated to protect the condition of grasslands in China during recent decades. However, grassland degradation is still severe and conditions have not been restored as intended. Chapter 5 investigates the effectiveness of Ecological Construction Programs for protecting the grassland condition in the extensive pastoral areas of China. One Ecological Construction Program that has been implemented widely on the grasslands, specifically the Subsidy and Incentive System for Grassland Conservation (SISGC), is taken as the concrete example for policy evaluation. The Normalized Difference Vegetation Index (NDVI), measured with remote sensing technology, is used to quantify the grassland condition between 2001 and 2014. With data from 54 counties in the pastoral areas of Inner Mongolia, we estimate the impact of SISGC on the grassland condition. A fixed effects model is employed to control for livestock production, climate, time trends and environmental heterogeneity. The model results provide quantitative evidence that the condition of the grasslands has improved significantly due to SISGC, but that the effectiveness of SISGC was offset to some extent by other socio-economic and climate factors, such as increased producer prices and high temperatures. This may explain why the actual grassland degradation has not been prevented as effectively as was expected. In addition, the impact of SISGC was stronger in counties with a worse initial grassland condition. Furthermore, the effects of producer prices and climate changes were also more pronounced in these counties. 
Chapter 6 concludes this research with the main findings as well as the contribution to the existing scientific debates. Moreover, policy implications are suggested based on the findings of this research. It is finalised with the research limitation and recommendations for future research. 


\section{Acknowledgements}

During these four years of study at Wageningen University, I have benefited a lot from the guidance and support of many people. Their contributions helped me finish my $\mathrm{PhD}$ training and grow into a "big girl". I would like to express my heart filled gratitude to all of them and mention a few particularly.

First of all, I would like to thank my four supervisors, Prof. Wim Heijman, Prof. Jikun Huang, Dr. Liesbeth Dries and Dr. Xueqin Zhu. Wim, thank you very much for your trust and encouragement in the course of my $\mathrm{PhD}$ training. No matter how difficult the issues I met, you encouraged me and helped me overcome them. Your international horizon taught me how to confront the differences of this world and inspired me to think about the same question from different perspectives. Most importantly, you helped me to start my journey of exploring this beautiful world. The same gratitude goes to Sonja, Wim's wife. Thank you for your very warm reception when I started my study in the Netherlands. Jikun, thank you so much for your professional guidance and generous support on the road of my academic career. You saved me from the most difficult position of my PhD study. You promised to help me when you did not even know me, only because you thought I am a student who needed help. You set a very good example to me on how to be a teacher. You also set a very good example to me on research by treating your work very conscientiously and enthusiastically. Liesbeth, thank you very much for being my supervisor as well as my close friend. You had a great contribution to my $\mathrm{PhD}$ study and my life in the Netherlands. You were always the first person who came to me and stood by me when I had any troubles or successes. My wish is to be a female scholar as elegant as you are. Xueqin, thank you so much for your guidance. You taught me to be independent, which is one of the most significant things I learned from my $\mathrm{PhD}$ training. I sincerely appreciate my amazing supervision team and remain deeply grateful to all of you.

Then, I would like to thank my other two supervisors who supervised me during my internship at the World Bank, Dr. Klaus Deininger and Thea Hilhorst. Thank you very much for giving me the chance to work with you and being patient to teach me about the new research domains. You are so helpful and thoughtful to guide me to develop my next career. Many thanks go to the other colleagues at World Bank, Daniel, Chala, Futoshi, Estella, Xinxin and Faye, a group of brilliant friends at Washington DC, Lily, James, Sofia, Hadrien, Dimitra, Cindy, and Laith, and the awesome family, Jenn, Karen, Marie, Barbara, Toly and Clara. Thank you very much for making me have a wonderful life in the United States. I also express my gratitude to Dr. Nico Heerink, Prof. Xiaoping Shi, Prof. Xiangzheng Deng, Prof. Linxiu Zhang, Prof. Jinxia Wang, Prof. Fujiang Hou, Dr. Zeng Tang, Prof. Shunbo Yao, Prof. Xuexi Huo, Prof. Minjuan Zhao, Prof. Xianli Xia, Prof. Tianjun Liu and Dr. Jundi Liu for your any suggestions and supports to my research and my $\mathrm{PhD}$ study. 
Next, I would like to express my gratitude to my best roommates, Anouschka, Valentina and Nadja. Thank you all for accompanying me, supporting me and taking care of me. Anouschka, thank you very much for your sharing, listening and supporting, and also being the paranymph of my PhD defence. I am absolutely delighted to have a thoughtful, respectful and trustworthy close friend like you. Valentina, thank you very much for being my sister. You accompanied me to get through the tough period of my $\mathrm{PhD}$ and taught me to confront the challenges optimistically. Nadja, thank you so much for supporting me and teaching me how to start my $\mathrm{PhD}$. You helped me get through the confused period of my $\mathrm{PhD}$ when I started my oversea life alone. I am so grateful for having all of you such fabulous girls. Also thanks to the girls' boyfriends, Hildert, Thomas and Robert. Thank you for giving me the happy girls during work time.

Many thanks to my other close friends who are around me during the past several years, Oriana, Elena, Yu Hong, Li Meng, Chuanlan, Shiyi, Zihan, Huimin, Haibo, Haoran, Tian Yu, Jin Zhang, and Yu Wang. Thank you very much for standing by me and listening to me. Many thanks go to my corridor mates, Anne, Maikel, Lana, Susan, Rung and Elia. Thank you for introducing the Dutch culture to me and teaching me how to bake. You eventually do not need to worry that I may burn the kitchen by accident when I cook. The special gratitude goes to the best PhD students in Agricultural Economics and Rural Policy Group, Sabrina, Esther, Qianqian, Jinghui, Evert, Thomas, Hoyga, Anastasia, Dadan, Eko, Undrakh, Niccolo, Shanshan, Chuka, Mohammed, Bek and Praxedis. Thank you all for making me feel not alone on the tough road of pursuing a $\mathrm{PhD}$ degree. Extra thanks to the other paranymph of my $\mathrm{PhD}$ defence, Evert. Many thanks go to my colleagues at AEP group, Justus, Jack, Koos, Rico, Dusan, Roel and Alexander. Thank you for teaching me and guiding me. The other special thanks go to the supporting team of AEP group, Karen, Dineke, Betty, Marian and Gre. Thank you for giving me a lot of help to make my life in the Netherlands much easier. Extra appreciation goes to Karen for helping me and supporting me with your optimism. I also would like to thank my friends and colleagues who are or were working in Chinese Academy of Sciences and Peking University, Linlin Hou, Xiaobing Wang, Wei Xie, Chengfang Liu, Renfu Luo, Tianhe Sun, Dan Wang, Cheng Xiang, Jiliang Hu, Yulan $\mathrm{Bu}$, Shukun Wang, Guolei Yang, Xia Wang, Yuanning Hu, Jie Zhou, Mi Tian, Yangjie Wang, Shi Min, Shaoze Jin, Yunhua Wu, Yuxian Lin and Li Wang. Thank you all for any help when I went back to China to work. Many thanks go to a lot of friends who I did not mention here yet.

Moreover, I would like to acknowledge the institutes who funded and supported my $\mathrm{PhD}$ program, China Scholarship Council, Center for Chinese Agricultural Policy (CCAP), LEB Foundation and Wageningen School of Social Sciences.

Last, but certainly foremost, I would like to appreciate my parents. Thank you so much for your understanding and supports. Being your daughter is the happiest thing of my life, love you always. 


\section{Biography}

Min Liu was born on the $26^{\text {th }}$ of April, 1988 in Hanzhong City, Shaanxi Province, China. She studied Tourism Management at Northwest Agriculture and Forestry University, China from 2006 to 2010 and got her Bachelor degree of management. She then was recommended for Master of Agricultural Economics and Management in Northwest Agriculture and Forestry University, and obtained her Master degree in 2012.

In October 2012, Min started to study at Wageningen University, the Netherlands, funded by Chinese Scholarship Council to pursue her PhD degree under the supervision by Prof. Wim Heijman, Prof. Jikun Huang, Dr. Liesbeth Dries and Dr. Xueqin Zhu at Agricultural Economics and Rural Policy group. During the final year of her $\mathrm{PhD}$, she joined in the Development Research Group of World Bank, Washington D.C. to work with Dr. Klaus Deininger. Her current research interests focus on socialecological systems, grassland degradation, livestock production, eco-environmental policies, land use and management, land tenure, rural household livelihoods and rural transformation. 
Min Liu

Wageningen School of Social Sciences (WASS)

Completed Training and Supervision Plan

*One credit according to ECTS is on average equivalent to 28 hours of study load

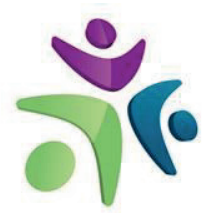

Wageningen School of Social Sciences

\begin{tabular}{|c|c|c|c|}
\hline Name of the learning activity & Department/Institute & Year & ECTS* \\
\hline \multicolumn{4}{|l|}{ A) Project related competences } \\
\hline Advanced Microeconomics (ECH-32306) & WUR & 2013 & 6 \\
\hline $\begin{array}{l}\text { Theories and Models in Environmental } \\
\text { Economics (ENR-30306) }\end{array}$ & WUR & 2013 & 6 \\
\hline Rural Economic Analysis (AEP-31306) & WUR & 2013 & 6 \\
\hline Advanced Econometrics (AEP-60306) & WUR & 2014 & \\
\hline $\begin{array}{l}\text { Cost-Benefit Analysis and Environmental } \\
\text { Valuation (DEC-31306) }\end{array}$ & WUR & 2014 & \\
\hline Agricultural Economics \& Policy & WASS & 2016 & 2 \\
\hline \multicolumn{4}{|l|}{ B) General research related competences } \\
\hline Workshop: interviewing professionals & WASS & 2012 & 0.5 \\
\hline Research Methodology: From topic to proposal & WASS & 2013 & 4 \\
\hline Doing systematic literature review & WASS & 2013 & 3.7 \\
\hline $\begin{array}{l}\text { WASS Introduction Course for new PhD } \\
\text { candidates }\end{array}$ & WASS & 2013 & 1.0 \\
\hline $\begin{array}{l}\text { Techniques for Writing and Presenting a } \\
\text { Scientific Paper }\end{array}$ & WASS & 2015 & 1.2 \\
\hline $\begin{array}{l}\text { 'Tragedy of the commons or tragedy of } \\
\text { privatization? The impact of land tenure reform } \\
\text { on grassland condition in Inner Mongolia, } \\
\text { China' }\end{array}$ & $\begin{array}{l}\text { - EAAE PhD Workshop, Roma } \\
\text { - WASS PhD day } \\
\text { - International Conference "Food in the Bio-based } \\
\text { Economy", Wageningen } \\
\text { - 29th International conference of agricultural } \\
\text { economists (ICAE), Milano }\end{array}$ & 2015 & 1 \\
\hline $\begin{array}{l}\text { 'What is the impact of land tenure reform on } \\
\text { livestock production in pastoral areas? An } \\
\text { empirical study conducted in Inner Mongolia, } \\
\text { China' }\end{array}$ & $\begin{array}{l}\text { - Workshop on tenure reforms in different land use types } \\
\text { in China, Beijing, China } \\
\text { - The Fourth International Conference on Natural } \\
\text { Resources and Agricultural Economics), Hohhot, China }\end{array}$ & 2015 & 1 \\
\hline $\begin{array}{l}\text { 'Individual and Social Optima of Rural Land } \\
\text { Allocation by Stakeholders: A Case Study on } \\
\text { Eco-fragile Areas of Northern China' }\end{array}$ & $\begin{array}{l}\text { The 29th International conference of agricultural } \\
\text { economists (ICAE), Milano, Italy }\end{array}$ & 2015 & 1 \\
\hline $\begin{array}{l}\text { 'The impact of Ecological Construction } \\
\text { Programs on grassland conservation in the } \\
\text { pastoral areas of China' }\end{array}$ & $\begin{array}{l}\text { - The } 2016 \text { China Conference of the Chinese Economists } \\
\text { Society, Shenzheng, China } \\
\text { - Lunch seminar at the Department of Agriculture, Food } \\
\text { and Environment, University of Pisa, Italy }\end{array}$ & 2016 & 1 \\
\hline \multicolumn{4}{|c|}{ C) Career related competences/personal development } \\
\hline Internship & Development Research Group, World Bank & 2016 & 6 \\
\hline Total & & & 40.4 \\
\hline
\end{tabular}

